\title{
A Comparison of Heuristic and Optimal Reserve Selection Algorithms Used in Systematic Conservation Planning
}

\author{
By \\ Robert P.D. Vanderkam
A thesis submitted to
the Faculty of Graduate Studies and Research
in partial fulfillment of
the requirements for the degree of \\ Master of Arts \\ Department of Geography and Environmental Studies \\ Carleton University \\ Ottawa, Ontario \\ September, 2005 \\ CC 2005, Robert P. D. Vanderkam
}




$\begin{array}{ll}\begin{array}{l}\text { Library and } \\ \text { Archives Canada }\end{array} & \begin{array}{l}\text { Bibliothèque et } \\ \text { Archives Canada }\end{array} \\ \begin{array}{l}\text { Published Heritage } \\ \text { Branch }\end{array} & \begin{array}{l}\text { Direction du } \\ \text { Patrimoine de l'édition }\end{array} \\ \begin{array}{l}\text { 395 Wellington Street } \\ \text { Ottawa ON K1A ON4 } \\ \text { Canada }\end{array} & \begin{array}{l}\text { 395, rue Wellington } \\ \text { Ottawa ON K1A ON4 } \\ \text { Canada }\end{array}\end{array}$

Your file Votre référence ISBN: 0-494-10074-5

Our file Notre référence

ISBN: 0-494-10074-5

NOTICE:

The author has granted a nonexclusive license allowing Library and Archives Canada to reproduce, publish, archive, preserve, conserve, communicate to the public by telecommunication or on the Internet, loan, distribute and sell theses worldwide, for commercial or noncommercial purposes, in microform, paper, electronic and/or any other formats.

The author retains copyright ownership and moral rights in this thesis. Neither the thesis nor substantial extracts from it may be printed or otherwise reproduced without the author's permission.
AVIS:

L'auteur a accordé une licence non exclusive permettant à la Bibliothèque et Archives Canada de reproduire, publier, archiver, sauvegarder, conserver, transmettre au public par télécommunication ou par l'Internet, prêter, distribuer et vendre des thèses partout dans le monde, à des fins commerciales ou autres, sur support microforme, papier, électronique et/ou autres formats.

L'auteur conserve la propriété du droit d'auteur et des droits moraux qui protège cette thèse. $\mathrm{Ni}$ la thèse ni des extraits substantiels de celle-ci ne doivent être imprimés ou autrement reproduits sans son autorisation.
In compliance with the Canadian

Privacy Act some supporting forms may have been removed from this thesis.

While these forms may be included in the document page count, their removal does not represent any loss of content from the thesis.
Conformément à la loi canadienne sur la protection de la vie privée, quelques formulaires secondaires ont été enlevés de cette thèse.

Bien que ces formulaires aient inclus dans la pagination, il n'y aura aucun contenu manquant. 


\begin{abstract}
Systematic conservation planning provides design recommendations for biodiversity conservation reserve networks. Reserve selection algorithms are components of systematic planning, and two types of algorithm, heuristic and optimal, are compared here. In order to further previous research, comparisons were made of their efficiency (i.e., the ability to use fewer sites to accomplish a given conservation goal) and related distribution patterns, their ability to provide alternative solutions, and their speed using regional datasets from Australia and two Canadian provinces.

The efficiency of heuristic algorithms was generally close or equal to that of an optimal algorithm, but a small number of results were extremely inefficient. Heuristic criteria affected efficiency but in unpredictable ways, and distribution patterns of networks from heuristic algorithms tended to converge with networks from an optimal algorithm as efficiency converged. Alternative solutions were provided more easily by the optimal algorithm, and both algorithms found solutions quickly for datasets of varying size.
\end{abstract}




\section{Acknowledgements}

I would like to thank a number of people for their support.

- My wife, Anna, for believing in me, encouraging me, supporting me, putting up with me, and staying with me. Thank you. We did it!

- Professor Douglas King of Carleton University for his professionalism, patience, flexibility and unflagging commitment to a part-time student.

- Rick Arnold of Carleton University for providing math and computer programming expertise on a shoestring budget and for showing great patience with my endless questions.

- Environment Canada, Canadian Wildlife Service management for financial and moral support (especially Ken Harris and Robert Hélie).

Thanks also to a number of people who gave freely of their time and expertise - Brett Bryan of CSIRO for assistance with the algorithm models, Dan Patterson of Carleton University for help with GIS scripts, and C-Plan support staff who were always there with an answer. Finally, thanks to all my family members, friends, and colleagues who helped me believe I could do it, especially Robert Hélie of the Canadian Wildlife Service. 


\section{Table of Contents}

Abstract..............................................................................

Acknowledgements ...............................................................ii

Table of Contents................................................................ iv

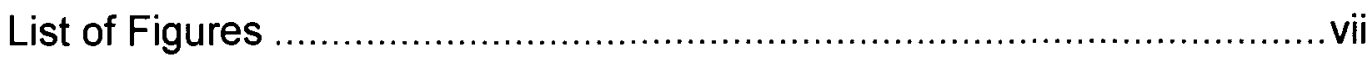

List of Tables.......................................................................

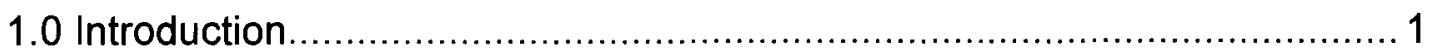

1.1 Research Objective .......................................................... 4

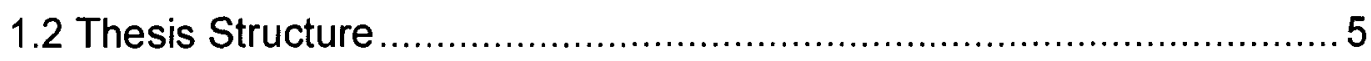

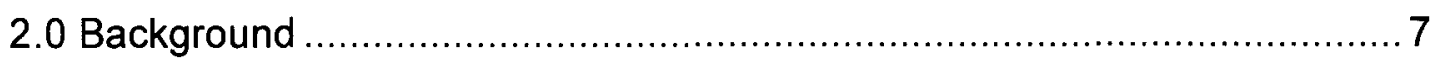

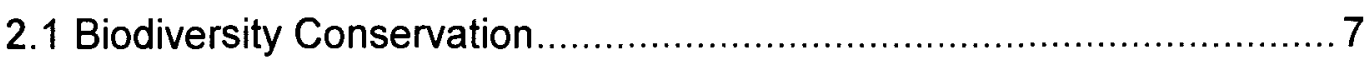

2.1.1 Conservation Reserves .......................................... 10

2.2 Systematic Conservation Planning ........................................ 11

2.2.1 Past Approaches to Selecting Reserves............................ 11

2.2.2 A Systematic Framework for Conservation Planning ............... 13

2.2.3 Selecting Potential Reserves ...................................... 20

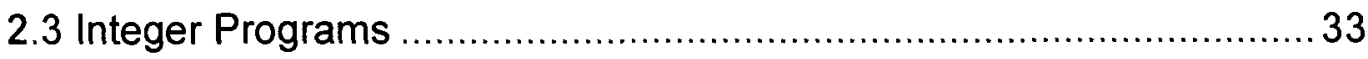

2.3.1 The Locational Set Covering Model.................................... 35

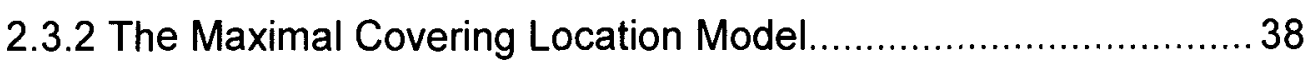

2.4 Two Algorithm Types for Solving Conservation Models ................... 39

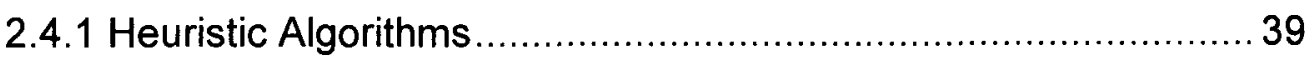

2.4.2 Optimal Algorithms ................................................. 46

2.4.3 Application of Reserve Selection Algorithms ......................50 
2.4.4 Comparing Heuristic and Optimal Algorithms

3.0 Methods

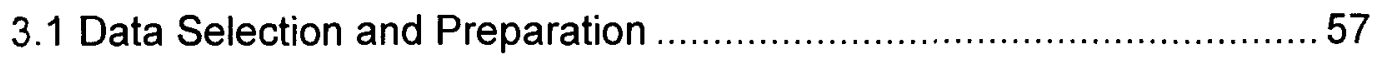

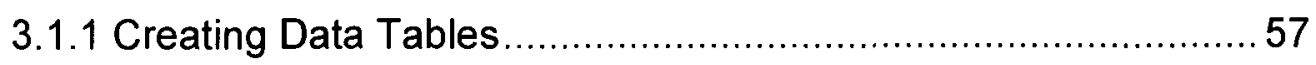

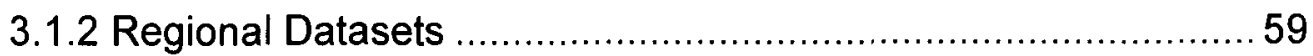

3.2 Implementation of Optimal and Heuristic Algorithms .........................64

3.2.1 Optimal Algorithm Software - ILOG OPL Studio .........................64

3.2.2 Heuristic Algorithm Software - C-Plan ......................................67

3.3 Optimal Algorithm Baseline Comparison........................................... 72

3.4 Heuristic and Optimal Algorithm Comparison .................................. 72

3.4.1 Output Solution Comparison ...................................................... 73

3.4.2 Gap Analysis Comparison ....................................................... 74

3.4.3 Algorithm Speed Comparison ................................................... 79

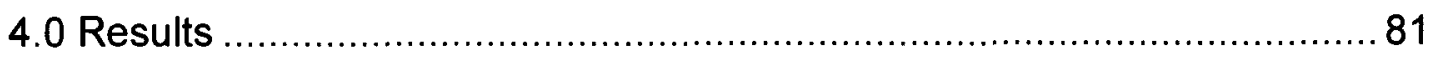

4.1 Optimal Algorithm Baseline Comparison........................................... 81

4.2 Heuristic and Optimal Algorithm Comparison ................................... 85

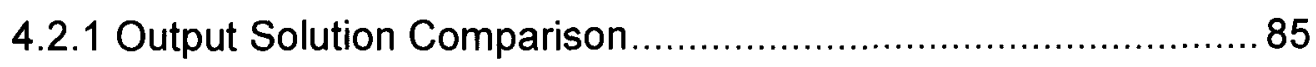

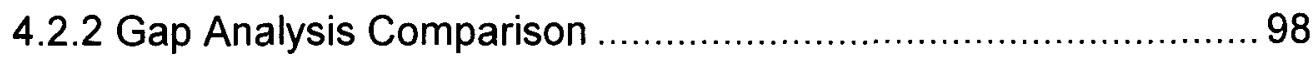

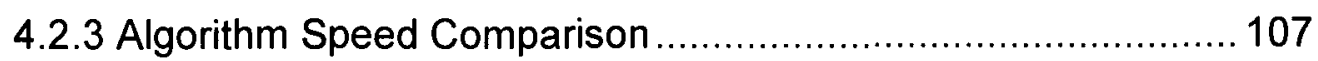

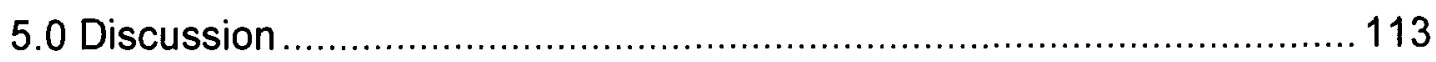

5.1 Optimal Algorithm Baseline Comparison....................................... 113

5.2 Heuristic and Optimal Algorithm Comparison ................................. 114

5.2.1 Output Solution Comparison................................................... 114

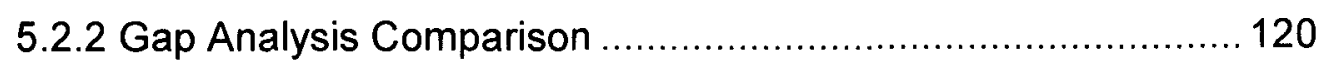

V 
5.2.3 Algorithm Speed Comparison

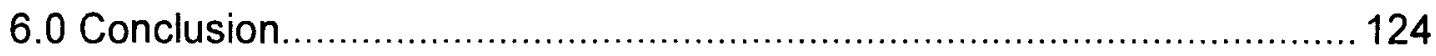

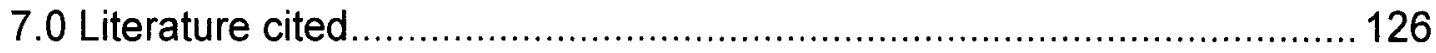




\section{List of Figures}

Figure 2.1: Stages in systematic conservation planning. See text for details on

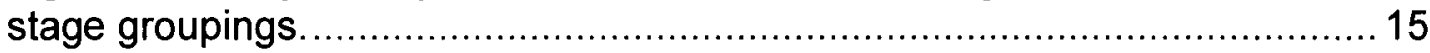

Figure 2.2: Cells with greatest species richness in British Columbia.............29

Figure 2.3: Cells classified by species richness illustrate the principle of complementarity, selecting cells' highest joint richness (2) instead of the highest individual richness (1).

Figure 2.4: Distributions of groups of cells around a region when selected using complementarity. This map of $\mathrm{BC}$ shows multiple groups of 7 cells (each group is composed of one cell of each different colour) (after Lindsay et al., unpublished scale as in Fig.2.1).

Figure 2.5: An example of a logical approach to selecting priority reserve sites from a regional data model as used in the ResNet software package (Aggarwal et al., 2000) (after Garson et al., 2002).

Figure 2.6: Hypothetical accumulation curve for optimal and suboptimal results to $\operatorname{MCLP}(n=1$ to 14$)$ and $\operatorname{LSCP}(n=14)$.

Figure 3.1: An example feature distribution map (in this case the species Myotis yumaensis) intersecting with the equal area grid cells (map scale is as in Fig.2.1).

Figure 3.2: Feature table output from the grid cell and features range maps overlay. See text for details.

Figure 3.3: $\mathrm{BC}$ birds' 1-0 table summed to produce a richness map (map scale is as in Fig.2.1).

Figure 3.4: Ontario Breeding Bird Survey grid classified by cell species richness

Figure 3.5: An example of tabular solution set output from OPL for BC amphibians. See the text for details.

Figure 3.6: The C-Plan interface windows. The program interface (top) and ArcView $3.2 \mathrm{GIS}$ interface (bottom).

Figure 3.7: All features vs. gap features. ON species richness for all birds (top) and "gap" birds (bottom). In both maps, cells with heavy blue outline show existing reserves (scale is as in Fig 3.5). 
Figure 3.8: Sample of existing British Columbia conservation reserves and the grid resulting from an intersection analysis. See text for details..................78

Figure 4.1 : LSCP solution sizes from OPL and minset size from C-Plan using 4 different prioritisation methods.

Figure 4.2: C-Plan MCLP solution distributions for $18 \mathrm{BC}$ amphibian species. The red circles highlight solution cell locations that are different for the tow criteria.

The number of species covered for each $n$ is shown with each map. 90

Figure 4.3: $\mathrm{BC}$ amphibian richness classes (map scale as in Figure 2.2) .....92

Figure 4.4: Sample MCLP suboptimality values for OPL and all C-Plan sorting criteria (BC birds). 93

Figure 4.5: Site distributions for different values of $n$ for $\mathrm{BC}$ birds. Columns are maps by number of sites $(n)$ with last column having $n$ for LSCP (where all 274

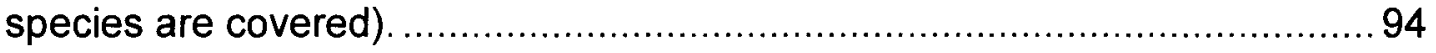

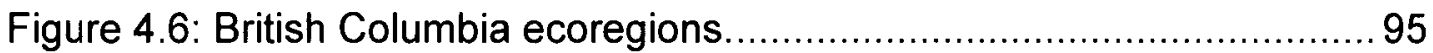

Figure 4.7 : Example results of a gap analysis as done in this study (C-Plan results for ON bird data using Summed Irreplaceability)...............................99

Figure 4.8: Distribution of $B C$ reptile solutions shown on a base map of species richness classes and overlain by existing reserves. 99

Figure 4.9: BC reptile data optimal solutions map (map scale as in Figure 2.2) (Lindsay et al., unpublished). 104

Figure 4.10: BC amphibian data optimal solutions map (map scale as in Figure 2.2) (Lindsay et al., unpublished). 105

Figure 4.11: Distribution of OPL irreplaceability values shown on a base map of species richness classes for the BC amphibian dataset (map scale as in Figure 2.2). 106

Figure 4.12: Distribution of C-Plan irreplaceability values for $B C$ reptiles. The legend and a priori irreplaceability values are created by the program. 108

Figure 4.13: Distribution of C-Plan irreplaceability values for $B C$ amphibians. The legend is as in Figure 4.12 109

Figure 4.14a: Times to solve LSCP for all nine datasets from Table 3.1. The bottom left corner is expanded for viewing in Figure 4.14b.

viii 
Figure 4.14b: Times to solve LSCP for seven smallest datasets from Table 3.1. These are shown separately from Figure 4.14a to show detail. 110

Figure 4.15: Graphs of the time required to find each solution by OPL for two datasets. In general, as more solutions were found, the time required to find each additional solution grew linearly. 112

Figure 5.1: Percent suboptimality occurrences from all 32 tests for the LSCP.116 


\section{List of Tables}

Table 2.1: A presence-absence array of data for 8 features (e.g., species) (columns) and 5 locations (e.g., map cells) (rows). Each location has a certain number of features present ( 1 ) and absent $(0)$.

Table 2.2: A presence-absence array of data for 8 features (columns) for 5 locations (rows). The goal of the LSCP is to find the smallest set of locations that covers all features at least one time.

Table 3.1: Dataset descriptions. 60

Table 4.1 : Results from the comparison between ILOG OPL and IBM OSL for the $\mathrm{BC}$ data. Three differences in solution set size are shown in dark grey. Numbers with a ">" symbol indicate that the programs were halted before all solutions were found (some OPL results extended beyond 1000 for Section 4.2.2).

Table 4.2: Spatial match of C-Plan minimum sets (i.e., LSCP) with any known optimal sets. 88

Table 4.3: MCLP solution set sizes (i.e., species accumulations) for OPL and all C-Plan sorting criteria for $\mathrm{BC}$ amphibians.

Table 4.4 : The number of cells for each algorithm solution that overlap with cells from existing reserves. For each algorithm, the highlighted text shows the number of cells in the smallest solution set and the number of those cells that overlap with existing reserve cells. See text for details. 101

Table 4.5: Number of totally irreplaceable cells for each taxon group by solver. 107

Table 4.6 : Time needed to find multiple solutions to LSCP model for each group. 


\subsection{Introduction}

The great increase in the world's human population in the last few centuries has resulted in equally large impacts on the landscape. These impacts include, at various scales, the loss and fragmentation of undeveloped land cover types and processes, the addition of toxic new substances and of common substances in toxic amounts, and the unsustainable consumption of wild biological resources (Vitousek et al., 1997; Sala et al., 2000). One result of these changes is a reduction in the variety of species and ecological processes (i.e., biodiversity) that make up our environment, and a consequent loss of basic ecological services such as clean water and healthy soil (Dasgupta et al., 2000; Loreau et al., 2001).

Many attempts are being made to assess and mitigate this reduction in biodiversity including regulation of the development and consumption of resources, encouragement of appropriate behavioural change in individuals and corporate entities, and improved social justice. One specific approach is the delineation of areas, such as parks, wildlife refuges, and conservation reserves, that limit human impacts in order to preserve biodiversity (Arcese and Sinclair, 1997; Scott et al., 2001; Margules et al., 2002). Delineation of these areas (referred to as reserves here) is an exercise in prioritisation. Since not all areas can be set aside from development, and different areas have varying conservation and real estate values, choices must be made as to which areas are the most appropriate to set aside. They can be evaluated, for example, by 
determining which locations contribute the most to regional or local goals for the least cost (Kingsland, 2002).

Reserves have been identified in various ways in the past and research is currently ongoing to develop approaches that are systematic as opposed to ad hoc or opportunistic. Systematic approaches have a number of advantages over other methods of prioritising areas for conservation. They allow the development of networks of reserves that make use of efficiencies of scale to increase the number of biodiversity features, such as species and other landscape elements, that can benefit from conservation efforts (Vane-Wright et al., 1991; Possingham et al., 2000; Margules and Pressey, 2000; Andelman and Willig, 2003; Sarkar, 2004). They also result in more justifiable arguments for creating and siting conservation reserves, an important consideration due to competition for space and management resources from short-term political and economic interests (Cortner, 2000; Kingsland, 2002).

The various stages of a systematic reserve selection process for a region include compiling the available data, defining goals, evaluating the contribution of existing reserves to that goal, selecting additional reserves, and implementing and managing the resulting plan (Margules and Pressey, 2000; Noss, 2003). Standards and criteria for each stage in a systematic process are explicitly defined in order to allow evaluation and input from experts and non-experts alike, and each of these stages requires development and testing of the assumptions and mechanisms involved. This study is concerned specifically with the methods 
used to select potential reserves. Biodiversity distribution data and conservation goals are used to create a mathematical problem or model that can be solved using reserve selection algorithms. The solutions found by the algorithms are linked to the site locations on the ground and represent potential reserves.

Algorithms, which are explicit quantitative instruction sets, have been in use in mathematics for 70 years (Beasley, unpublished) and have been adopted by the conservation community in the last 20 years (Sarkar, 2004). They are, however, a complex and somewhat arcane part of the planning process, and may appear as a "black box" to non-specialists, with numerous characteristics that remain unclear (Pressey, 1999a). In particular, there are two types of algorithm in common use, the heuristic and the optimal algorithm, that employ different approaches to solving mathematical models. Heuristic algorithms are a class of algorithm that prioritise potential reserve locations by using iterative procedures to select one at a time to build a set that satisfies the model goals (such as providing at least one reserve location within the range of every species). They come in a number of forms (Reeves, 1996) but a common variation known as the "greedy heuristic" has played a key role in conservation reserve selection to date and is examined here. This form is called "greedy" because once a location is selected, that location remains part of the solution while additional iterations select more sites even if it should later prove redundant or superfluous to the overall set. Optimal algorithms are another type of algorithm differ from heuristic algorithms by not containing any redundant or superfluous 
sites in the solutions. They use complex mathematical methods to output only the entire set of sites that satisfy the model exactly rather than compiling the set one site at a time. They are also available in a variety of software packages. They are commonly used as business and resource management optimisation tools but some forms have been found to be suitable for resolving reserve selection problems.

Each algorithm has different capabilities in terms of providing flexible solutions and providing them quickly enough for interactive use. As well, each algorithm can output sets of locations that differ in number and distribution across the landscape. These differences have been the topic of research and discussion for the past decade and this thesis furthered that research using a number of new datasets of varying size and structure. The goal was not to evaluate or make recommendations about the effectiveness or appropriateness of resulting networks of conservation reserves for a given situation. It was, rather, to evaluate the differences in the use of the algorithms and the networks that each identified.

\subsection{Research Objective}

The objective of this research was to compare the use and outputs of heuristic and optimal algorithms by 1) evaluating the differences in the number of sites that each selected, 2) evaluating the differences in the distribution of sites that each selected, 3) assessing their ability to provide multiple solutions, and 4) measuring the differences in time needed by each to provide solutions. 
Differences in the number of sites is a measure of efficiency, since only the unpredictable inclusion of redundant sites increases the solution set size. It was expected, due to past assessments, that there would only be minor differences in efficiency. Differences in the distribution of the sites were examined with respect to the level of inefficiency found in the first test. It was expected that when heuristic results were closer in efficiency to optimal results, the distributions would also be more similar. With regard to flexibility, optimal algorithms have the capacity to find the many different configurations of solution sets that solve the model exactly, and, as will be shown, this has implications in finding alternative sets as well as determining the relative importance of individual sites (i.e., irreplaceability) for satisfying the conservation goals. Finally, it was expected that a heuristic algorithm would find solutions more quickly, as previously reported in the literature.

\subsection{Thesis Structure}

Chapter 2 provides background historical, social, and scientific context for the issue of reserve selection. It covers the development of the main goals and methods of modern reserve network design and reviews published arguments and technical details about the issues examined in this thesis. Chapter 3 describes data preparation, software implementation, and the tests conducted to compare the two algorithm types. The results and analysis of those tests are presented in Chapter 4. Chapter 5 places the results in context with other studies that have been done. It also discusses the shortcomings of the results and the 
opportunities that were generated for further research. Chapter 6 is a short conclusion that summarises what was found. 


\subsection{Background}

This chapter provides background and scope for this research. Section 2.1 is a broad overview of the field of biodiversity conservation, its use of reserves, and specific changes in reserve selection methods that have occurred in the last few decades. Section 2.2 describes a systematic approach to reserve network design, focussing finally on how and why efficiency is becoming an important focus. Section 2.3 depicts the representation of the conservation situation as integer program (IP) models. Finally, Section 2.4 introduces reserve selection algorithms for solving the IP models, including the two algorithms that were compared in this thesis. It describes the differences in methods and results and what differences were tested in this thesis.

\subsection{Biodiversity Conservation}

The term "biodiversity" refers to the variety of the forms of living things, of their taxonomic groupings, and of the spatial processes they create at every scale from molecules to ecosystems (Sarkar and Margules, 2002; Margules and Pressey, 2000). The Convention on Biological Diversity (United Nations Environment Programme, 1992) defines biodiversity as:

"...the variability among living organisms from all sources including, inter alia, terrestrial, marine and other aquatic ecosystems and the ecological complexes of which they are part; this includes diversity within species, between species and of ecosystems." (Article 2) 
The term 'biodiversity' came into being in the mid-1980's with the development of the field of conservation biology, for which it became a focal idea (Sarkar, 2004). The roots of this field are found in the 1960's in the efforts to describe and apply biological and ecological principles to slow or stop the large scale losses of habitats and species in the developing world (as summarised in Sarkar, 2004; Kingsland, 2002; Janzen, 1986). Today the term is in widespread use and conservation of biodiversity conservation is a popular idea.

Human impacts on ecological patterns and processes have been increasing with population growth (Vitousek et al., 1997). Their effects are acknowledged by efforts to identify and mitigate the loss of unimpacted landscapes and their associated biodiversity. By the 1970's, guiding principles for the identification and protection of areas of biological importance were being developed. A concept called "island biogeography" likened the processes of extinction and repopulation in blocks of land to the situation with islands of various sizes and configurations (MacArthur and Wilson, 1967; Diamond, 1975; Kingsland, 2002; Sarkar, 2004). Population dynamics (Kupfer, 1995) modelled the extinctions and recolonisations of metapopulations, or multiple populations, of various species over large areas. It eventually became apparent, however, that broad, conceptual theories were not easy to apply to conservation goals, such as selecting or designing reserves, because the complexity of the concept was difficult to translate into general goals. Planning projects often had to consider many locally specific variables, such as forest canopy cover, geology and soil types, drainage, ground cover, 
species migrations, season, and others that could not always be guided by broad theories such as "single large or several small" (SLOSS) reserves (Diamond, 1975; Kingsland, 2002; Sarkar, 2004; Margules and Pressey, 2000). These planning challenges led, in 1985 , to the founding of a new approach and a new community, the Society for Conservation Biology. A primary goal of the Society, partly due to a new realization that reserve design recommendations needed to be applied in a political world, included the prioritising of sites of higher importance for biodiversity and protecting those areas by collaborating with local stakeholders. As well, design was to consider, when possible, local economic consequences, the type of species or features in question, the need for movement of ecosystem components across the landscape, and other factors besides just setting aside as much land as possible (Kingsland (2002) provides a historical perspective on this topic).

The use of biodiversity as an indicator for conservation value developed from previous work that had attempted to evaluate more specific attributes, such as species richness or rarity. Richness is the number of species or features of interest that are present in an area. Rarity is the richness of specifically defined rare species. Justus and Sarkar (2002) review examples from the 1970's, when the idea of using conservation value to prioritise sites was becoming established. At the same time, changes were being made in reserve selection methodology from ad hoc, expert based identification of sites, to systematic methods (Noss et al., 2002; Margules and Pressey, 2000; Pressey, 1999a; Davis et al., 1999; 
Sarkar 2004). Today, there are a number of specific approaches to biodiversity conservation, involving the maintenance, management, and recovery of biodiversity elements. Biodiversity conservation, then, is an applied activity, requiring political action in specific times and places (Sarkar, 2004) to conserve the diverse biological elements that make up our world (Pressey et al., 1996).

\subsubsection{Conservation Reserves}

The main approach to conserving biodiversity to date has been to control land use in order to minimise land cover and habitat change (Andelman and Willig, 2003; Chown et al., 2003). This is often accomplished with regulations that control activities in a region, often in conjunction with the setting aside of lands through purchase, lease, or other legal means. The cornerstone of most conservation strategies today is the use of reserves where activities are controlled or limited (Arcese and Sinclair, 1997; Possingham et al., 2000; Margules and Pressey, 2000; Scott et al., 2001; Groombridge and Jenkins, 2002), and most countries are committed to creating them by a number of international agreements (Rodrigues et al., 1999; Secretariat of the Convention on Biological Diversity, 2004). However, reserves are not necessarily appropriate in all situations or cultures, nor are they always located and delineated using the same methods, procedures, or goals. Conflicts can occur because local people may have no alternative to living off these and nearby lands, or because some legislative mechanisms are not stable or effective due to lack of long term 
management resources (World Resources Institute, The World Conservation Union, United Nations Environment Programme, 1992).

Reserves come in many shapes and sizes as well as with many different types of land use control mechanisms, such as legislation or policy. The United Nations Environment Programme (UNEP) and the World Conservation Union (IUCN (formerly the International Union for the Conservation of Nature)) have developed a classification system to facilitate analysis and reporting of reserved sites worldwide by the level of priority that biodiversity conservation and protection is given on the site by legislation (World Conservation Union, 1994). Reserves whose primary justification is the conservation of biodiversity, and that allow no human use except conservation-related research, are at one end of the scale. At the other end are those that are used primarily for the sustainable harvest of ecosystem products. Governments and researchers (e.g., Andelman and Willig, 2003; Rodrigues et al., 2004) have analysed and reported on the protection of biodiversity worldwide using these classifications.

\subsection{Systematic Conservation Planning}

\subsubsection{Past Approaches to Selecting Reserves}

Past approaches for selecting areas for protection from development have been varied just as our cultural world view has changed over time. The following summary considers the situation from a North American perspective. Aside from small, common areas for use as gathering spaces and urban recreation, parks began their history as mechanisms for saving rare and spectacular natural areas 
from development. These are the natural monuments associated with the work of John Muir (Noss and Soulé, 1998). As the 20th century progressed, proponents of a wilderness movement emerged that called for delineation of more common undeveloped areas to be conserved in its undeveloped state rather than, for example, being converted to agriculture or urban uses (lbid.). These were the first lands to be identified for their value as being representative of common but threatened types.

At the same time a third approach identified areas of special value by their species richness (Ibid.). Accumulated data about the biological and ecological richness of areas such as wetlands allowed evaluation of their relative value for conservation. Databases in various government organisations and agencies grew to allow the recognition and identification of hotspots of biodiversity, centres of endemism, and habitats containing rare and endangered species. This information in turn supported the development of population and ecosystem models in the 1970's and 1980's (as summarised in Williams et al., 2004; Sarkar, 2004). Expert analysis of these models and data provided recommendations on where reserves were needed and how big they should be. Additionally, recognition of the dynamic nature of habitats and landscapes fuelled an appreciation for the structures and ecosystem processes that are integral to the biology of places (Noss and Soulé, 1998). In the past two decades, as described above, the development of conservation biology saw advances in methods that were systematic and therefore transparent and defensible (Pressey, 1999a; 
Rodrigues et al., 2000). That is, as much as possible, the methodologies were explicitly described and developed in a collaborative environment in order to be repeatable and to enlist support from decision makers. Details on these and other characteristics of systematic planning follow in 2.2.2.

\subsubsection{A Systematic Framework for Conservation Planning}

The main characteristic of the systematic approach is the use of an explicit and open methodology to assess a situation and make recommendations (Williams, 1998; Noss, 2003). A review by Justus and Sarkar (2002) marks a 1971 paper by Ratcliffe as possibly the first attempt to change the reserve selection process from an intuitive problem to a technical one, and, therefore, the beginning of the systematic approach. Ratcliffe (1971) suggested ordering sites based on "the application of agreed standards" (p.294) and, in theory, use of a scoring system in order to make the selection of sites more objective. Margules and Pressey (2000) summarised new methodologies that evolved over the next three decades. These included (see Figure 2.1) choosing surrogates for biodiversity, defining data needs, setting explicit representation targets while taking existing reserves into consideration, reserve creation, planning for long term assessments and maintenance, and periodically reviewing the entire process to incorporate changes to such variables as land costs, land use, or species diversity (extinctions or invasions) (Kingsland, 2002). Figure 2.1 shows that gap analyses and site selection can be done in different order depending on

needs (divergent paths after stage 2). This is discussed in detail in Section 3.4.2. 
The figure also shows which stages contribute to the development of the IP model (blue circle) from those that actually solve it, using algorithms to find sets of locations that may become reserves (red circle). The details of these steps, and the benefits arising from this framework, are discussed in the following paragraphs.

\section{Regional, Multi-feature Perspectives}

The use of computers and GIS to display the distribution of multiple features across a landscape has allowed visualisation of spatially relative and complementary landscape elements, a capability that can enhance expert knowledge (Cowling et al., 2003; Hoctor et al., 1999; Aspinall, 1999). Systematic planning methods take that capability further by processing the attributes of the visual display using geospatial processes and computer models. The extended abilities that result from using computers with explicit data, models, and methods include being able to identify interrelated sites spread across a region (VaneWright et al., 1991). Regions can be landscapes, watersheds, ecosystems, or large political entities such as states or provinces and the result is a network of reserves instead of a collection of individual reserves. The network consists of multiple reserves designed to achieve goals jointly. This is more complex than selecting numerous individual sites based on reasons unrelated to the whole (Root et al., 2003). Planning conservation strategies for more than one purpose in a single area can result in conflicting recommendations (Simberloff, 1998). 
Figure 2.1: Stages in systematic conservation planning. See text for details on stage groupings.

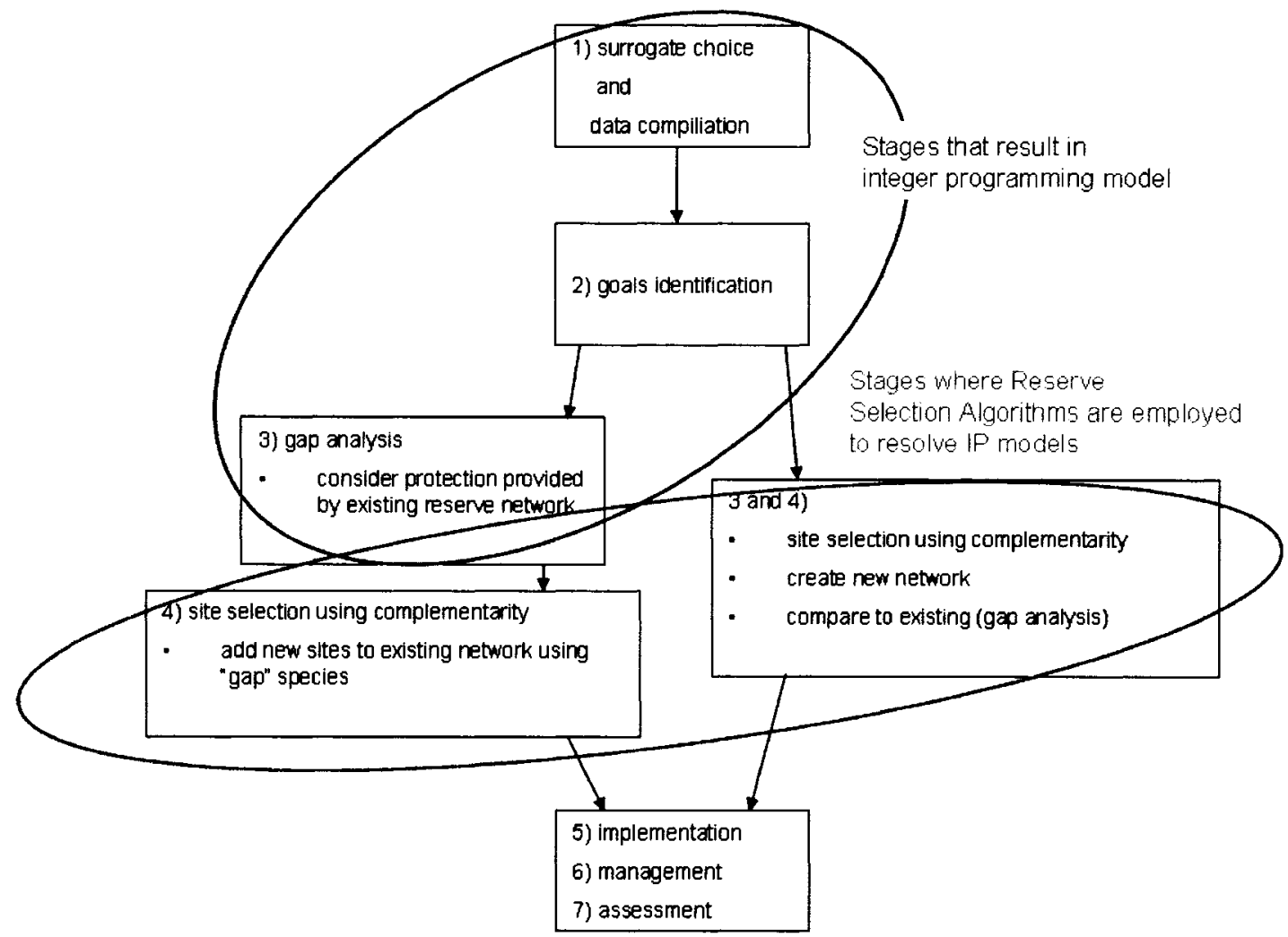

As well, different sites identified for each goal may contribute the same amount or type of conservation benefit for the region. This can make some sites redundant with respect to the particular conservation goals that need to be achieved, and the resources used to make the additional sites could have been used to address additional conservation goals (Rodrigues et al., 1999).

As well, a regional network design approach proactively addresses the ongoing loss of habitat due to human economic development activities (Jennings, 2000; Williams, 1998). Rather than reacting to emergency situations where a species or habitat is nearly extirpated or extinct, a regional approach looks at all 
species or features of interest as a whole and this can result in protection action being taken for species that are still common. The United States Geological Survey Gap Analysis Program (GAP), for example, has the motto "Keeping Common Species Common". The GAP is a decision support program based on a systematic methodology for identifying species that do not have protection from existing reserves, regardless of whether or not they are endangered (Scott et al., 1993; Jennings, 2000; Scott et al., 2001). Although to some this may detract from the importance of reserve recommendations, it can add weight to arguments for reserves if the common species are swept along at no extra cost (i.e., they don't need extra reserves).

Regional planning also allows systematic methods to incorporate spatial ideas, including those from earlier approaches to reserve design. During the 1970s and 1980s, when there was a debate on the benefits and drawbacks of using single large or several small (SLOSS) reserves, there was an underlying assumption that spatial relationships mattered (Diamond, 1975). A network of small, disconnected sites could have different impacts on conservation than a contiguous site. Current research is also looking into other spatial questions, such as how to distribute reserves along migratory pathways (Malcolm and ReVelle, 2002).

\section{Flexibility}

A key capability in the selection of sites in a reserve network is the ability to consider alternatives. Any hypothetical network that cannot be adjusted to meet 
on-the-ground realities, such as sites that are priced too high, sites that are already too highly impacted by development, or even a public that is hostile to a recommended plan, will be unlikely to come to fruition (Chown et al., 2003; Arthur et al., 1997).

As well as being able to find alternative sites or combinations of sites in the provisional network, the software used to find the network sites must work quickly enough to allow interaction in workshops or similar venues. Alternative scenarios, using variations of the IP model parameters, should be solved in a reasonable time or the flexibility of the program is reduced (Sarkar, 2004). Changes in the model can require running the program numerous times.

\section{Efficiency}

Systematic methods allow scientists to improve on the efficiency of reserve design outcomes (Scott et al., 2001; Saetersdal et al., 1992; Kupfer, 1995). That is, conservation and protection of areas from disturbance and development is often in direct competition with the activities that form the economic foundation of human culture (Dasgupta et al., 2000; Chown et al., 2003; Scott et al., 1993). This competition requires the reserve design process to be not only transparent and therefore more defensible (see below) but also to produce reserve networks that are efficient with respect to configuration (e.g., number and total area of reserves should be minimised) and effective (number of features of interest that are conserved, e.g., species, should be maximised) (Sarkar, 2004; Possingham et al., 2000). Identifying potential sites for a reserve network with minimal 
redundancy is key. Redundancy in this case refers to the duplication of the characteristics that are being conserved, such as species or vegetation types. Redundancy of ecosystem elements can improve the resilience of an ecosystem by providing alternative pathways for providing energy and material flows, but competition for locations requires that conservation goals are accomplished with minimal duplication, at least as a first step. Finding the most efficient network of locations provides a backbone upon which further reserves can be added but which has the advantage of being explicitly and efficiently defined. Systematic methods accomplish this by modelling the problem in a computer system using logical and mathematical methods (described in detail in Section 2.3).

\section{Transparency and Accountability}

Improving the transparency of the decision making process in the systematic framework is meant to enlist public and professional support (Justus and Sarkar, 2002). Past decisions for purchase of reserve lands have often been made for reasons other than biodiversity conservation, such as political gain, control of resources, scenic, recreational, political, and theoretical reasons, or even to enhance access to remote areas for the purposes of resource development and harvesting (Possingham et al., 2000; Sala et al., 2002; Kingsland, 2002). In those cases where they actually have been selected for conservation purposes, consideration might only have been given to single species, local politics, or land costs, thus resulting in relatively low conservation effectiveness (Ibid.; Scott et al., 2001). Even when all of these issues were dealt 
with professionally and to the best of scientist's abilities, they might still not be accepted by the public due to the lack of defensibility of the expert-based process (Kingsland, 2002). On the other hand, of course, some may view decisions made by experts as more objective and less influenced by special interest groups. In any case, the systematic approach explicitly describes the goals and results that are being sought in order to make the procedure open for collaboration and comment by interested parties (Kingsland, 2002; Simberloff, 1998; Possingham et al., 2000; Margules and Pressey, 2000; Cowling et al., 2003). Klosterman (1999) outlines the benefits of this approach as described for his decision support software product named What if?:

"By involving the public directly in the planning process, it constrains the discretion of professionals and political insiders, reduces the knowledge differential between professionals and laymen, and gives the public a sense of ownership in the plans and proposals which are developed.

Acknowledging the limitations of planners' knowledge, information, and resources, the model abandons the unrealistic goal of producing a single "exact" prediction of the future for the preparation of a range of alternative scenario-based forecasts which reveal a range of potential futures. Recognizing that models are only useful in a policy context if they are understood by policy makers, What if?'s [sic] underlying structure, relationships, and assumptions are made as explicit and clear as possible." (p.3) 
Noss (2003) made a similar point: "Methodological rigor and scientific defensibility are enhanced by conceptual frameworks, standards, and criteria for guiding and evaluating individual plans" (p.1270). Of course, it is true that public participants may be more interested in non-science agendas, or may be untrained and incapable of evaluating scientific reasoning, but the costs of not doing things openly are that the entire process may fail due to complaints to decision makers about a lack of opportunity to be heard.

Another reason for the popularity of transparent methods over expert decisions is the increasing competition for land. As land becomes scarcer, and prices go up, public scrutiny of decisions regarding sequestration of land units and use of public funds has increased. Explicit planning methodologies, applied in a collaborative environment, provide a level of confidence that reserve selection decisions have taken all pertinent factors into consideration (Kingsland, 2002; Pressey, 1999a; Noss, 2003).

\subsubsection{Selecting Potential Reserves}

The systematic process for selecting reserves is based on a number of actions as described in Figure 2.1. Selecting reserves is done by applying a reserve selection algorithm (RSA) software to mathematical models that represent the conservation problem. The output is a provisional, or potential, set of reserves which may be useful as a core or nucleus for conservation activities (Gaston et al., 2001; Rodrigues and Gaston, 2002; Noss, 2003). The contribution of existing reserves, using gap analysis methodologies (described in Section 
2.2.3.1), should be taken into account as much as possible, as a foundation on which to build additional reserves (Pressey, 1999a). After knowing where new reserves could be located to accomplish the stated conservation goals, appropriate management objectives for those sites must be designed. This can mean making plans that are affordable and practical as well as effective for the conservation needs of each site. Finally, the management plans must be carried out as specified for the particular sites. If at this stage, or any other, a site is deemed to be unsuitable for accomplishing the goal, adjustments to the plans may be made to compensate, the site can be given up and alternatives from the results of the RSA can be examined, or the parameters of the RSA, such as goals or available sites, can be adjusted.

Details on these stages and general information about the pre-selection stages follow in Section 2.2.3.1. This study focusses on the reserve selection stages of a larger systematic process of conservation planning that is itself one tool of many used to inform politicians and other decision makers. Reserve selection algorithms and gap analysis are dealt with together here because they are closely linked (Jennings, 2000). Pressey and Cowling (2001), for example, refute comments by Prendergast et al. (1999) that the two are alternative tools for doing the same thing. They are, instead, two different tools that complement each other, as will be shown. 


\subsubsection{Reserve Selection Modelling}

The application of the reserve selection process requires a number of preparatory decisions regarding data, goals, and their spatial resolution. The following subsections describe the process of creating an IP model from a regional conservation situation. The term "model" in this paper refers to an IP model unless otherwise specified.

\section{Choosing Biodiversity Surrogates}

First, as biodiversity cannot be completely measured, surrogates must be selected. These are features, e.g., animal or plant species or other elements of a landscape, that can be measured and are indicative of various aspects of biodiversity. A number of types of surrogates have been used in the past including umbrella, flagship, or keystone species (Kerr, 1997; Simberloff, 1998; Roberge and Angelstam, 2002; Andelman and Fagan, 2000), environmental classes (Faith, 2003b; Williams et al., 2002; Bryan, 2003), richness or rarity (Kerr, 1997), habitat types, or complementarity, which is the amount of similarity that exists in the features of various sites (Faith and Walker, 1996; Reyers et al., 2000). Umbrella species are species that require habitat or reserves that might coincidentally provide protection to other species. Umbrella species that require larger areas are often used (Simberloff, 1998) because large areas generally afford protection to more species (but see Kerr, 1997, who found carnivores were a poor umbrella species for invertebrate taxa). However, larger areas can be problematic, with increased costs and management difficulties. Flagship species are those that have a high public profile and therefore may provide coincidental 
protection to other species. Keystone species are those that are considered to be crucial elements of an ecosystem, so that protecting them protects other species by coincidence as well.

More complex approaches to choosing indicators of biodiversity include using a GIS to find those areas that have certain physical characteristics or high spatial complexity. This is the premise behind environmental classes, where any number of habitat, climate, geology, soils, or other data can be combined and analysed to find the most important sites to protect. Finally, areas where more species are found (richness) or where rare, endemic species are found can also be used as surrogates for biodiversity. These approaches allow biodiversity to be represented by multiple species, often as a representative sampling of all taxa (Carignan and Villard, 2002; Faith and Walker, 1996). They can be taxonomic groups (e.g., all birds, reptiles, etc.) or lists of species of choice (e.g., endangered species (e.g., IUCN Red List species (see http://www.redlist.org/)) or COSEWIC species (Committee on the Status of Endangered Wildlife in Canada (see www.cosewic.gc.ca)) or other species of concern).

\section{Collecting Data}

Data that represent the distributions of the surrogate features across the region must then be collected and compiled. Issues of concern in data collection for use in models are quality and quantity of data (Poiani et al., 2001; Gaston and Rodrigues, 2003), the use of distribution models that infer presence from association with other landscape elements (Iverson and Prasad, 1998; Loiselle et 
al., 2003; Rosenzweig et al., 2003), sampling bias (Williams et al., 2002), integration of different data types (Bowker, 2000), and the effects of scale on distribution data collection (Stoms, 1994).

\section{Identifying the Conservation Goal}

Next, an explicit conservation goal must be defined. Intuition may suggest that goals should be set before surrogates are identified and data collected, but goals are often constrained by the available data (Margules and Pressey, 2000; Sarkar, 2004). The goal for many reserve IP models is usually a network of locations or grid cells that will provide a certain level of representation of the surrogate features in the region, such as having all species represented at least one time or having a certain percentage of each species' range included. For example, Rodrigues and Gaston (2002) have listed 32 systematic reserve studies known to them and included the goal for each one. They include finding the most features that can be contained in a given number of locations, finding the smallest number of locations that can contain some portion of every feature's range, finding a set that contains at least $5 \%$ of each land system in question, and a number of others.

Particular goals must be the starting point for a conservation plan, but they may not be the ending point (Williams, 1998). The goal of feature representation in a network of sites ensures only the inclusion of each feature, and there is no guarantee that these reserves will sustain viable populations of those features (Gaston et al., 2001). Therefore, these sets are often seen as a minimum or core 
set that should be built on (Rodrigues and Gaston, 2002; Chown et al., 2003), often under the direction of experts (Pressey and Cowling, 2001; Cowling et al., 2003). As well, this stage serves the purpose of a coarse filter, where general localities are identified but which will require fine filter approaches in order to ensure that the conservation activities that are eventually carried out will be effective (Csuti et al., 1997; White et al., 1999).

The point of the explicit method of setting goals is to work with transparent parameters that can be adjusted if required. The goals might not, for example, provide an assurance of long term persistence of the surrogates in the region. Population viability analyses are more suited to predicting persistence and work is being done to investigate ways to consider viability in reserve selection IP models (Gaston et al., 2001; Cabeza and Moilanen, 2003; Williams and Araújo, 2000; Williams and Araújo, 2002; Rodrigues and Gaston, 2002).

\section{Gap Analysis}

It is often the case that a region will have existing conservation reserves. However, as discussed, the development of systematic conservation planning as an approach has occurred partly because pre-existing reserves virtually never achieve regional biodiversity conservation goals (Cowling, 1999; Jennings, 2000; Sarakinos et al., 2001) although this is not always the case (Rodrigues et al., 1999). The difference between the protection offered by existing reserves and the protection levels set in comprehensive, regional plans is quantified by the gap analysis process (Scott et al., 1993; Margules and Pressey, 2000; Noss, 2003). 
This is often done by identifying the features targetted for protection in the regional plan that are not protected to a defined degree by the extant reserves (Kiester et al., 1996; Nantel et al., 1998; Andelman and Willig, 2003). These are "gap" features, so-called because they are the result of gaps in the coverage of the existing collection of reserves. By identifying gaps in the current coverage of protected areas, resources can be directed to those needs instead of potentially adding protection that is not as important as in other areas. In the interests of efficient regional use of resources, it is also possible to identify those existing reserves that are providing duplicate or no coverage to targetted features and are therefore not needed to achieve the planned goals (although they may still be important for reasons that are not in the model). This is done by using all features of interest instead of just gap features, then the new provisional network can be examined for coincidence or overlap with existing reserves. Any existing sites that do not coincide with the provisional sites may be examined for potential redundancy (Kiester et al., 1996; Nantel et al., 1998; Andelman and Willig, 2003).

\section{Mapping the Data as Discrete Locations}

The surrogate distribution data must be represented in the region in a way that allows precisely delineated locations to contain a value for the surrogate feature, either as a variable amount or a presence or absence indicator. The region or landscape is divided into a collection of spatial units, such as watersheds or political units, or as a cartographic grid, such as latitude/longitude lines or constructed equal area cells (White, 2000; White et al., 1999). Individual 
cells can be excluded from the model if they are known to be inappropriate for conservation activity for biological or socio-political reasons.

The appropriate size (area) of grid units is decided in conjunction with the scale or resolution of the surrogate data and the conservation goals (Pressey and Logan, 1998; Warman et al., 2004). For example, using a grid of small cells may not be appropriate for low resolution feature distribution (e.g., species range maps) data. It also may not be desirable to select cells that are too coarse to represent the reality of high resolution feature data such as provided by remotely sensed images (Aspinall, 1999). It has also been shown that the resolution of the cells affects the percent of the area required to meet the conservation goals, with smaller cells requiring less total area (Rodrigues and Gaston, 2001; Warman et al,. 2004, Pressey et al., 1997; Pressey and Logan, 1998).

Typically, the feature distribution data are overlaid on the grid cell map layer in order to create a binary table of presence/absence data that is used by the reserve selection software. That is, the records represent the individual locations (or cells or sites in this paper) and contain fields for each feature (often species in this paper). The records would be connected to the map by way of a lookup table that used the map cell ID\#. This is a common approach (Rodrigues et al., 2000; McDonnell et al., 2002), and many case studies consider a feature to be present if any portion of the known range overlaps with any portion of the grid cell, but certain percentages of overlap of range maps with cells can also be required before being considered present (Kiester et al., 1996). This binary, feature-by- 
locations table (Table 2.1) is therefore a model of the conservation situation under consideration (but not an IP model, as will be shown). It contains information on the biodiversity surrogates presence or absence in the individual locations and can be used as input, along with the conservation goals, into reserve selection software. The creation of models that represent a mathematical (integer programming) problem by adding defined conservation goals is presented in Section 2.3, followed in Section 2.4 by the algorithms that resolve those IP models. First, however, the key concept of efficiency in network design is presented.

Table 2.1: A presence-absence array of data for 8 features (e.g., species) (columns) and 5 locations (e.g., map cells) (rows). Each location has a certain number of features present (1) and absent (0).

\begin{tabular}{|l|l|l|l|l|l|l|l|l|}
\hline & Spp A & Spp B & Spp C & Spp D & Spp E & Spp F & Spp G & Spp H \\
\hline Location A & 0 & 0 & 1 & 1 & 1 & 1 & 1 & 0 \\
\hline Location B & 1 & 1 & 1 & 1 & 0 & 0 & 0 & 0 \\
\hline Location C & 0 & 0 & 0 & 0 & 1 & 1 & 1 & 1 \\
\hline Location D & 1 & 1 & 1 & 0 & 0 & 0 & 0 & 0 \\
\hline Location E & 0 & 0 & 0 & 0 & 0 & 1 & 1 & 1 \\
\hline
\end{tabular}

\subsubsection{Solving IP (Conservation) Models Efficiently}

If the goal is to find a set of reserves where all indicator species occur at least once, then once a certain species is included, it would not be efficient to select another site that contained that species (Pressey et al., 1996) unless it was included incidentally. When a collection of sites is ordered, or prioritised, by various attribute values such as species richness, the top sites will often include many of the same features because they are often located in the same general 
area and populated by the same species. Figure 2.2 shows in bright blue outline the 7 sites with greatest species richness for British Columbia (Lindsay, pers. comm., 2004). There is little doubt that many of these sites will contain many of the same species because of their contiguity. The six clumped sites all contain 67 species and the one lone site contains 68 , including one that only occurs in that one site in British Columbia. This method of prioritising potential reserve locations is known as scoring (Ratcliffe, 1971; Williams, 1998; Saetersdal et al., 1992; e.g., Scudder, 2003).

Figure 2.2: Cells with greatest species richness in British Columbia.

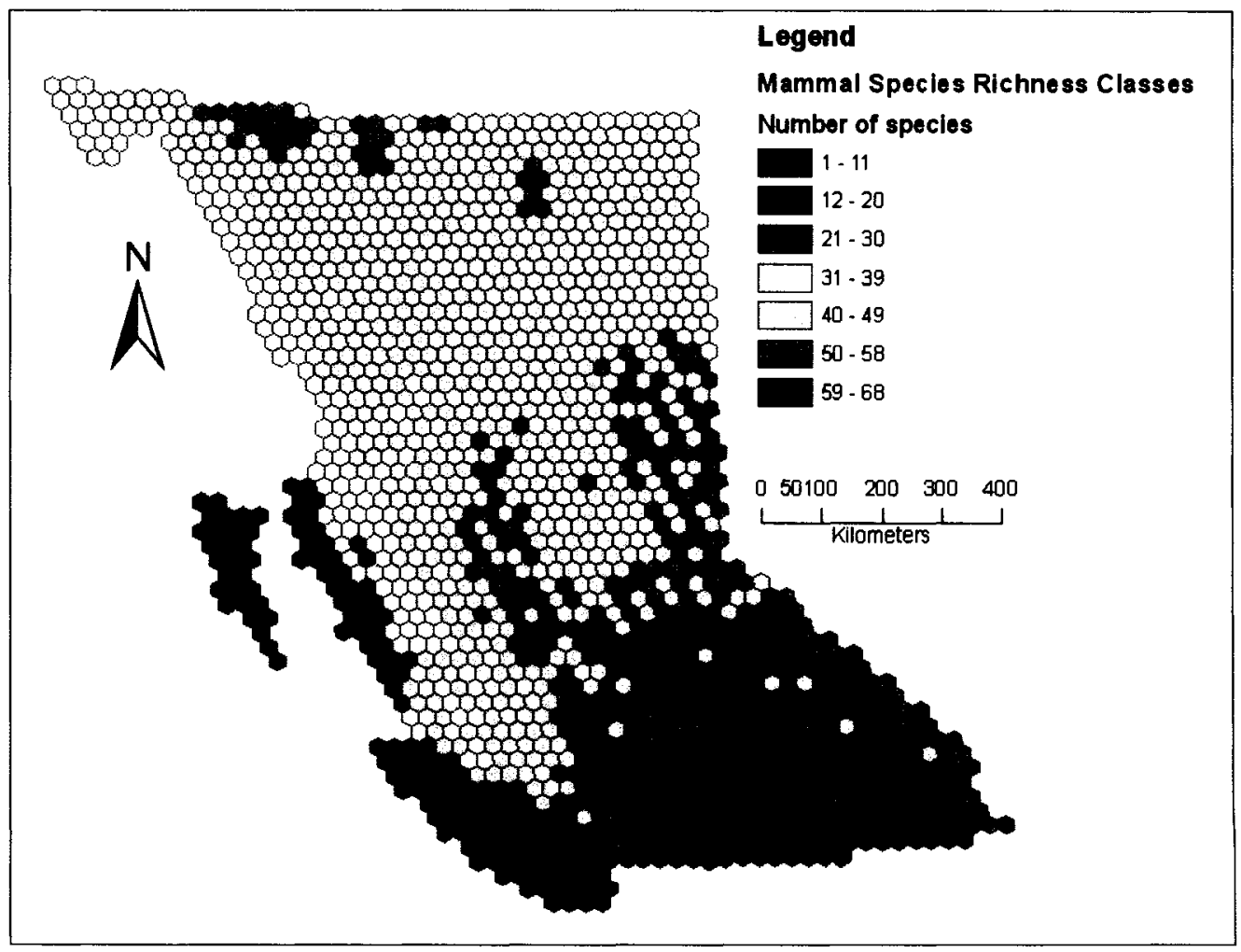

Although it may be ecologically beneficial to represent features more than once in a set of reserves, it may be more efficient to find a similar number of sites 
that covers more features by reducing the number of redundant features (VaneWright et al., 1991; Church et al., 1996). This is easily done by selecting the top site, then removing the species that are included in that site from the model and therefore from further consideration in any other site. The next best site will be the one that has the most species that are so far unprotected (Kirkpatrick, 1983). The process can continue in this fashion, removing features that are covered by each selection of an interim reserve before selecting the next richest site.

Figure 2.3 illustrates this procedure. In this example, two provisional reserves (cells) are selected as steps in identifying a reserve system where the goal is to include the maximum number of species. Those two cells can be selected by scoring so that the two cells with the greatest overall species richness are used (60 spp. in total in Figure 2.3). Alternatively, using the procedure described above where complementary features are removed at each iteration (methodology details are provided in the next section), there may be two sites that jointly include more spp. in total (70 spp. in total in Figure 2.3) even though neither site is among the richest overall. Normally, more features are covered in the same number of sites this way, and, conversely, it takes fewer sites to cover all the features in the model (Vane-Wright et al., 1991; Williams, 1998; Justus and Sarkar, 2002).

This idea, known as the principle of complementarity in the reserve selection literature (see Pressey (2002) or Justus and Sarkar (2002) for an indepth historical review), has become central to reserve selection methodologies 
used today. It should not be taken to mean that the fewer times a species is provided refuge the better because of the reduced cost. Instead, it can be seen as an opportunity to have the greatest conservation impact for a given, and often limited, resource budget (Rodrigues et al., 2000). As well, it may be that a surrogate feature that requires a smaller set of sites for protection will have greater chance of being protected (Ferrier et al., 2000).

Figure 2.3: Cells classified by species richness illustrate the principle of complementarity, selecting cells' highest joint richness (2) instead of the highest individual richness (1).
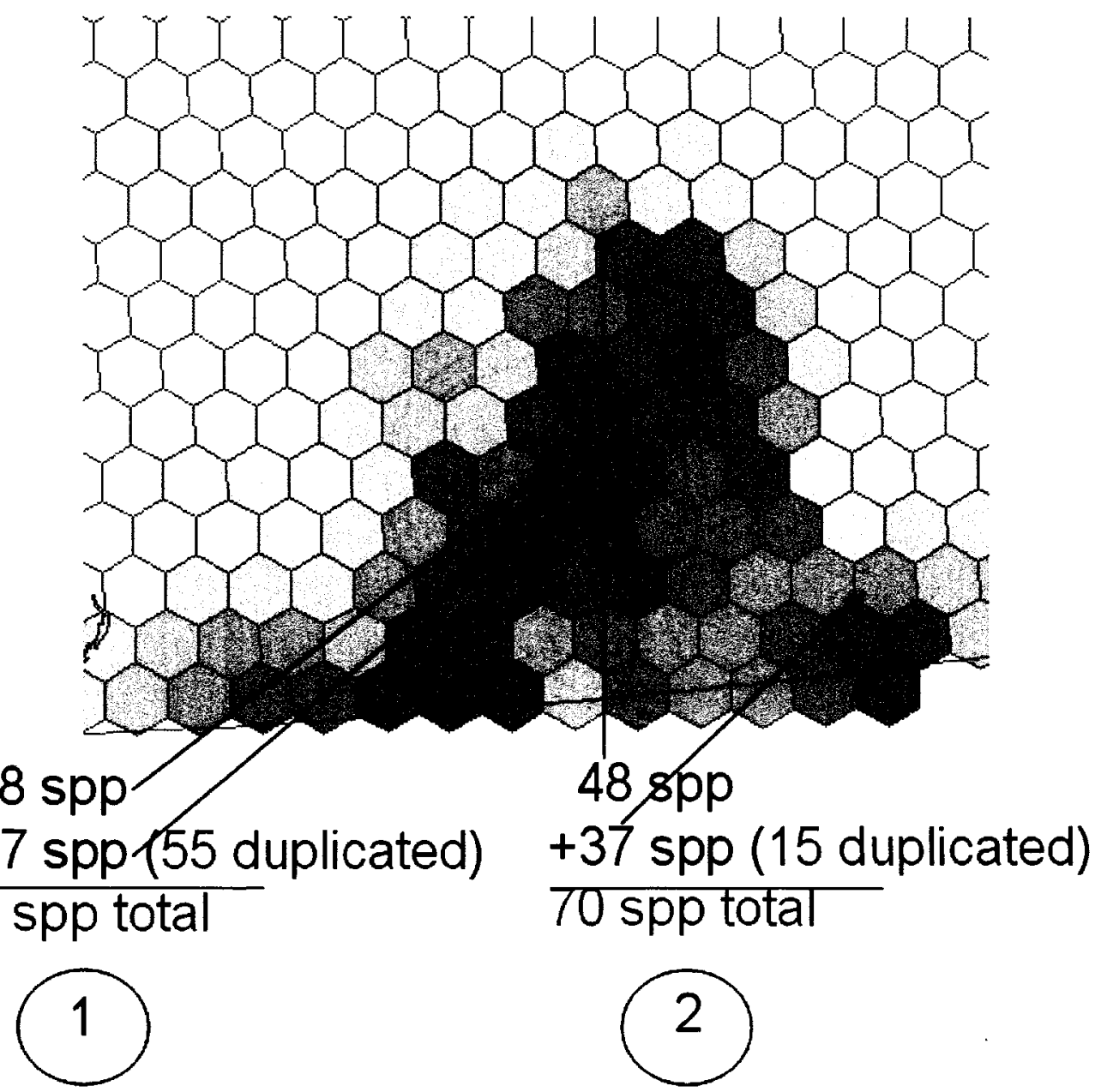
Spatial Characteristics of Solution Sets Using Complementarity

Using the principle of complementarity, the network of provisional sites

tends to be spatially distributed around the region instead of clumped in smaller, species-rich areas as in Figure 2.2. This reflects the contributions of complementary ecosystem structures and functions (White et al., 1999; Csuti et al., 1997; Moritz et al., 2001; Bryan, 2003; Williams et al., 2004). In practice, there are advantages and disadvantages, in parallel to the SLOSS debate, to both the clumped and distributed configurations and there is no single configuration that provides advantages in all respects. Costs may be higher for a more highly distributed network of sites, but this assumes that management costs are related to distance from an arbitrary centre and that land costs are not higher in the region of clumped sites. A highly distributed set of sites may provide conditions for better viability of biodiversity (or its surrogates) as the impacts of local extinctions and extreme conditions may be buffered by the inherent redundancy (McDonnell et al., 2002; Bryan, 2003; Williams et al., 2004). On the other hand, less fragmented, more connected sites may provide better viability for more species. A set of solutions that can provide a diversity of configurations in response to changing priorities is often advantageous.

Figure 2.4 illustrates how provisional networks of cells selected using the principle of complementarity can be distributed around the region. The figure also illustrates that more than one set of cells can represent a given number of species, as discussed in Section 2.4.3. Mathematical models that incorporate the 
data tables and goals described above, and feature this efficiency principle, are described next.

\subsection{Integer Programs}

This thesis is concerned with conservation data represented as 0-1

(absence-presence) feature-by-location tables, 0-1 (no-yes) representation goals, and the incorporation of efficiency principles described previously. Mathematical models that incorporate those elements are well developed in Operations

Figure 2.4: Distributions of groups of cells around a region when selected using complementarity. This map of BC shows multiple groups of 7 cells (each group is composed of one cell of each different colour) (after Lindsay et al., unpublished - scale as in Fig.2.1).

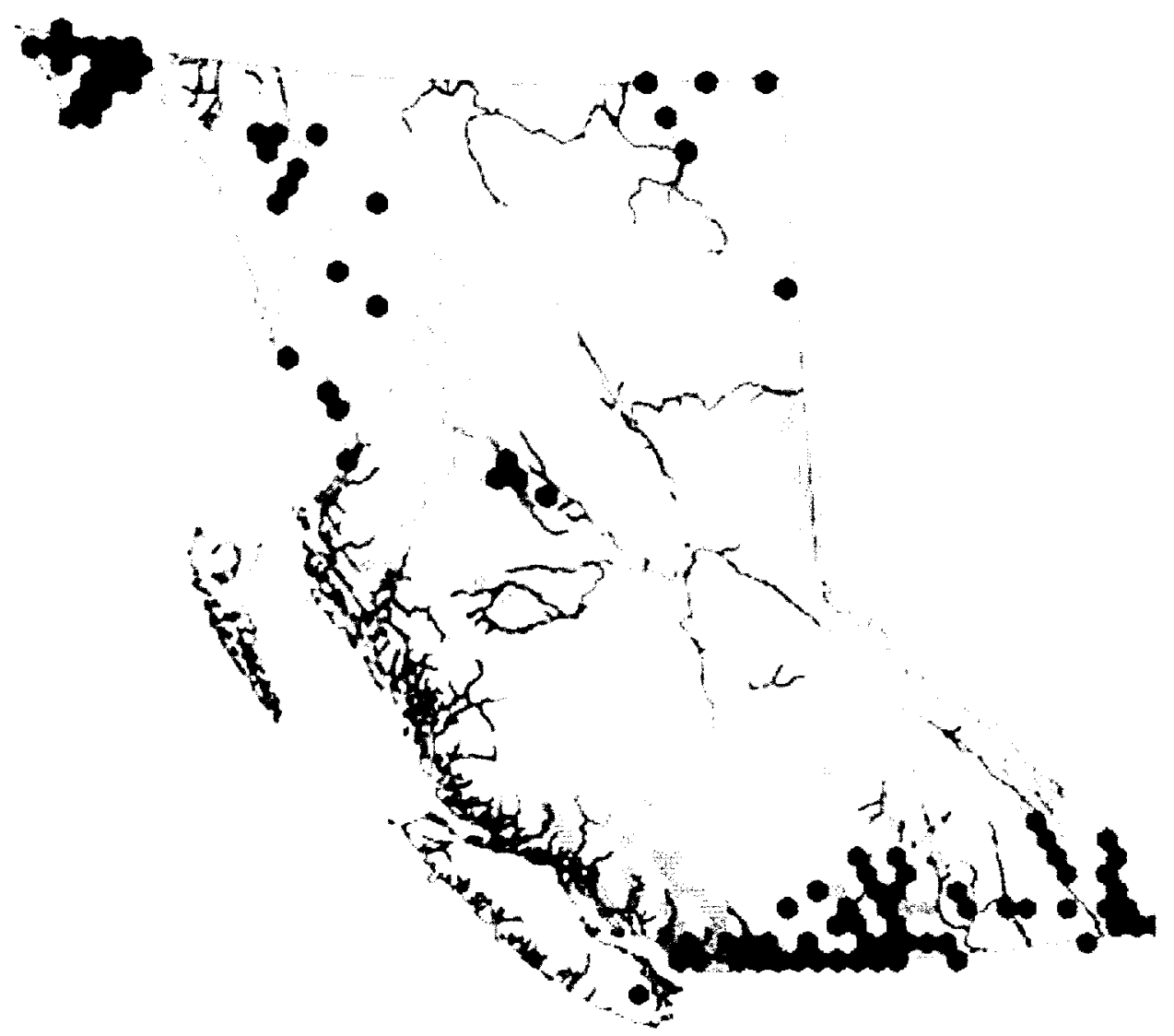


Research (OR), a field of mathematics that emerged in the late 1930's (ReVelle et al., 2002). OR initially came about because of the needs of the British military to make use of new technologies efficiently and effectively in national defence. The practical goals of OR were, and still are, to make optimal use (i.e., maximally efficient in terms of cost, time, energy and other criteria) of human and material resources using methods that allowed objective, and therefore defensible, decisions to be made (Beasley, unpublished; Kingsland 2002; Cabeza and Moilanen, 2001; Rodrigues and Gaston, 2002).

One class of mathematical problems being dealt with in OR are linear programs (LP). Over the past decades, numerous solution methods have been developed for them (Arthur et al., 1997). In a linear program, generally speaking, certain variables can be represented as one or more linear functions that are optimised (maximised or minimised depending on the situation) subject to certain constraints such as limits on materials, time, or other variables. Species richness models can be represented as a type of linear program, where the LP takes on the additional constraint that the variables, which are locations or features, are either fully included in, or excluded from, the solution. This type of LP is called an integer program (IP), because the variables must maintain an integer form. As well, the variables have only two possible states - included or not included in the solution. Integer programs often require variables to be part of a discrete set, such as this type of binary set, where 1 represents a yes or go situation and 0 represents a no or no-go situation. The goals of this IP are slightly different than 
an LP in that the number of locations or features are optimised instead of a linear function. For example, an IP may require all feature variables to be represented a certain number of times or to sum to a certain total. The former case is one in which the model objective may be to find the least number of sites that can include one occurrence of every feature. The latter case could be where a number of sites is allowed and locations must be selected that include the maximum sum of features.

Numerous forms of IP models (also called, simply, integer programs or IP) have been developed to deal with a wide variety of efficiency problems in business and industry such as facility/site location, network design, transportation logistics, scheduling, sequencing, and resource-allocation. Two common forms of IP that have been adopted unchanged for use in reserve selection are the set covering problem and its variant, the maximal covering problem (Church et al., 1996; Arthur et al., 1997; ReVelle et al., 2002; Kingsland, 2002). Their formula variations and application are described in the following sections.

\subsubsection{The Locational Set Covering Model}

The goal of the set covering IP as a reserve selection problem, called the Locational Set Covering Problem (LSCP) in this study (sensu Church et al., 1996, but also called the Species Set Covering Problem by ReVelle et al., 2002), is to minimise the number of locations/sites subject to the constraint that all model features (e.g., species) are included in at least one location. The mathematical notation, from Rodrigues et al. (2000) but available in numerous 
other papers (e.g., Cabeza and Moilanen, 2001; Bryan, 2003; Arthur et al., 1997; ReVelle et al,. 2002), is as follows (terms have been adjusted, as identified with square brackets, to match the vocabulary used above):

Minimise $\sum_{j=1}^{n} x_{j}$

Subject to $\sum_{j=1}^{m} a_{i j} x_{j} \geq 1, \quad i=1,2, \ldots, m$

$$
x_{j} \in\{0,1] \quad j=1,2, \ldots, n
$$

"where $\mathrm{n}$ is the number of [locations], $\mathrm{m}$ is the number of [features], $a_{i j}$ is 1 if feature $i$ is present in [location] $j$ and 0 if otherwise, and variable $x_{j}$ is 1 if and only if [location] $j$ is selected. "The objective function (I) is to minimise the number of [locations] selected. Inequalities (II) ensure that each of the $\mathrm{m}$ [features] must be present at least once.

The integrality restrictions (III) state that each variable $x_{j}$ is either 0 or 1 , forcing each [location] to be treated as in indivisible unit (thereby avoiding solutions that would select fractions of each [location])" (Rodrigues et al., 2000, p.566).

A common example of a Location Set Covering Problem would be to find the smallest set of locations that collectively contain at least one occurrence of every species of interest in a region, or that collectively contain at least $5 \%$ of the total regional extent of a soil type (see Rodrigues et al., 2000 for a number of examples from the literature). 
Choosing "at least one occurrence" of each species or feature in the LSCP is counterintuitive to the idea that features of concern should be protected to the maximum extent possible. However, the goal of an efficient, regional approach is to identify a network of sites that taken together provides the most conservation impact given likely competition with other land uses. As mentioned before, this can then serve as a backbone set of reserves which can be expanded if desired, with the advantage that they are being added to a core network that is an explicit solution to a defined IP model.

Despite the use of the term "location" in the name of the IP by some authors, information pertaining to the physical locations of the cells, and therefore the spatial relationship of each site with respect to other sites (topology), is not stored in the IP model (Church et al., 1996). The locations are the binary variables that are to be optimised, either including or excluding each one. The physical locations of the cells are identified using lookup tables that join to each record, and the results can be mapped in a GIS. Then, since each cell has a unique list of species, different percentages of the range of each feature may be covered, or contained, in different sets of locations. It is also possible to modify the IP in many ways, including changing the objective to optimise a spatial attribute, such as the boundary-area ratio or between site distances so that fragmentation of sites is influenced (e.g., Possingham et al., 2000; McDonnell et al., 2002; Malcolm and ReVelle, 2002; Williams et al., 2004). 


\subsubsection{The Maximal Covering Location Model}

An alternative to the LSCP is the Maximal Covering Location Problem (MCLP) (sensu Church et al., 1996, but also called the Maximal Covering Species Problem by ReVelle et al., 2002), where the objective function and variables are reversed. Instead of finding the minimum number of locations that can contain all features, its goal is to find the maximum number of features that can be included in a limited number of locations. The number of locations is added as a constraint in the model. This is often used when the land allocation budget is predefined and the greatest coverage of features is desired for a certain size of network.

As with the LSCP, the topology, or spatial relationships of the cells, are not represented in the model but the results can be mapped in a GIS and analysed spatially. Since each cell has a unique list of species, different sets of features or percentages of the range of each feature can be contained in different solutions when more than one solution exists (see Section 2.4 below).

The LSCP and the MCLP are closely related (Camm et al., 1996; Church et al., 1996; Rodrigues et al., 2000; ReVelle et al., 2002; Arnold, pers. comm., 2004). The solution to the LSCP is a certain number of sites given the constraint of including a certain number of species in the model, and the solution to the MCLP is a certain number of species given the constraint of using a certain number of sites. However, it is possible that the number of sites constraining the MCLP be equal to the number of sites that the LSCP finds are needed to cover 
all species. When this is the case, the MCLP will be able to cover all species and both models are identical.

Once a problem is formulated as an IP, it can be solved using logical or quantitative algorithms. Section 2.4 introduces the algorithms relevant to this research and describes differences between them that can affect their use and results in systematic conservation reserve planning.

\subsection{Two Algorithm Types for Solving Conservation Models}

\subsubsection{Heuristic Algorithms}

The task of the reserve selection process is to identify a network of sites that will satisfy the goal of the model (e.g., of the LSCP, MCLP or other models) while optimising the efficiency of the reserve coverage using the principle of complementarity. The use of heuristic methods to accomplish this first took place in the early 1990's, incorporating logical, iterative methodologies to process the data. Heuristic algorithms use a decision tree procedure as follows, assuming that the goal in this case is to represent all species (or other surrogate features) in at least one location in the region (i.e., LSCP):

1. sort the sites according to one or more conservation attribute values such as species richness

2. select the site with the highest value for that attribute and place it in a new list (If this step finds more than one site with the same value, any second attribute value can be used to break the tie. If a tie still exists, 
another attribute value can be used, and so on, or one of the tied sites can be chosen by order of occurrence or at random.)

3. remove all the features from the analysis that are now covered by the site placed in the new list

4. if the conservation goal is not met, recalculate the prioritisation attributes without the removed features and start again at step one

Step 3 would need to be adjusted if a different goal was used, such as to represent a certain percentage of a species' total range. Note also that stopping this iterative process (which intends to solve the LSCP) at any step is equivalent to solving the MCLP, where the most species possible are covered by a given number of reserves (i.e., steps in the procedure). This is because at each step the maximum number of species that the algorithm can find for the given conservation attribute type and the given number of sites are included.

Figure 2.5 illustrates the logical approach in flow chart form (after Garson et al., 2002) from a package called ResNet (Aggarwal et al., 2000). As well, a large number of possible variations of criteria and steps can be found in Csuti et al. (1997) and Pressey et al. (1997). ResNet orders location cells by feature rarity and, when necessary (i.e., when two or more cells have equal rarity values), by complementarity (the site with the highest number of additional features). Any ties remaining after sorting by complementarity can be selected at random, by proximity (if using a GIS) or, as in this case, by occurrence in the table. Pressey et al. (1997), for example, used an algorithm that breaks ties with random 
Figure 2.5: An example of a logical approach to selecting priority reserve sites from a regional data model as used in the ResNet software package (Aggarwal et al., 2000) (after Garson et al., 2002).

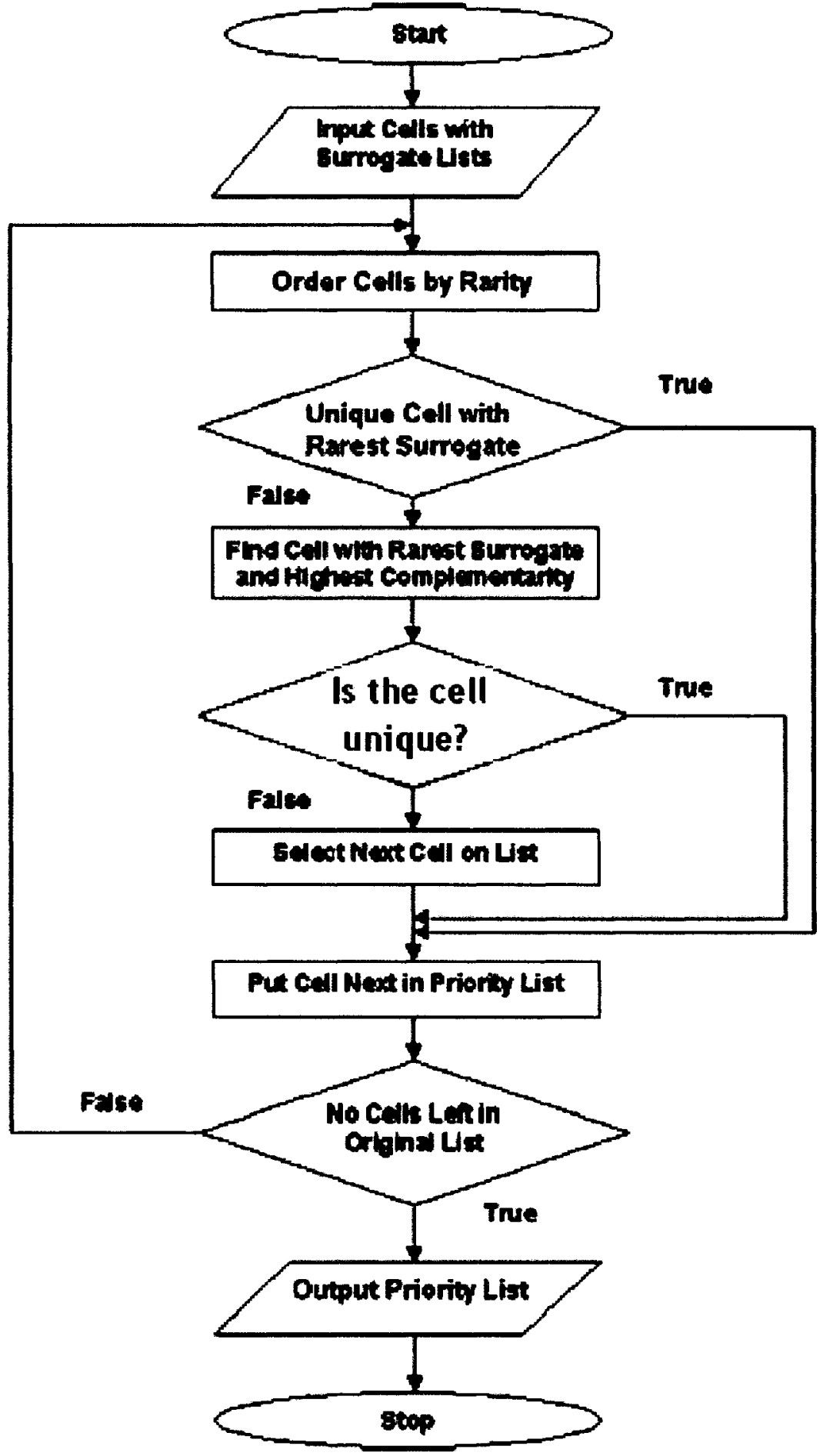


selection of tied sites with the result that each run of the same data can produce different sets of sites. On the other hand, those algorithms that break ties by selecting the first site based on the cell identification code, or the nearest site, using spatial proximity, will always find the same solution set each time the algorithm is used.

Other packages may use similarly straightforward criteria like species richness, but some use more complex calculated criteria. The various sorting criteria, then, singly or in various combinations, are the basis of the prioritisation of cells for selection into the solution set.

\section{Suboptimality of Heuristic Solutions}

The logical heuristic approach to sorting and selecting potential reserve sites using complementarity was developed independently of operations research collaboration. As mentioned previously, it was an extension of the research that called for evaluation and sorting of conservation elements, adding efficiency as an integral aspect. The fact that logical sorting approaches were duplicating the design of set covering and maximal location IP models seems to have gone unmentioned until two authors pointed it out in close succession (Possingham et al., 1993; Underhill, 1994). This was despite the fact that a small number of researchers had already applied OR methods to conservation problems (e.g., Cocks and Baird, 1989; Saetersdal et al., 1992). Underhill noted that the logical, iterative methods were comparable to the type of algorithm used in operations research known as heuristic algorithms (or just heuristics (sensu 
Reeves, 1996)). Both Possingham's group and Underhill pointed out that heuristic algorithms, including the logical approaches used by the conservation community, could not guarantee optimal results, nor could they inform the user of the degree of suboptimality in the solution. Optimality, in the sense used by Underhill, and adopted here, referred to the minimal number of sites needed to cover all features or the maximum number of features covered by the given size of network.

Pressey et al. (1996) held that suboptimality should be minimised. They and others (Willis et al., 1996; Rosing et al., 2002) also pointed out that suboptimality may not be a drawback in the real world where a number of vague ecological and political factors may influence final decisions and effectiveness. However, they recognised that low suboptimality was an important goal for every heuristic, stating that iterative heuristics should be specifically designed to minimise suboptimality (see also Possingham et al., 2000; Cabeza and Moilanen, 2001; McDonnell et al., 2002).

A suboptimal result could occur when using a heuristic algorithm with an LSCP or an MCLP. For the former, the result would be selection of more sites than the minimum needed to cover all species, and for the latter, coverage (protection) of fewer species than the maximum possible by a given number of sites. If the site with the highest feature richness should not be part of the most efficient solution set (as shown in Figure 2.4) and that site is selected first, the most efficient solution cannot be found. Most heuristic algorithms are not able to 
drop such sites in favour of others with greater joint richness, and are therefore susceptible to being caught in a "local minimum" (Reeves, 1996; Church et al., 1996; McDonnell et al., 2002). These type of algorithms are also known as "greedy" heuristics because they have no mechanism for releasing sites that have been previously selected.

The hypothetical accumulation curves in Figure 2.6 (created here for explanatory purposes only) show how suboptimality of heuristic algorithms could vary with the number of required sites for the MCLP. At $n=1$, a richness-based heuristic algorithm will find the optimal solution to the model, since the model goal is to cover the most features and richness selects cells with the most features. A rarity-based heuristic algorithm, on the other hand, still tries to find the most features, but only the kind that have restricted ranges. At $n=2$ and further, for the richness-based algorithm, there may be a divergence from an optimal set. For the rarity-based algorithm, it is possible that as fewer endemics are left the remaining features may be covered. It has been reported that as $n$ grows towards the size required to cover all features (i.e., LSCP) when rarity is the attribute used, there is often a convergence towards optimality (Csuti et al., 1997). For LSCP, the figure shows how results can be suboptimal, as not all features have been covered and additional sites are needed.

As well, there is no mechanism available to evaluate the suboptimality of the solution before or after running a heuristic algorithm unless another algorithm capable of finding an optimal solution is run in parallel. This problem works 
against the principles at issue, namely to use clear logic to optimise the efficiency of the reserve design and have an accountable, repeatable, systematic method (Rodrigues et al., 2000; Williams et al., 2004). Underhill (1994) summarised his comments on the use of heuristics by stating that algorithms that guaranteed optimal results were the proper branch of research to follow because results that were of an unknown degree of suboptimality may not be providing exactly complementary reserve sets and may be causing unacceptable increases in network costs.

Figure 2.6: Hypothetical accumulation curve for optimal and suboptimal results to MCLP ( $n=1$ to 14$)$ and $\operatorname{LSCP}(n=14)$.

\section{Hypothetical Optimal and Suboptimal Solutions for MCLP and LSCP}

$\rightarrow$ Optimal Results

$\rightarrow-$ Suboptimal using Richness

— Suboptimal using Rarity

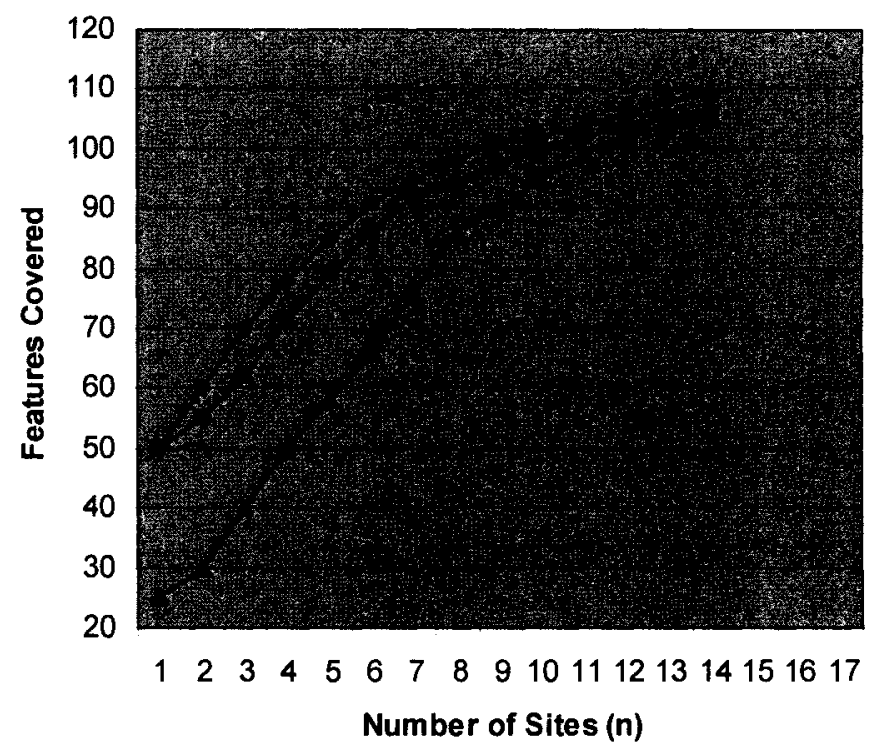

Suboptimal solutions are acceptable to certain users, especially in business or materials management, because a problem may not require an exact solution, 
or use of an approximate solution may be less costly than waiting for an optimal one (Beasley, unpublished). In biodiversity conservation, there may also be an acceptable amount of suboptimality, but it is preferred that the exact amount of suboptimality be known when making decisions (Rodrigues et al., 2000), especially when results can vary. There are some specialised heuristic algorithms that have the ability to escape local minima in some cases. For example, the simulated annealing algorithm (Reeves, 1996; Possingham et al., 2000) will randomly and temporarily drop some of the sites from the priority list to look for better (i.e., less suboptimal) scores. A variation of the greedy heuristic that uses multiple runs with random seeding of the initial set has also given good results (Rosing et al., 2002). As with all heuristic solutions, there is no way of knowing how close to optimal the solutions from these heuristics are without using an optimal algorithm for comparison (see next section).

Heuristic algorithms for conservation reserve selection are available in a number of software packages that run on common desktop computers. These packages allow users to input their datasets and goals into tables which are resolved using the built-in algorithms and produce site location sets for the selected criteria and constraints.

\subsubsection{Optimal Algorithms}

As mentioned, optimal algorithms are those that guarantee an exact solution (sensu Reeves, 1996 and Mitchell, 2002), where one exists, to the objective function of the IP model. They do this by using a more robust and 
thorough set of mathematical procedures such as complete enumeration or branch-and-bound procedures, described below. In turn, these methods generally require higher computational costs compared to heuristics, costs which can grow exponentially as the problem size becomes larger (Possingham et al., 2000; Rodrigues et al., 2000; Cabeza and Moilanen, 2001; McDonnell et al., 2002; Moore et al., 2003).

For very small datasets, optimal solutions can be found by visual inspection. For example, Table 2.2 (from Underhill, 1994) represents an array of cell and feature data, where each array element indicates if a feature (column) exists (1) or not (0) for a location or site (row). The objective of the LSCP, for example, is to find the minimum number of sites (rows) where the sum of each column is $\geq 1$. This is accomplished optimally with rows 2 and 3 since no fewer rows will "cover" every feature. No other combination of two records will solve the problem, but other combinations of records will solve it suboptimally, such as rows 1,2 , and 5 . Suboptimal solutions would be found using a heuristic that selected locations based on richness, since once location 1 is selected (the richest), the algorithm has no choice but to add 2 more sites. One of the suboptimal solutions in that scenario could even be sites 1,2 and 3, the richest site plus the optimal set of sites.

The solutions to the IP problem based on this small dataset are apparent by visual inspection, but finding them with a computer requires complete enumeration. Complete enumeration involves having the computer check every 
Table 2.2: A presence-absence array of data for 8 features (columns) for 5 locations (rows). The goal of the LSCP is to find the smallest set of locations that covers all features at least one time.

\begin{tabular}{|l|l|l|l|l|l|l|l|l|}
\hline & Spp A & Spp B & Spp C & Spp D & Spp E & Spp F & Spp G & Spp H \\
\hline Location A & 0 & 0 & 1 & 1 & 1 & 1 & 1 & 0 \\
\hline Location B & 1 & 1 & 1 & 1 & 0 & 0 & 0 & 0 \\
\hline Location C & 0 & 0 & 0 & 0 & 1 & 1 & 1 & 1 \\
\hline Location D & 1 & 1 & 1 & 0 & 0 & 0 & 0 & 0 \\
\hline Location E & 0 & 0 & 0 & 0 & 0 & 1 & 1 & 1 \\
\hline
\end{tabular}

possible combination of rows (locations) to see which, when summed, produce a value of at least 1 in every column, then finding those combinations with the minimum number of locations (the optimal sets). This is not difficult for small or medium sized sets but quickly grows to become too large to solve in reasonable times in very large datasets. As an illustration, Beasley (unpublished) points out that a problem with only 100 integer variables each with 2 possible values has $2^{100}$ (approximately $10^{30}$ ) possible solutions, and would require over 10 billion years to resolve if $4 \times 10^{12}$ possibilities were checked every second. A 2004 supercomputer can perform $100 \times 10^{12}$ calculations every second and would require 400 million years to solve the same, relatively simple, problem.

For the MCLP, on the other hand, the goal is to find the records (locations) that have the most columns (features) with at least one '1' for a constrained number of locations. This does not require complete enumeration because not every combination of every size must be compared, but it can still grow to a large computational problem quickly. 
Some of the problems resolved in this study have many more variables than this but were solved quickly because complete enumeration is not the only available means to solve IPs optimally. A mathematical method called branchand-bound, or tree search, involves a relaxation of the integrality constraint so that the problem becomes a linear program (LP). The LP, which is much simpler to solve, is divided into two branches that provide upper and lower bounds. The solution to each LP is not the same as to the IP but quickly provides new information that can be used iteratively in a divide and conquer approach to reduce the number of possible solutions that need to be examined in order to solve the problem (Beasley, unpublished; Mitchell, 2002; Önal, 2003). This sometimes leads to a faster solution but not always, depending on the type of IP problem (Reeves, 1996). An improvement on branch-and-bound is branch-andcut, which quickly identifies impossible solutions and defines planar functions that isolate those solutions (Mitchell, 2002; ReVelle et al., 2002; Rosing et al., 2002). Overall, there seems to be no generalised form of the branching procedures that can guarantee tractable solutions, i.e., solutions that are found relatively quickly with respect to the size of the dataset. Fast solution times are required in order to be part of flexible and responsive planning scenarios but Önal (2003) suggests that the very real problem of long analysis times for some types of problem may require some relaxation of the ideal standard of finding optimal solutions in every case. 
There are specialised or proprietary ways to design and apply these procedures that have been successful for specific problems, but they require additional development time and costs (e.g. Camm et al., 1996; Church et al., 1996; Beasley, unpublished). Still, recent users of optimal algorithms for set covering problems in conservation (Rodrigues et al., 2000; Bryan, 2003; Moore et al., 2003) have found solutions to moderately sized problems in seconds and minutes and state that this is no longer an issue when finding optimal solutions. It is not clear that this is the case for all forms of conservation reserve design problems, however. Rosing et al. (2002) suggest that Church et al. (1996) may have solved their problem quickly because it was a simple form of a reserve selection IP. Both teams of authors, as well as Önal (2003), agree that other cases may still prove to be intractable.

Optimal algorithms are generally available as commercial and noncommercial software packages that can solve most types of linear and integer problems. Each will make use of a proprietary combination of quantitative methods in order to enhance performance while guaranteeing optimal solutions.

\subsubsection{Application of Reserve Selection Algorithms}

Conservation planners work to identify individual reserves as well as groups and networks (networks are groups that contribute jointly to conservation goals) of reserves. They do so for regions of varying size using different scales of landscape data and with the goal of identifying different sizes of reserve(s). However, although the use of systematic tools in developing reserve network 
plans is common in academic research, they have only rarely been successfully used in the implementation of reserve networks (Justus and Sarkar, 2002, provide a review).

There could be a number of explanations for this. Arguments can be made that many of the stages in systematic planning (described in section 2.2.3.1) are simplistic and unable to integrate complex considerations, such as highly generalised range maps and interspecific interactions between species. Recent research acknowledges these weaknesses, as well as being compelled by existing reserve collections that over-represent some features and underrepresent others. Studies have examined long term persistence of species (e.g., Polasky et al., 2000; Gaston et al., 2001; Cabeza and Moilanen, 2003), alternate indicators of biodiversity value (e.g., Ando et al., 1998; Cowling, 1999), multiple biodiversity surrogates (e.g., Rothley, 1999; Williams and Araújo, 2002; ReVelle et al., 2002; Davis et al., 2003), population models (Haight et al., 2000), and the effects of landscape pattern (Williams et al., 2004 provide a review). As well, practitioners have already begun to find ways to integrate systematic planning tools into more traditional approaches (as reviewed by Justus and Sarkar, 2002).

\subsubsection{Comparing Heuristic and Optimal Algorithms}

While the aforementioned investigations form the core of the theoretical research into the use of IP models for regional conservation reserve network design, differences between the two types of algorithms used to solve those models are also of interest. The need for appropriate tools for research and 
planning is growing and differences between algorithms are important to understand (Williams et al., 2004). Researchers and planners making use of systematic planning methods must choose which type of algorithm to employ based on a number of factors, many that have been studied in the literature but are not clearly resolved. For example, new heuristics have recently been developed to address strengths and weaknesses found in different in algorithms. These new algorithms claim improvements in suboptimality and flexibility as well as control of some spatial aspects of the solution network such as clumping of sites (Possingham et al., 2000; Rosing et al., 2002).

Issues of particular interest, then, that make up the areas of inquiry in this thesis, include the potential suboptimality of results from heuristic algorithms, differences in distribution patterns related to suboptimality, differences in the ability to provide multiple solutions, and the potential intractability of optimal algorithms. This thesis is not an evaluation of the comparative benefits of each algorithm's results to any particular conservation policy or plan, although better knowledge of the attributes of each algorithm may strengthen the argument for one recommendation over another.

\section{Context of This Study}

No papers are known that suggest suboptimal results are preferred over optimal results. The potential to derive exact solutions may encourage users to invest energy in defining data and goals more accurately because changes in solutions can be tied directly to changes in model parameters (Pressey et al., 
1999, Rodrigues et al., 2000). However, researchers often state that the advantages in flexibility and speed of heuristic solvers over optimal solvers are more important than the drawback of a potentially suboptimal result. This probably depends on the suboptimality of the output (Rodrigues and Gaston, 2002; Önal, 2003), and many users state that they expect heuristic algorithms to give results that are optimal or close to optimal (e.g., McDonnell et al., 2002). A small number of studies in the past have measured suboptimality for a variety of heuristic algorithms on single datasets and found that the degree of suboptimality varied, and it was difficult to objectively assess the value of varying suboptimal results (see Rodrigues et al., 2000 for a summary; also Rosing et al., 2002). One other study compared multiple datasets using different heuristic configurations (Moore et al., 2003) and reached the same conclusion. This is the approach taken in this thesis research. The suboptimality of solution set size was measured for 4 different heuristic algorithms using 8 datasets of varying size.

This research also examined the spatial distribution of solution sites for each dataset. Only a few studies have looked at the spatial configuration of sites in optimal and suboptimal solutions for both the MCLP and LSCP (e.g., Csuti et al., 1997; Polasky et al., 2000) and it is unclear if there is a relationship between them. The locations on the landscape of the solution sites are not part of these models, and spatial relationships between sites are not known until they are linked to the cell locations in a GIS. There may, however, be configurations that are more or less clumped, patchy, or connected from among the existing 
solutions and these characteristics may aid selection of a network from sets of optimal or suboptimal networks found by either algorithm.

Acceptance of these tools and their results by decision makers and the public is affected by flexibility in the algorithms. For example, it is common for there to exist numerous sets of locations that solve the reserve selection models exactly (Arthur et al., 1997) and more that are suboptimal in size (Rosing et al., 2002). Additional alternative solutions, which provide different spatial configurations, allow decision makers to have some choice in which sites are used, since all social, economic, physical, and biological factors affecting decisions cannot be built into the model. Some authors have even stated that a small degree of suboptimality may be helpful if it provides additional configurations of sites for consideration (Pressey et al., 1996; McDonnell et al., 2002; Rosing et al., 2002). Optimal algorithms can be adjusted to find additional solutions (e.g., different configurations of the optimal number of sites) by adding previous solutions as a constraint in the model (Arthur et al., 1997; Arnold, pers. comm., 2004) and solving the full dataset again. This can be repeated until all the optimal solutions are found (Rosing et al., 2002). Presumably, larger sets of suboptimal solutions can also be found. As described above, some heuristic algorithms, such as simulated annealing, can be programmed to find optimal solutions, while others, such as the logical, iterative types may or may not, depending on how ties are broken and if they are run multiple times. 
The number of alternative solutions that exist is limited and is a function of the goals of the model and the rarity and spatial overlap of features in a region. For example, using two features in a regional LSCP model, if both have a distribution of one cell and do not overlap (i.e., perfect allopatry (Pressey et al., 1999)), there will be only one solution of two cells that will include both features. If their ranges are more than one cell in size and do not overlap, a number of two-cell solutions (that trade the range cells for each feature) exist. If the two features are one cell in size and overlap, a single, one-cell solution exists. If they are more than one cell in size and overlap partially or completely (variable spatial overlap (lbid.)), then a number of combinations of one and two set solutions exist, again depending on whether the solution is optimal in size or not. For the MCLP model, the combinations are based on which sets of a given number of sites can contain the most features, and it is expected that there is also a limited number of these.

Providing different levels of access to multiple solutions results in increased flexibility for researchers and planners. The algorithms compared here were examined in a gap analysis scenario for differences resulting from their ability to provide multiple solutions. That is, the reserve selection algorithms were combined with a gap analysis procedure that illustrated the benefits or weaknesses of having multiple solutions.

Visualising the spatial distribution of single solutions is straightforward but visualising multiple solutions is problematic. This issue is important for the ability 
to discover alternative spatial configurations. Csuti et al. (1997) and Lindsay et al. (unpublished) (see Figure 2.4) have mapped a limited number of solution sets. This thesis examines the problem of displaying multiple solution sets in a GIS to further illustrate the differences in output from the two algorithms.

Finally, as mentioned above, Önal (2003) suggests that intractability is still a very real problem when seeking optimal solutions to IP reserve models, despite the very fast results reported in a few recent studies (e.g., Rodrigues and Gaston, 2002; Bryan, 2003; Moore et al., 2003). This study measured and compared the time required to find solutions by each algorithm. 


\subsection{Methods}

The goal of this research was to compare two types of algorithm used to solve conservation reserve selection problem models. As described in Section 2.3, problems in reserve design have been formulated mathematically as integer programs (IP), allowing the use of algorithms to find efficient solutions. Two main types of algorithm exist, heuristic and optimal, and software packages (called solvers) employing each type were used to apply and compare their use and results. In this research, the optimal solver outputs were first compared to outputs from another optimal solver (section 3.3). Then, the number (i.e., size) and spatial distribution of the solution set sites of one of the optimal solvers were compared to those of a heuristic solver. Additional comparisons were made of the ability of each solver to generate multiple solutions and of the speed at which each solver found solutions (Section 3.4). Data preparation is described in Section 3.1 and solver implementation in Section 3.2.

\subsection{Data Selection and Preparation}

\subsubsection{Creating Data Tables}

The two algorithms, optimal and heuristic, used the same input data preparation procedure. Geographical regions of interest (described in Section 3.1.2 below) were divided into a grid of cells on a map in order to delineate specific localities (e.g., Figures in Section 2.2.3.2). Biodiversity information from various sources (see Section 3.1.2) was then provided to each cell using a GIS. Each cell had a value indicating the presence or absence of each biodiversity 
surrogate feature at that location (Figure 3.1). If a cell overlapped any part of the distribution range of the feature, it was given a 1; if no overlap occurred, it was given a 0 . This information was stored in tabular format in the GIS where records (rows) represented cells and fields (columns) represented features (Figure 3.2).

These tables were used as the IP model input.

Figure 3.1: An example feature distribution map (in this case the species Myotis yumaensis) intersecting with the equal area grid cells (map scale is as in Fig.2.1).

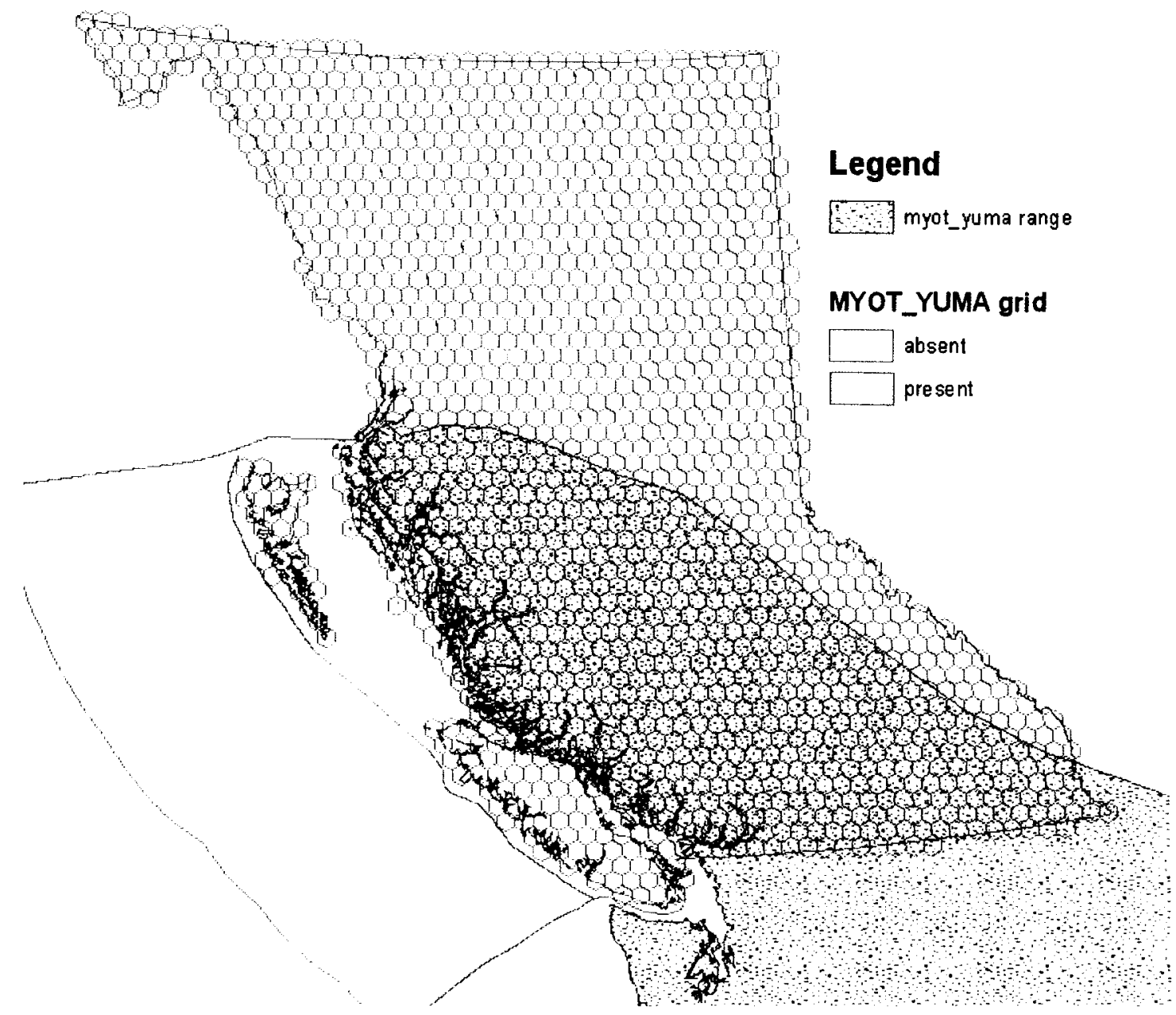


Figure 3.2: Feature table output from the grid cell and features range maps overlay. See text for details.

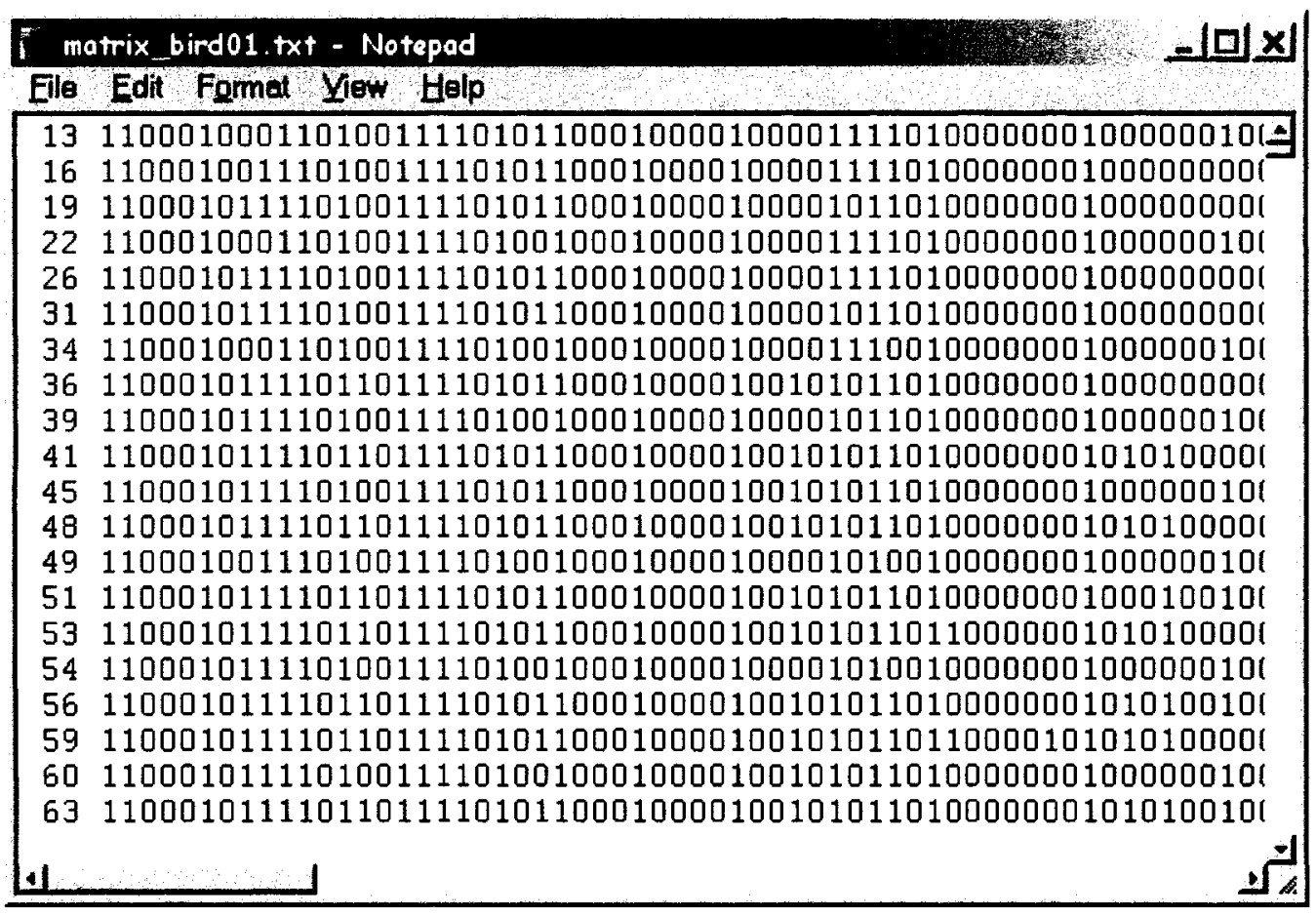

\subsubsection{Regional Datasets}

The datasets used here were from three geographical regions; British

Columbia $(\mathrm{BC})$, a portion of Ontario $(\mathrm{ON})$, and the Carrickalinga Creek watershed near Adelaide, Australia (AU). They were acquired from existing reserve selection projects (Lindsay et al., unpublished; Olsen, M.Sc. thesis ongoing; and Bryan, 2003, respectively). The datasets varied in biodiversity surrogate type, and size and number of grid cells (Table 3.1) (grid cell size varied between regions but not within regions).

These datasets were selected for various reasons. The $\mathrm{BC}$ and $\mathrm{ON}$ data provided a variety of feature by cell table sizes, which was useful to test variability in output and speed. The $B C$ data had been used in a previous 
Table 3.1: Dataset descriptions.

\begin{tabular}{|c|c|c|c|c|}
\hline Region & $\begin{array}{l}\text { Biodiversity } \\
\text { Surrogate } \\
\text { Features }\end{array}$ & $\begin{array}{l}\text { Number of } \\
\text { Features in } \\
\text { Group (F) }\end{array}$ & $\begin{array}{c}\text { Number of } \\
\text { Grid Cells (G) }\end{array}$ & $\begin{array}{l}\text { Total Number of } \\
\text { Table Elements } \\
\text { (FxG) }\end{array}$ \\
\hline$B C$ & Reptile Species & 15 & $\widehat{1,048}$ & 15,720 \\
\hline $\mathrm{BC}$ & $\begin{array}{l}\text { Amphibian } \\
\text { Species }\end{array}$ & 18 & 1,551 & 27,918 \\
\hline $\mathrm{BC}$ & $\begin{array}{l}\text { Species of } \\
\text { Concern }\end{array}$ & 25 & 1,589 & 39,725 \\
\hline $\mathrm{BC}$ & $\begin{array}{l}\text { Species At } \\
\text { Risk }\end{array}$ & 59 & 1,588 & 93,692 \\
\hline$B C$ & $\begin{array}{l}\text { Mammal } \\
\text { Species }\end{array}$ & 102 & 1,589 & 162,078 \\
\hline ON & $\begin{array}{c}\text { Bird } \\
\text { Species }\end{array}$ & 213 & 1,203 & 256,239 \\
\hline $\mathrm{BC}$ & $\begin{array}{c}\text { Bird } \\
\text { Species }\end{array}$ & 274 & 1,589 & 435,386 \\
\hline $\mathrm{BC}$ & $\begin{array}{l}\text { Bird Species } \\
\text { (modified) }\end{array}$ & 255 & 15,890 & $4,051,950$ \\
\hline$A U$ & $\begin{array}{c}\text { Soil and Climate } \\
\text { Variables }\end{array}$ & 65 & 89,376 & $6,166,944$ \\
\hline
\end{tabular}

study (Lindsay et al., unpublished) with a different optimal solver than the one intended for this research, so comparison amongst the two optimal and one heuristic solver was possible. The ON dataset had been previously used with a heuristic solver, so it was applied here using an optimal solver for evaluation of the degree of suboptimality of the heuristic results. The AU data were selected because of the large number of cells and large table size as well as its cell size which was much smaller than the other two datasets. This variety of datasets provided an effective range of number of cells, number of features, and cell size, to compare the reserve design outputs and the speed of the two algorithm types.

The surrogates for biodiversity ("Surrogate Features" in Table 3.1) used in each study are described below and were used in this research as provided by the original data developers. Surrogate feature data were all converted to binary, 
presence-absence attributes (Figure 3.2) so that the only difference between datasets was the overall table size and the spatial richness patterns.

Table 3.1 shows that each biodiversity surrogate was a group made up of species from a single taxon. The number of species in each group is shown in the next column, "Number of Features in Group". The next column, "Number of Grid Cells", refers to the number of grid cells that covered the entire group of features. They vary for $\mathrm{BC}$ because overall ranges of some taxa do not cover the province.

The grids used here were also taken from the respective studies. Details follow in the paragraphs below. Although the datasets from each region used different grid cell sizes, only a single cell size was used within each region. They were also more or less equal in area, thus reducing scale effects.

\section{British Columbia Data}

The $\mathrm{BC}$ grid of $640 \mathrm{~km}^{2}$ equal-area hexagonal cells was developed by White (2000) and used by Lindsay et al. (unpublished) for six IP analyses using OPL. They used a maximum of 1589 cells that overlaid terrestrial areas. Each analysis used a sub-group of provincial species based on taxonomy or conservation status as the biodiversity surrogate features (Table 3.1). To create the database table for each group, they digitised the range of each species from a field guide and intersected these range maps with the grid in a GIS to provide values of 0 or 1 for each species in each cell (see Figure 3.1). The resulting table can be shown as an array (Figure 3.2) or a richness map (e.g., Figure 3.3) where 
the cells are classified according to the number of 1's (species) in each. The ranges were coarse scale generalisations of distribution data, so the richness classes tended to vary smoothly across the region.

Figure 3.3: BC birds' 1-0 table summed to produce a richness map (map scale is as in Fig.2.1).

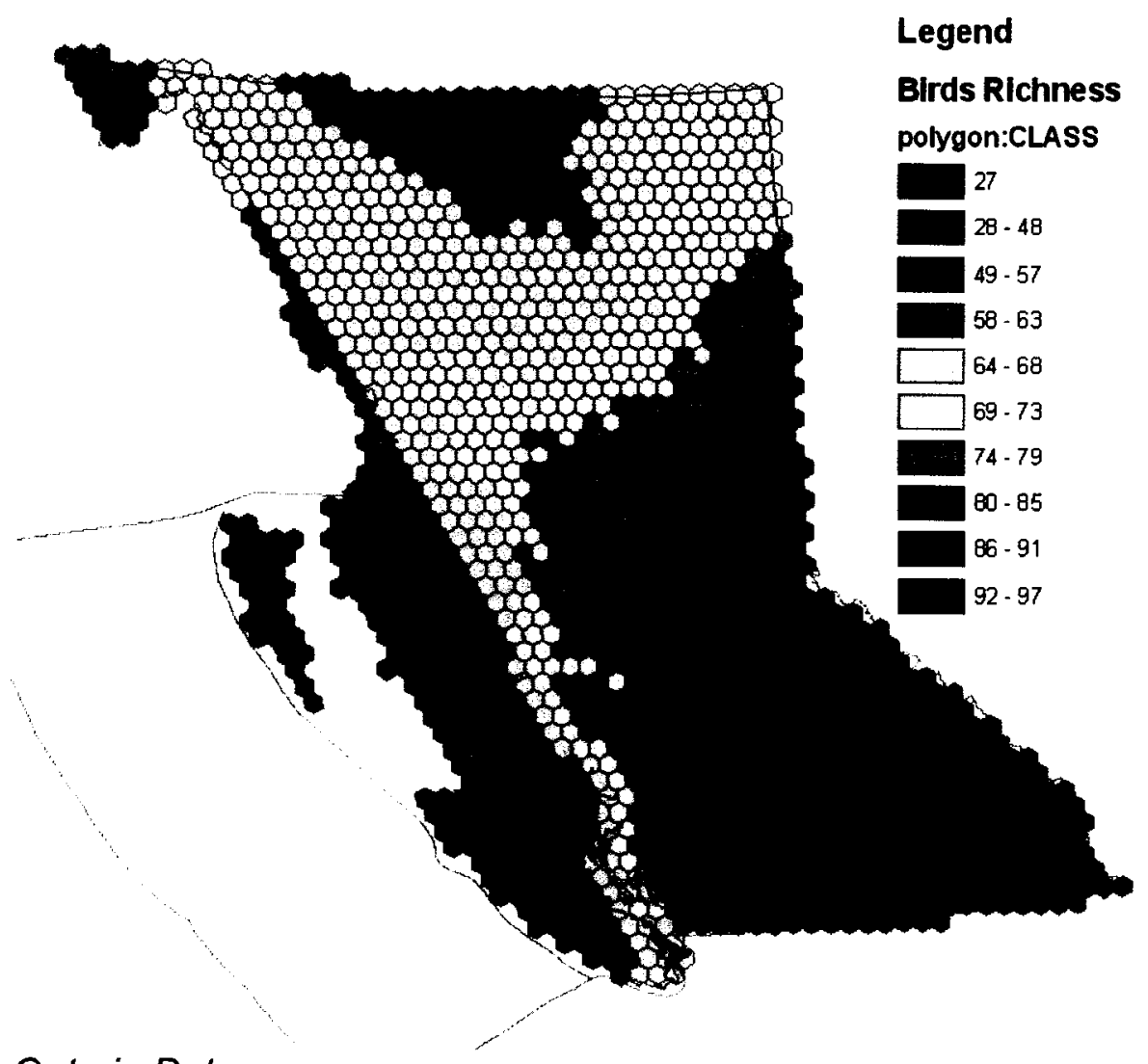

Ontario Data

The ON grid was a subset of cells from the Ontario Breeding Bird Atlas project (2005 - http://www.birdsontario.org). These were nominally square $100 \mathrm{~km}^{2}$ cells (Figure 3.4), based on the Universal Transverse Mercator (UTM) grid system, for management of annual data collection activities. The data were provided in tabular format with no need for an overlay intersect analysis to 
determine richness as done for the BC dataset. Data from 2001 - 2004 were included (the Atlas project will run until 2005) for 244 bird species, of which 31 had no presence, leaving a feature group size of 213 . Since the data were collected by cell, instead of being translated from generalised range maps as in BC (Figure 3.1) and because the cell size was smaller, the distribution of species richness classes did not vary as smoothly across the region (Figure 3.4).

Figure 3.4: Ontario Breeding Bird Survey grid classified by cell species richness

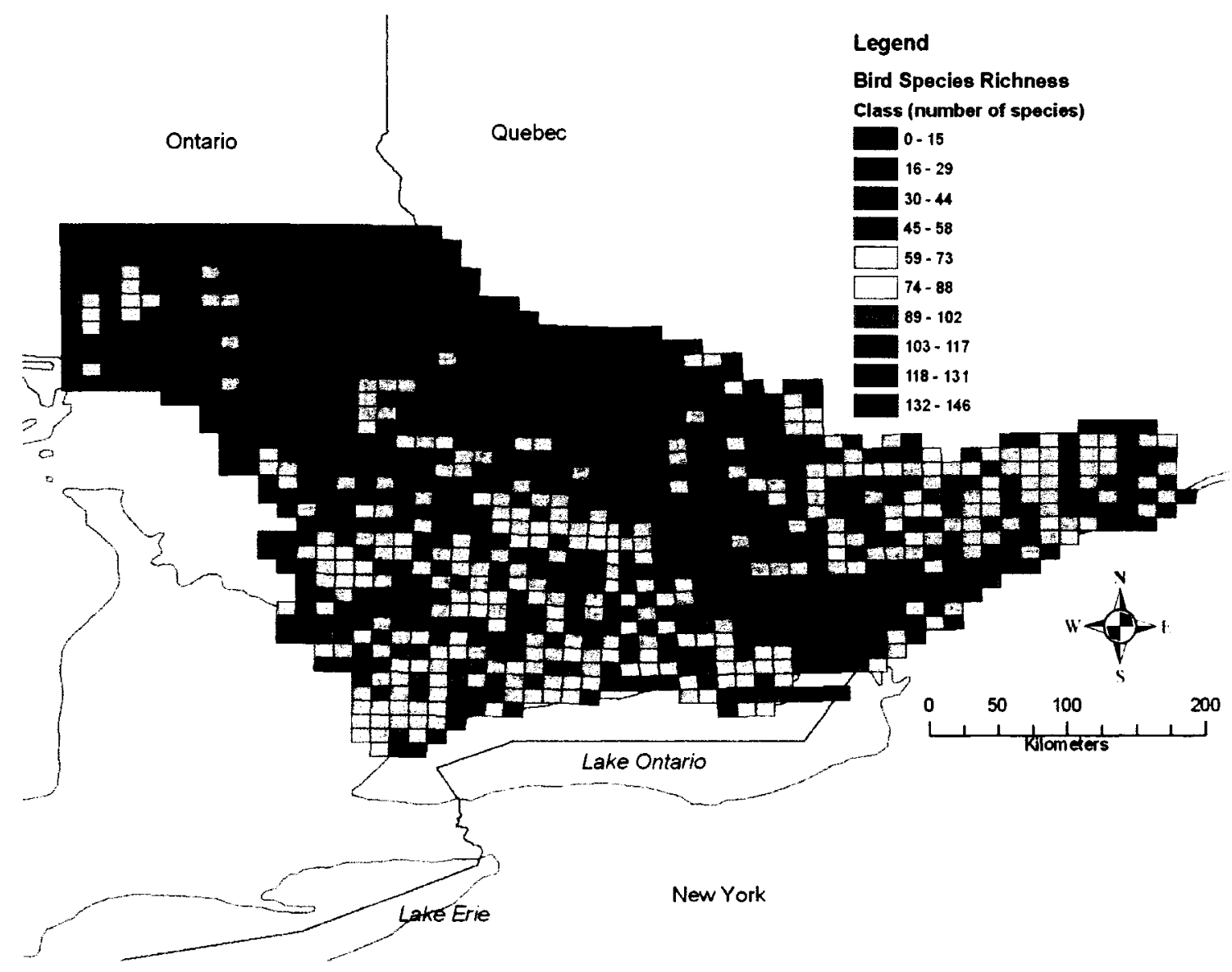




\section{Australia Data}

The AU grid consisted of 89,376 cells in a $25 \mathrm{~m}$ array of raster pixels that cover the 23,000 ha Carrickalinga Creek drainage basin $60 \mathrm{~km}$ south of Adelaide. There were 65 features in the single analysis for that study (Bryan, 2003). Twenty-nine were non-overlapping environmental classes classified from climate variables, while 36 were non-overlapping 1:50,000 soil landscape units that had been overlaid on the $25 \mathrm{~m}$ grid. The data were provided as a $0-1$ table.

\subsection{Implementation of Optimal and Heuristic Algorithms}

Each software package (solver) used its own methods to provide solutions to the IP problems. The following sections describe the solvers used in this study and illustrate some of the differences between the algorithms. The computer used for all tests had dual Pentium IV (tm) $2.66 \mathrm{GHz}$ CPU's with 1 GB RAM and a Windows XP Professional (tm) operating system.

\subsubsection{Optimal Algorithm Software - ILOG OPL Studio}

The software used for the optimal algorithm was OPL Studio (Optimisation Programming Library Studio) v.3.7 from ILOG, Inc., of Mountain View, California. Integer programming problems were solved using OPL's "CPLEX MIP" (v.9.0) algorithm. This is a general purpose solver that makes proprietary use of a number of techniques such as branch-and-bound, branch-and-cut, two families of heuristics, pre-processing, and probing (ILOG Support, pers. comm., 2004). In common terms, these techniques allow nodes and feasibility regions of the objective function to be identified, thus preventing the need for complete 
enumeration to solve the IP (Arnold, pers. comm., 2004). Complete enumeration (see Section 2.3.2) is unfeasible for all but very small datasets, as the computational requirements quickly become too large for any computer to solve in a realistic time as the dataset increases in size. The solutions for integer program problems solved using OPL are always optimal for the defined objective. This software was selected because it ran on a common desktop computer. An academic license for OPL was purchased by Environment Canada for this study.

The proprietary OPL code for the LSCP and MCLP models were provided by B. Bryan (pers. comm., 2004) of the Commonwealth Scientific and Industrial Research Organisation (CSIRO), Australia. Modifications were made to the MCLP code and an interface for both models was written by Richard Arnold of Carleton University (pers. comm., 2004). This interface allowed the user to choose the model to be solved and implement the algorithm. The user could also choose to run the model repeatedly if multiple solution sets were desired. The first complete solution set was stored in memory and used as a model constraint (Camm et al., 1996, Arthur et al., 1997; Church et al., 1996; Kiester et al., 1996; White et al., 1999; Rosing et al., 2002).

Figure 3.5 shows the user interface, with models loaded and script running to find solution sets for a reserve selection scenario. Below the standard menu bars, the top left window shows which scripts, models, or data were loaded into the program, the top right window displays the code for these files, and the bottom window displays the results of the CPLEX MIP algorithm analysing the 
data model. When the LSCP objective function size was requested, the number was displayed in the results window. When the solution sets of MCLP or LSCP were requested, each row in the results window contained a solution set plus assorted additional attributes as determined by the script. In this case, columns show, left to right, result number, solution cell ID's (columns $2-6$ ), time to find this solution, total time to find all solutions so far, and objective function solution value.

Figure 3.5: An example of tabular solution set output from OPL for BC amphibians. See the text for details.

OPL Studio - $[M: \backslash$ Thesis \links and POFs veserve modelling $\mathbf{I L C O W}$. |U Ele Edit Wew Broject Execution Debug Options Window Help $\quad$ ela $\mathbf{x}$

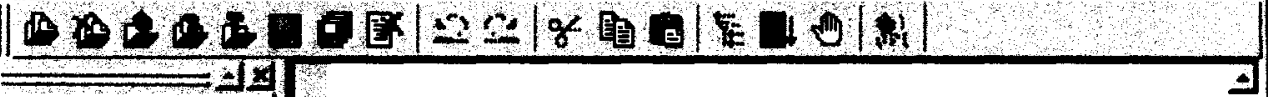

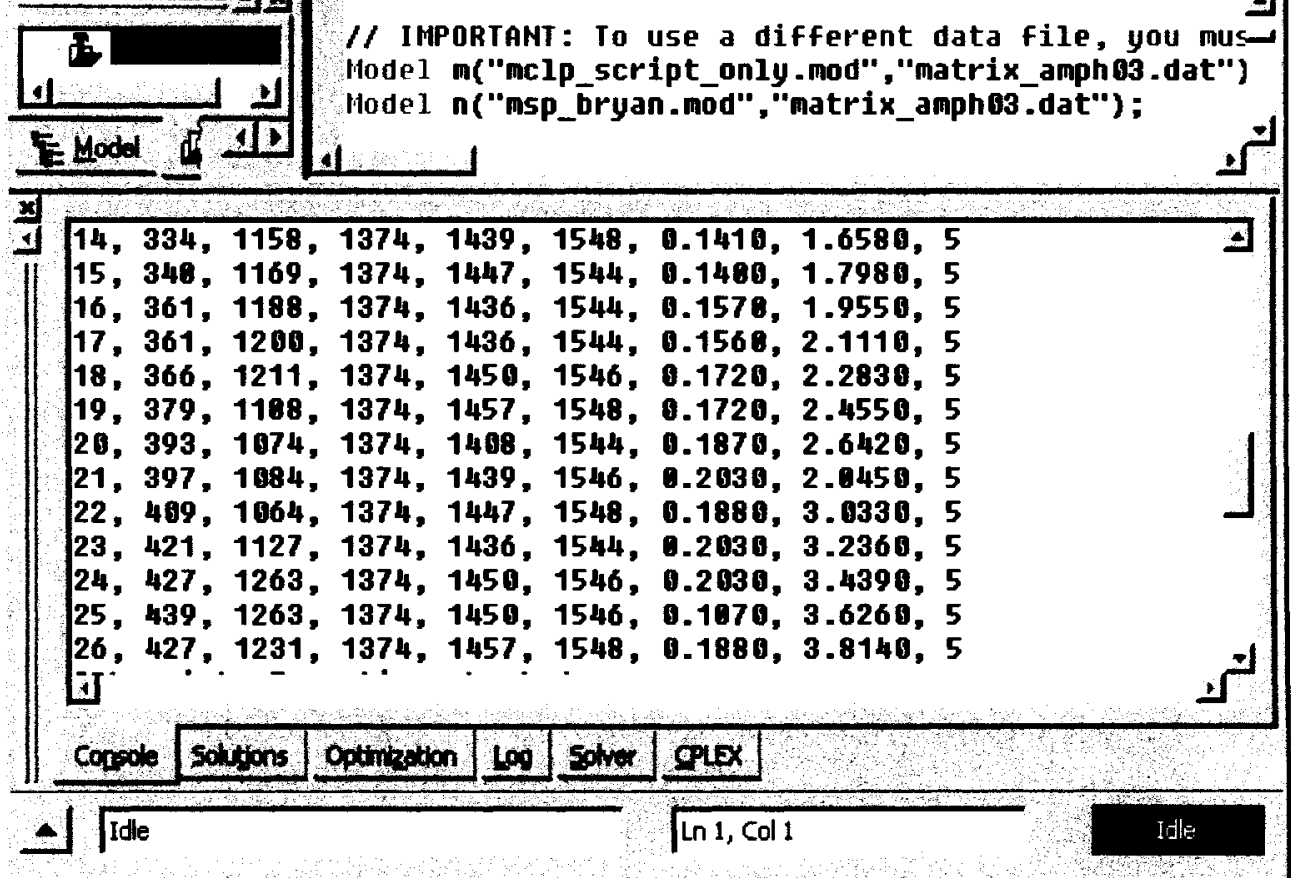




\subsubsection{Heuristic Algorithm Software - C-Plan}

The software used to implement a heuristic algorithm in this study was CPlan (Conservation Planning Program) from the New South Wales National Parks and Wildlife Service, Australia. The software was created specifically to aid in the design of conservation reserve networks and used a specialised form of algorithm called a greedy heuristic (Section 2.3.1). It employed an iterative twostage process to sort then select locations for speculative reserve networks, and provided multiple prioritisation methods for the sorting stage (Pressey et al., 1996, Ferrier, et al., 2000). This proprietary application was available for download from the C-Plan Internet site free of charge (http://members.ozemail.com.au/ cplan/). It was selected because it ran on a standard desktop computer, it had been used by numerous other researchers, was easily accessible, incorporated a familiar GIS for visualisation of results (i.e., ESRI ArcView v3.2), and used a variety of important attributes for prioritisation of cells.

As with OPL, a database was loaded into the system using the program interface. No scripts or proprietary model codes were required as all functions were built into the program. Figure 3.6 shows the interface. The top image shows the program interface and the bottom image shows the ArcView v3.2 mapping interface that is linked to the program to identify input areas and display results. Most reserve selection functions were available from the standard menu bars along the top. The buttons below the menu bars provided access to other common functions. The windows at the bottom displayed the cell/site address 
numbers. The left window showed those cells that are not selected and the right windows (there were more than two that could be shown) show cells that had been classified into various temporary or final reserve categories. Loading data into the program entailed using a separate software interface to format it into a proprietary format, after which it could be opened by C-Plan. When loading it, CPlan automatically added a number of additional fields to the database. These fields contained calculated values, such as richness or irreplaceability, which were used by the operator to prioritise potential reserves.

Solving a problem model using C-Plan is done manually, automatically, or using a combination of both. The manual process involves using the interface to build the priority site list one location at a time. For each selection, various attributes and characteristics of the features and base data are evaluated using information calculated by C-Plan and additional expert knowledge. This gives added flexibility to the outcome since the important attributes do not have to be selected beforehand and can be changed at any point in the process. The attributes of each site can include feature richness, rarity, site area or other summary information or they can include information that is calculated by C-Plan such as irreplaceability or the percent contribution of a site to remaining targets. Also, because the data are connected to a GIS, the operator can examine and select or deselect sites based on attributes or spatial relationships of interest at any stage using any background layers. The output of this interactive method is a 
single, priority list of sites. Various lists of different sites can result if it is run more than once with difference choices made each time.

Figure 3.6: The C-Plan interface windows. The program interface (top) and ArcView 3.2 GIS interface (bottom).
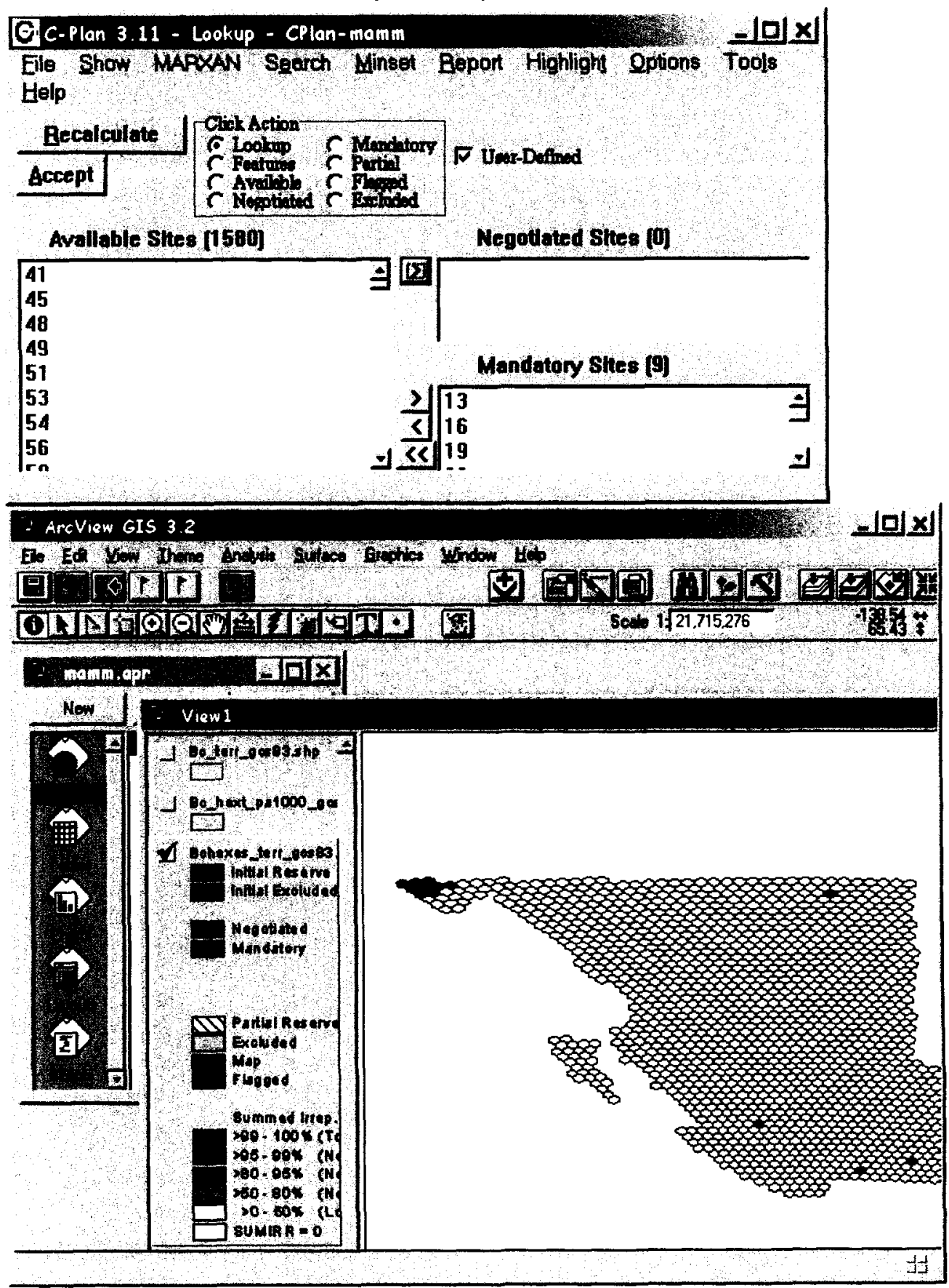
The term used to describe the final solution list is "minimum set" (minset) since the complementarity criteria is meant to minimise the size (number of sites) of the list (LSCP). Coincidental to the goals of this study, halting the minset procedure after a certain number of sites have been selected provided a maximised number of features for that number of sites, which is the solution to the MCLP model. The minimum set procedure involved preselecting the attributes that were used as criteria to prioritise the sites, and letting the program cycle through the iterations until the goal of including all features in at least one location was met. After each selection, the features that were covered by the selected site were removed from further consideration, the attribute values were recalculated without using the removed features, and the process continued. The greedy heuristic used by C-Plan did not solve the objective function of the IP problem per se, but the number of reserves in the output set is comparable to the solution value of an IP's objective function for the same type of model. For this project, the minimum set procedure was used for all tests, and the following four attributes were used individually to prioritise and select cells for the minimum sets:

- Rarity

- Richness

- Irreplaceability

- Summed Irreplaceability 
Richness and Rarity were selected because they are common choices in reserve selection algorithms and are calculated by C-Plan. Richness is simply the sum of the number of different features present in that site and Rarity is calculated as a fraction (inverse of feature frequency $\times 100$ ) (Pressey et al., 1994). Irreplaceability (Pressey et al., 1994; Ferrier et al., 2000) and Summed Irreplaceability (Ferrier et al., 2000) were selected because they were developed by the designers of C-Plan and were expected to perform well. Both are statistical measures of the likelihood that a site/cell will be required in order to meet the goals of the model. Since complete enumeration of the entire spectrum of possible solution sets of various sizes is impossible a priori, these measures are calculated using predictive statistics (i.e., the central limit theorem) on random combinations of possible solutions of an estimated size (Ferrier et al., 2000). A site that contains the only occurrence of one of the biodiversity indicator species will be essential, and therefore irreplaceable, to the goal of providing one site with every species. As well, the most recent development of Irreplaceability includes a measure of the redundancy of a site, where redundancy is increased for those sites whose removal would lower the existing species or feature coverage least. Summed Irreplaceability is the sum of all Irreplaceability values for each feature that occurs in a cell.

The above sorting criteria were each used separately in individual minset runs. This was done because it was assumed that if combinations of the criteria were used, the suboptimality values of the results would be equivalent to the 
results from the best single criterion and it would be difficult to analyse the effects of each criterion individually.

\subsection{Optimal Algorithm Baseline Comparison}

Optimal algorithms have been used since 1989 to solve IP reserve problems. No known study has compared the outputs of two different optimal algorithms, even though they often employ different combinations of common and proprietary methods. This is probably because optimal solvers are designed and expected to guarantee optimal solutions. Since there are a limited number of optimal solutions for any particular model, no difference is expected in the size of the solution set, the number of solutions, and the cells involved in the solutions from either optimal algorithm or either model.

The optimal solver used by Lindsay et al. (unpublished) using the British Columbia species groups was IBM OSL (Optimization Solutions and Library http://www.ibm.com). This study repeated part of their analysis using OPL. It compared the sizes of the optimal solutions for the LSCP and MCLP, the number of species found in each MCLP, and the number of solutions generated. A comparison of the spatial distribution of solutions was also done.

\subsection{Heuristic and Optimal Algorithm Comparison}

Following the test in 3.3, the heuristic (C-Plan) and optimal (OPL) algorithms were compared in a number of ways. First, the solution set sizes for the LSCP were compared. As described previously, C-Plan does not actually 
solve an objective function per se, but the number of sites contained in its minimum set is comparable to the number of sites in the OPL solution. Second, spatial differences for LSCP and MCLP results were compared. Third, the overlaps of the results from each algorithm were compared to existing reserves (i.e., gap analysis) in order to highlight differences in the number of solution sets output from each solver. Fourth, the speed of each algorithm in finding the solutions was compared. The following subsections describe each of these three exercises in more detail.

\subsubsection{Output Solution Comparison}

\section{Comparing solution set size}

The goal of the LSCP was to find the smallest group of cells that satisfied the constraint that biodiversity was conserved as per the agreed criteria (i.e., every surrogate feature included in the model was represented in at least one cell), which is one of the most common model goals in the conservation literature (Rodrigues et al., 2000; but see Williams et al., 2004 for alternatives). One of the differences in the two algorithms was how well each accomplished that goal. In fact, the question was actually how well the heuristic algorithm accomplished that since OPL guarantees the smallest, or optimal, solution set for the LSCP model. The term "optimal" could have referred to other characteristics of the algorithm output, such as ecological, economic, or spatial character, but this study follows the most common usage in the conservation reserve design literature. To do this, OPL LSCP solutions were obtained for the $\mathrm{ON}$ and $\mathrm{AU}$ datasets as they had 
been for the $\mathrm{BC}$ datasets from the previous section. C-Plan was then used to run reserve selection analyses for the same three datasets, using one of the four prioritisation criteria each time, and the numbers of cells in the solutions from CPlan were compared to the size of the solution sets from OPL.

\section{Comparing spatial distribution}

It was expected that any solutions found by C-Plan that were actually optimal would be part of a limited set of possible optimal solutions. In order to test this assumption, C-Plan LSCP solution sets, optimal and suboptimal, were checked for matches with the OPL solutions using cell ID. If OPL had found all possible optimal solutions, then any C-Plan optimal solution would be identical spatially to one from OPL.

Spatial distribution patterns were compared by visual inspection. Since CPlan MCLP results could be suboptimal to different degrees depending on the sorting criteria used, the distribution of solutions from each sorting criteria were examined. Comparisons between solutions of a given size for different criteria were made, as were comparisons of changes between solutions when solution sets grew in size.

\subsubsection{Gap Analysis Comparison}

In the interests of efficient use of resources, it is necessary that the contribution of existing reserves to regional goals is considered and utilised. One way to do this is to find the model features that are not already covered by a reserve (i.e., gap features) and add new reserves that cover those features. 
Alternatively, a provisional system can be created using all the selected features in a region (Kiester et al., 1996; Nantel et al., 1998; Andelman and Willig, 2003). This new set can be compared to the existing reserves in order to identify overlaps and only those provisional sites that do not overlap with an existing site need to be considered for new reserves. Existing reserves that do not overlap with the new configuration of reserves may be redundant to the model in question, and decision makers can consider redirecting resources used for their management to other areas. The difference between full and gap feature datasets is illustrated in Figure 3.7. The top image shows richness classes for all 213 bird species in the $\mathrm{ON}$ region and the bottom image is the richness classes for the 27 gap species whose ranges do not overlap with an existing conservation reserve cells.

In this study, the latter form of gap analysis was implemented. The results were used to highlight the differences in the output of the two algorithms. That is, new solutions from each algorithm were compared to the pre-existing set of reserves to find the amount of overlap with the network of existing reserve sites. The method for defining and identifying existing conservation areas is described next, followed by the process for comparing these to the reserve selection output of each algorithm. The feature datasets that were used in this section included those from $B C$ and $O N$ only. The $A U$ data did not have a data layer representing existing reserves (see Table 3.1). 


\subsubsection{Defining and Preparing Existing Conservation Reserve Data} There are many different types and sizes of conservation reserves so it was necessary to determine which of the existing reserves to include in the gap analyses. Since there is no standard approach for determining gap features (Jennings, 2000), the set used here was selected to mirror what might be a logical choice in an actual reserve design project. Only those conservation reserves that were over 1000 ha in size and classified as IUCN I to III (of I to VI) were included. These higher IUCN classifications represent strict limitations on the types of resource extraction and land use activities permitted (WRI-IUCNUNEP, 1992) and are often used to filter out the less effective existing reserves (Andelman and Willig, 2003; Rodrigues et al., 2004). The size was selected because smaller reserves may not contribute to the viability of certain species in the reserve (Rodrigues et al., 2004). Reserves of any type or designation were used (parks, wilderness areas, wildlife reserves, etc.) that fell into the IUCN and size categories and were owned and managed by either the federal of provincial governments.

For this analysis, a digital map of existing conservation reserves was intersected with the same grid used to represent the species distribution in each region. A cell was identified as a reserve cell when any portion of an existing reserve overlapped with any portion of the cell. An alternative approach could be to require a certain area or percentage of overlap. Figure 3.8 shows an example for one portion of British Columbia. The conservation reserve data were 
Figure 3.7: All features vs. gap features. ON species richness for all birds (top) and "gap" birds (bottom). In both maps, cells with heavy blue outline show existing reserves (scale is as in Fig 3.5).

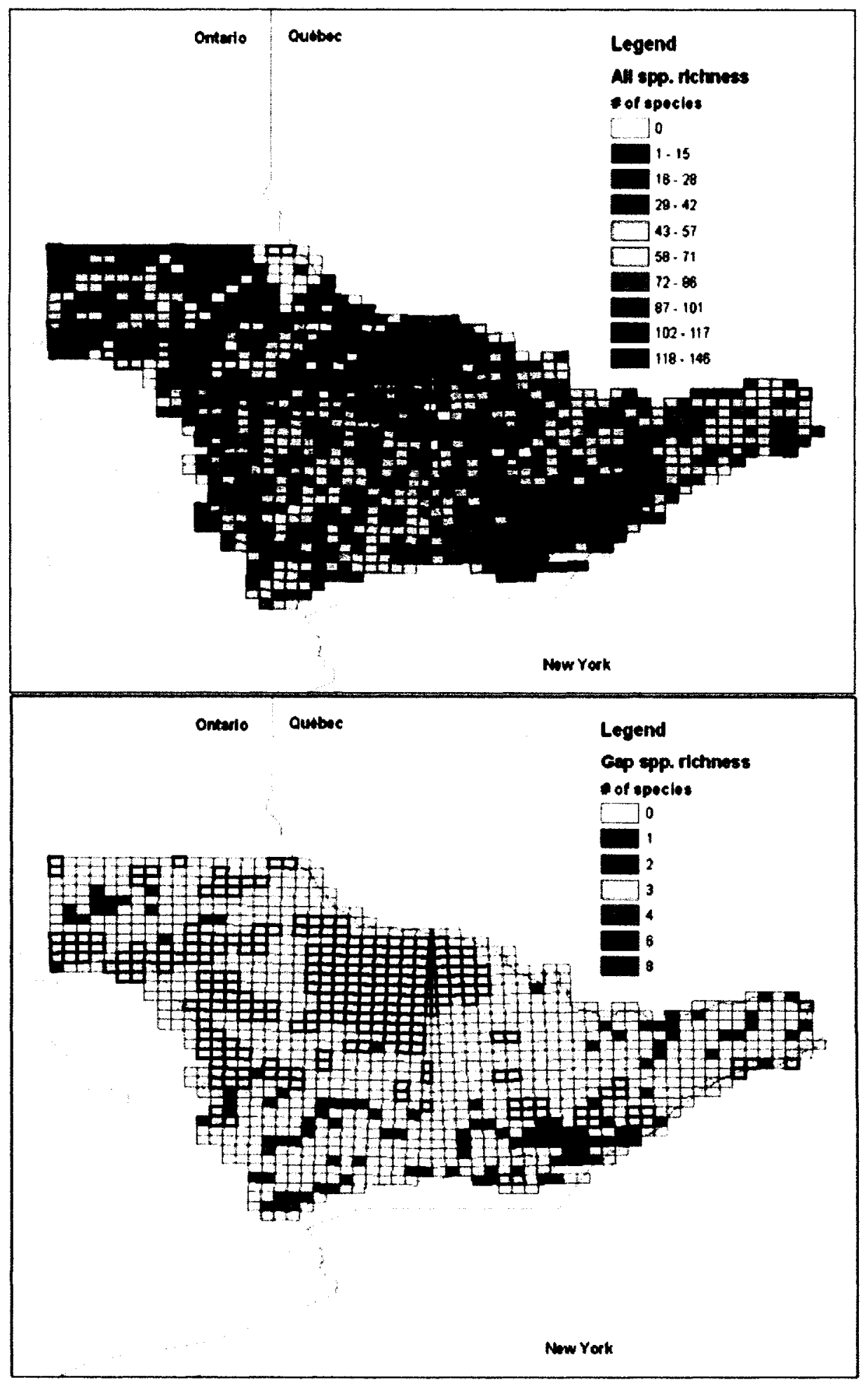


provided by the Canadian Council on Ecological Areas (CCEA, pers. comm., 2004) from their Canadian Conservation Areas Database project (CCAD) in 2004

Figure 3.8: Sample of existing British Columbia conservation reserves and the grid resulting from an intersection analysis. See text for details.

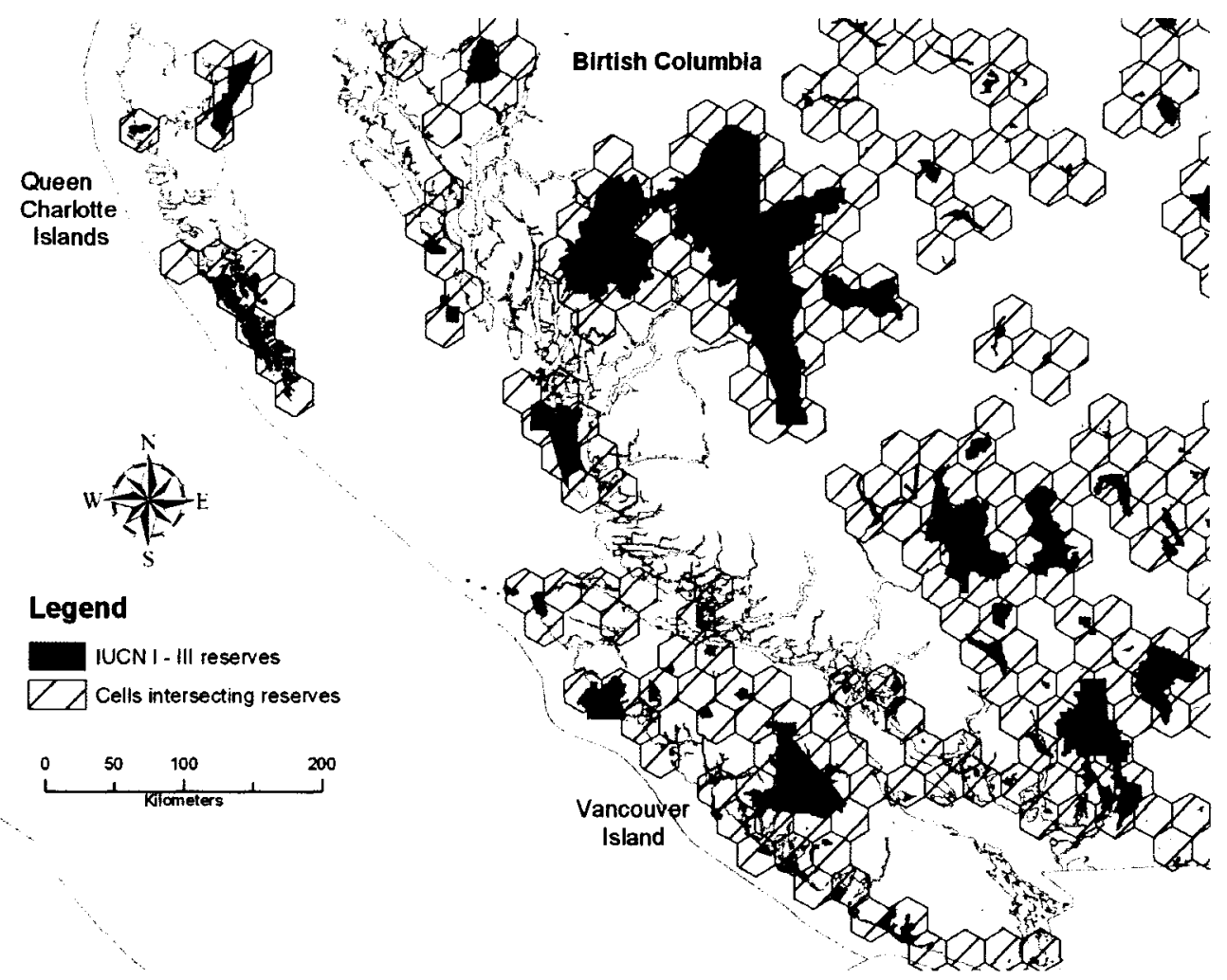

\subsubsection{Comparing Heuristic and Optimal Algorithm Outputs in a Gap Analysis}

Once the IP solution sets were identified by the heuristic and optimal algorithms for the LSCP model, they were compared to the existing reserve set for their region. Solution sets generated by C-Plan in Section 3.4.1 were displayed in the GIS so that the number of cells overlapping with the existing 
protected areas could be counted. The sets from OPL were processed in a different way because of the multiple optimal solutions that were produced. All optimal solution sets were transferred to a spreadsheet in the form shown in Figure 3.5 (solution sets are in rows and cell identifiers are in columns). The number of cells in each solution set that matched with existing conservation reserves (using cell ID) were displayed in a new column and the entire sheet was sorted by that number, with the solution sets with most matches at the top. The records at the top were therefore the optimal solutions to the LSCP that had the highest possible number of sites that overlapped with existing reserves.

\section{Mapping Multiple Sets}

In order to make use of multiple sets, it may be helpful to visualize many of them on a map at one time. In order to compare the usefulness of results from each algorithm, OPL data were mapped using procedures developed in previous research and compared to the mapping solutions provided by C-Plan. Mapping a single set of sites is straightforward but mapping multiple sets can be problematic because a given site may be part of more than one solution set. These difficulties are described in Chapter 4 and discussed in Chapter 5.

\subsubsection{Algorithm Speed Comparison}

A common statement in past literature is that optimal algorithms are either intractable and cannot deliver a solution in a reasonable time, or, even when mathematical methods are used to avoid intractability, are too slow to be useful for real-world reserve selection except for the smallest datasets (Willis et al., 
1996; Pressey et al., 1997; Possingham et al., 2000; Rosing et al., 2002;

McDonnell et al., 2002; Lawler et al., 2003; Sarkar, 2004). Even when optimal algorithms are fast enough to be useful in real time, they are still expected to be slower than heuristic algorithms (Rosing et al., 2002; Moore et al., 2003). To test the speed of the algorithms, a number of the reserve selection exercises carried out in previous sections were timed. All datasets from all three regions were used for this test. In addition, one dataset, the BC birds taxon group, was modified by replication 10 times to create an artificial table of 255 species and 15890 cells (see Table 3.1). This was done to provide a dataset of intermediate size along with the smaller (BC and $\mathrm{ON}$ ) and larger (AU) datasets.

The test measured the time to find a solution to the LSCP (OPL) or the minimum set (C-Plan). In C-Plan, a stopwatch was used to measure the time from when the prioritisation attribute was selected and the minset process was started until the minimum solution set was completed. In OPL, the time to find the solution to the IP objective function and the time to find a solution set for that number of cells were added together, the former measured using a stopwatch and the latter using script code. Timing was stopped after only one solution set was found in order to match the single minimum set solution found using C-Plan. 


\subsection{Results}

\subsection{Optimal Algorithm Baseline Comparison}

Solutions to the Location Set Covering Problem (LSCP) and the Maximal Covering Location Problem (MCLP) for the BC datasets using ILOG OPL were compared to results for the same datasets done previously using a different optimal solver, IBM OSL (Optimization Solutions and Library) (Lindsay et al., unpublished). The solution size for the MCLP, which is the number of species covered for a given number of input cells, was equal for both solvers for all 6 feature groups (column 1) (all column references are for the Output section of Table 4.1), as was the LSCP solution which was the number of cells that included each species at least once (column 2). However, there was a difference in the number of solutions found between OSL and OPL for some of the models (columns 3 and 4 respectively) even when the solution sizes were the same. The number of solutions were equal in 26 of the 29 cases where either algorithm found less than 1000 solutions. Of the remaining $3, \mathrm{OPL}$ found more solutions than OSL in 2 cases. For the remaining 26 runs, the algorithms were terminated after 1000 solutions had been found, except OPL was run longer for each LSCP (this information is used elsewhere). The number of solutions, however, did not always increase with the number of sites. This is consistent with the results from Csuti et al. (1997) and shows that the number of possible combinations of solution sets is not dependent wholly on the number of sites, but is also probably affected by the configuration of the distribution of features. 
Table 4.1 : Results from the comparison between ILOG OPL and IBM OSL for the BC data. Three differences in solution set size are shown in dark grey. Numbers with a ">" symbol indicate that the programs were halted before all solutions were found (some OPL results extended beyond 1000 for Section 4.2.2).

\begin{tabular}{|c|c|c|c|c|c|}
\hline & INPUT & \multicolumn{4}{|c|}{ OUTPUT } \\
\hline $\begin{array}{c}\text { Feature } \\
\text { Group }\end{array}$ & $\begin{array}{c}\text { MCLP } \\
- \\
\# \text { of } \\
\text { cells }\end{array}$ & $\begin{array}{c}\text { MCLP } \\
\text { Obj.fn. solution } \\
\text { (number of spp.) } \\
\text { (OSL and OPL) }\end{array}$ & $\begin{array}{c}\text { LSCP } \\
\text { Obj.fn. solution } \\
\text { (\# of cells req'd) } \\
\text { (OSL and OPL) }\end{array}$ & $\begin{array}{c}\text { OSL } \\
\text { \# of } \\
\text { solutions }\end{array}$ & $\begin{array}{c}\text { OPL } \\
\begin{array}{c}\text { \# of } \\
\text { solutions }\end{array}\end{array}$ \\
\hline \multirow{5}{*}{$\begin{array}{c}\text { BC } \\
\text { Amphibians } \\
1551 \text { cells } \\
18 \text { species }\end{array}$} & 1 & 11 & & 9 & 9 \\
\hline & 2 & 15 & & 9 & 9 \\
\hline & 3 & 16 & & 445 & $>1000$ \\
\hline & 4 & 17 & & $>1000$ & $>1000$ \\
\hline & 5 & $18(100 \%)$ & 5 & $>1000$ & $>4368$ \\
\hline \multirow{5}{*}{$\begin{array}{c}\text { BC } \\
\text { Reptiles } \\
1048 \text { cells } \\
15 \text { species }\end{array}$} & 1 & 10 & & 11 & 11 \\
\hline & 2 & 12 & & 59 & 59 \\
\hline & 3 & 13 & & 291 & 291 \\
\hline & 4 & 14 & & 376 & 376 \\
\hline & 5 & $15(100 \%)$ & 5 & 144 & 144 \\
\hline \multirow{6}{*}{$\begin{array}{c}\text { BC Species } \\
\text { of Concern } \\
1589 \text { cells } \\
25 \text { species }\end{array}$} & 1 & 15 & & 6 & 6 \\
\hline & 2 & 20 & & 72 & 72 \\
\hline & 3 & 22 & & 792 & 792 \\
\hline & 4 & 23 & & $>1000$ & $>1000$ \\
\hline & 5 & 24 & & $>1000$ & $>1000$ \\
\hline & 6 & $25(100 \%)$ & 6 & $>1000$ & $>3566$ \\
\hline \multirow{7}{*}{$\begin{array}{c}B C \\
\text { Mammals } \\
1589 \text { cells } \\
102 \text { species }\end{array}$} & 1 & 68 & & 1 & 1 \\
\hline & 2 & 84 & & 4 & 4 \\
\hline & 3 & 95 & & 2 & 2 \\
\hline & 4 & 98 & & 46 & 46 \\
\hline & 5 & 100 & & $>1000$ & $>1000$ \\
\hline & 6 & 101 & & $>1000$ & $>1000$ \\
\hline & 7 & $102(100 \%)$ & 7 & $>1000$ & $>3141$ \\
\hline
\end{tabular}

(continued on next page) 
Table 4.1 (cont'd)

\begin{tabular}{|c|c|c|c|c|c|}
\hline \multirow[b]{2}{*}{$\begin{array}{c}\text { Feature } \\
\text { Group }\end{array}$} & \multirow{2}{*}{$\begin{array}{c}\text { INPUT } \\
\text { MCLP } \\
- \\
\text { \# of } \\
\text { cells }\end{array}$} & \multicolumn{4}{|c|}{ OUTPUT } \\
\hline & & $\begin{array}{c}\text { MCLP } \\
\text { Obj.fn. solution } \\
\text { (number of spp.) } \\
\text { (OSL and OPL) }\end{array}$ & $\begin{array}{c}\text { LSCP } \\
\text { Obj.fn. solution } \\
\text { (\# of cells req'd) } \\
\text { (OSL and OPL) }\end{array}$ & $\begin{array}{c}\text { OSL } \\
\text { \# of } \\
\text { solutions }\end{array}$ & $\begin{array}{c}\text { OPL } \\
\text { \# of } \\
\text { solutions }\end{array}$ \\
\hline \multirow{14}{*}{$\begin{array}{c}\text { BC } \\
\text { Birds } \\
1589 \text { cells } \\
274 \text { species }\end{array}$} & 1 & 188 & & 1 & 1 \\
\hline & 2 & 226 & & 1 & 1 \\
\hline & 3 & 249 & & 3 & 3 \\
\hline & 4 & 256 & & 279 & 279 \\
\hline & 5 & 262 & & 894 & 894 \\
\hline & 6 & 264 & & $>1000$ & $>1000$ \\
\hline & 7 & 266 & & $>1000$ & $>1000$ \\
\hline & 8 & 268 & & $>1000$ & $>1000$ \\
\hline & 9 & 269 & & $>1000$ & $>1000$ \\
\hline & 10 & 270 & & $>1000$ & $>1000$ \\
\hline & 11 & 271 & & $>1000$ & $>1000$ \\
\hline & 12 & 272 & & $>1000$ & $>1000$ \\
\hline & 13 & 273 & & $>1000$ & $>1000$ \\
\hline & 14 & $274(100 \%)$ & 14 & $>1000$ & $>3201$ \\
\hline \multirow{18}{*}{$\begin{array}{c}\text { BC } \\
\text { Species } \\
\text { at Risk } \\
1588 \text { cells } \\
59 \text { species }\end{array}$} & 1 & 17 & & 2 & 2 \\
\hline & 2 & 30 & & 2 & 2 \\
\hline & 3 & 36 & & 2 & 2 \\
\hline & 4 & 40 & & 3 & 3 \\
\hline & 5 & 43 & & 3 & 3 \\
\hline & 6 & 45 & & 31 & 31 \\
\hline & 7 & 47 & & 50 & 50 \\
\hline & 8 & 48 & & 53 & 1411 \\
\hline & 9 & 50 & & $>1000$ & 212 \\
\hline & 10 & 51 & & $>1000$ & $>1000$ \\
\hline & 11 & 52 & & $>1000$ & $>1000$ \\
\hline & 12 & 53 & & $>1000$ & $>1000$ \\
\hline & 13 & 54 & & $>1000$ & $>1000$ \\
\hline & 14 & 55 & & $>1000$ & $>1000$ \\
\hline & 15 & 56 & & $>1000$ & $>1000$ \\
\hline & 16 & 57 & & $>1000$ & $>1000$ \\
\hline & 17 & 58 & & $>1000$ & $>1000$ \\
\hline & 18 & $59(100 \%)$ & 18 & $>1000$ & $>2040$ \\
\hline
\end{tabular}


In general, the results from both optimal algorithms were close to identical. All solution sizes were the same and differences only existed in a few runs in terms of the number of solutions each solver produced. All mismatches existed at the cusp of where solution numbers became greater than 1000 which may have suggested that more mismatches might have occurred as the solution numbers grew larger. On the other hand, only two datasets showed mismatches at that point and many showed equivalent results at very high numbers. What can be stated with confidence is that 26 of the 29 lowest solution numbers matched for both solvers. Where they did not match, the number of solutions was quite large, so differences between them would probably not be important from a conservation planning perspective.

Differences in spatial configurations for the solutions were not expected. That is, the same solution cells were expected to be selected by both algorithms. This could not be compared here due to limitations of the OSL dataset obtained except when all solutions had been found for a dataset. In that one case (BC reptiles), the overall set of cells involved in the solutions could be compared and were identical. Since the same cells and the same number of combinations were found, it suggests the sets were also identical in each case, but this could not be confirmed due to limitations of the OSL results provided. (Maps of BC reptile distribution and reserve solution sets are provided in Figure 4.8 as part of the gap analysis comparison.) 


\subsection{Heuristic and Optimal Algorithm Comparison}

\subsubsection{Output Solution Comparison}

The optimality test compared the number of cells selected by OPL for LSCP to the number of cells selected using the C-Plan minset function. Results are shown in Figure 4.1. Here, suboptimality refers to the increase in the number of sites found by the heuristic algorithm above the optimal number.

Figure 4.1 : LSCP solution sizes from OPL and minset size from C-Plan using 4 different prioritisation methods.

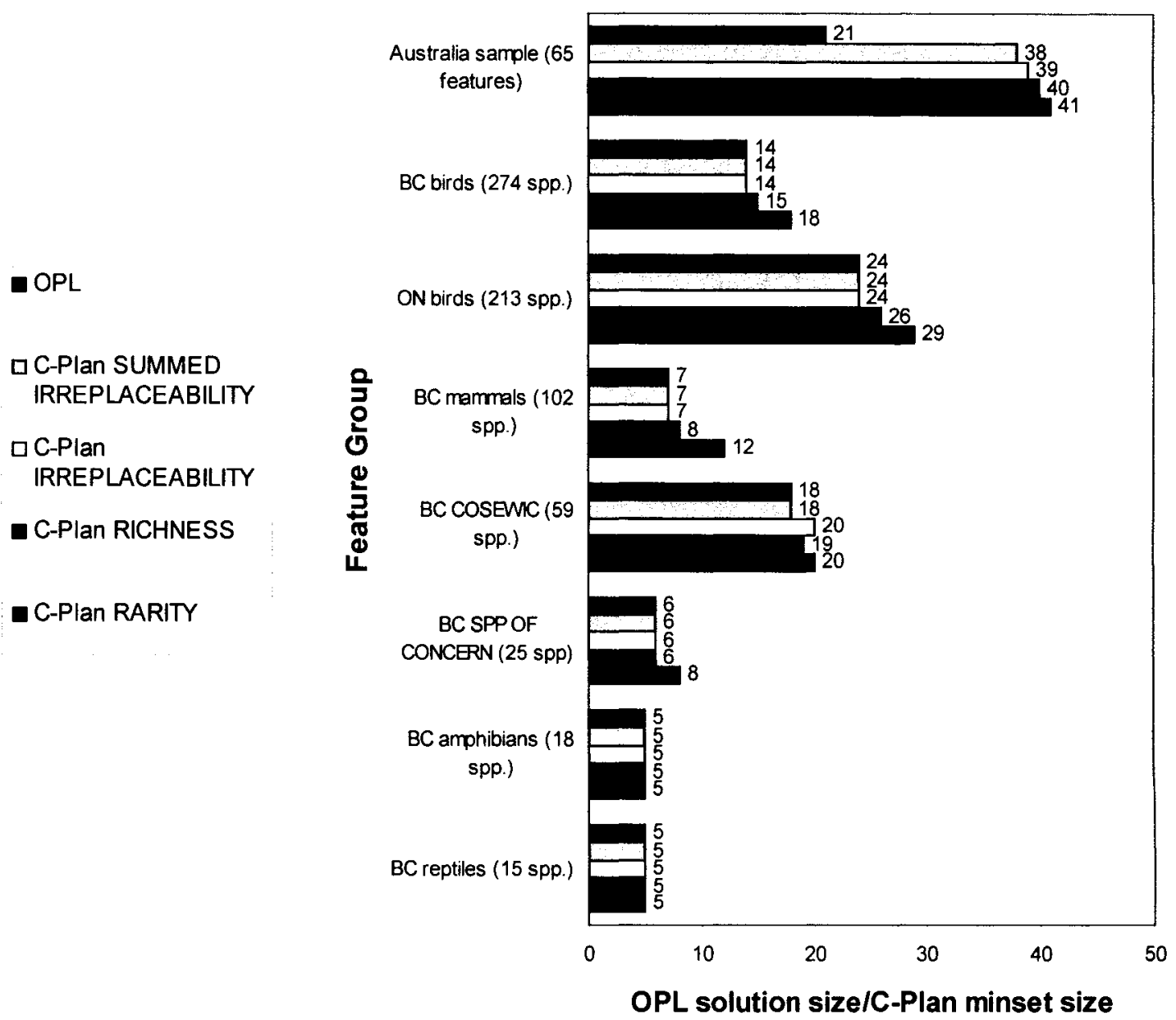


As expected, the number of sites selected by OPL for the LSCP was never larger than the number selected by C-Plan for any of the tests conducted. CPlan, in most cases, gave results that were closer to optimal when the two statistical prioritisation attributes (Irreplaceability and Summed Irreplaceability) were used and less so when the two algebraic criteria (Richness and Rarity) were used. The irreplaceability measures calculated the importance of each site to the conservation goal, whereas richness and rarity were "hotspot" (counts of certain feature types) evaluations. Summed Irreplaceability also calculated redundancy as an additional sorting criterion. It produced the same number of sites as OPL in seven of eight datasets, while Irreplaceability did so for six of the eight. For Richness and Rarity, only three and two of eight, respectively, produced the same \# of sites as OPL, with Rarity requiring many more sites than OPL in several of the datasets. Rarity usually had greater suboptimality than Richness regardless of the mix of feature configurations in each region. There may be a weak relationship between suboptimality and dataset size, as the smallest and largest sets have corresponding amounts of suboptimality; however, some of the intermediate sized datasets do not. Nor is there a consistent increase in the amount of suboptimality with an increase in the optimal solution set size. Suboptimality of MCLP results was not measured for this analysis, but some were measured for the section below regarding spatial patterns of solution sets. 
In general, these results fit the standard disclaimer that heuristic algorithms often carry. That is, heuristic results were often optimal or nearly so most of the time. However, it was not possible to know how suboptimal the results were without having optimal results for comparison, and the results did not always fit the standard pattern (as shown by the Australia results). It is unclear why the results for the Australia data are so poor. They consist of two completely allopatric datasets overlain on each other and that likely mimics a scenario with many endemic species, where less overlap also probably occurs. Endemic species data would normally be expected to give results close to optimal for most algorithm criteria.

\section{Spatial Pattern for Optimal LSCP Results}

The spatial distributions of the sites in optimal LSCP solutions from C-Plan were expected to match with the finite number of possible optimal and suboptimal sets. Verifying that there was a match could not always be done if all optimal sets had not been found but comparisons were made to those optimal solutions that had been found. Table 4.2 shows which C-Plan optimal sets did overlap with a known OPL optimal set. As expected, all C-Plan optimal sets matched known optimal sets when all optimal sets were found (BC reptile data only). The other positive matches, where optimal sets that had not been fully itemised, support the idea that not finding a match is probably only due to not having all optimal sets available for comparison. This is true regardless of which prioritisation attributes were used. 
Table 4.2: Spatial match of C-Plan minimum sets (i.e., LSCP) with any known optimal sets.

\begin{tabular}{|c|c|c|}
\hline $\begin{array}{c}\text { Dataset } \\
\text { (and \# of optimal OPL } \\
\text { solutions found) }\end{array}$ & $\begin{array}{c}\text { Sorting criteria that } \\
\text { produced optimal sets in } \\
\text { C-Plan }\end{array}$ & $\begin{array}{l}\text { Match of optimal } \\
\text { C-Plan solution with any } \\
\text { of the OPL solutions? }\end{array}$ \\
\hline $\mathrm{AU}$ & none & - \\
\hline $\mathrm{BC}$ birds & Summed Irreplaceability & no \\
\hline (3201) & Irreplaceability & no \\
\hline ON birds & Summed Irreplaceability & no \\
\hline$(3434)$ & Irreplaceability & no \\
\hline BC mammals & Summed Irreplaceability & no \\
\hline$(3141)$ & Irreplaceability & no \\
\hline BC COSEWIC & Summed Irreplaceability & no \\
\hline$(2040)$ & & \\
\hline $\mathrm{BC} \mathrm{SPoC}$ & Summed Irreplaceability & no \\
\hline$(3566)$ & Irreplaceability & YES \\
\hline & Richness & YES \\
\hline BC amphibians & Summed Irreplaceability & no \\
\hline$(4368)$ & Irreplaceability & no \\
\hline & Richness & no \\
\hline & Rarity & no \\
\hline BC reptiles & Summed Irreplaceability & YES \\
\hline (144 - all) & Irreplaceability & YES \\
\hline & Richness & YES \\
\hline & $\mathrm{Ra}$ & YES \\
\hline
\end{tabular}

\section{Spatial Pattern for Optimal and Suboptimal MCLP Results}

The same set matching situation, due to limited optimal and suboptimal solution sets, was expected for the MCLP results. That is, regardless of the number of sites (referred to as $n$ hereafter), there were one or more possible optimal and suboptimal solutions that would match any optimal or suboptimal solution (of the same number of cells) from a heuristic algorithm. The difference between this and the LSCP analysis is that there were changes in suboptimality 
as $n$ changed for any single dataset and sorting criterion. Table 4.3 provides solutions, i.e., species accumulations, to MCLP for each $n$ for the different sorting criteria for BC amphibians. It shows that suboptimality for all sorting methods for this dataset converged on an optimal solution for the largest $n$. The Richness results were all optimal and the other attributes were identically suboptimal for all values of $n$. When criteria showed similar levels of suboptimality, there was still a possibility that the species involved were the not the same, especially if the sites selected were different.

Table 4.3: MCLP solution set sizes (i.e., species accumulations) for OPL and all C-Plan sorting criteria for $\mathrm{BC}$ amphibians.

\begin{tabular}{|c|c|c|c|c|c|}
\hline$n$ (MCLP) & OPL & $\begin{array}{c}\text { C-Plan - } \\
\text { Summed } \\
\text { Irreplaceability }\end{array}$ & $\begin{array}{c}\text { C-Plan - } \\
\text { Irreplaceability }\end{array}$ & $\begin{array}{c}\text { C-Plan - } \\
\text { Richness }\end{array}$ & $\begin{array}{c}\text { C-Plan - } \\
\text { Rarity }\end{array}$ \\
\hline 1 & 11 & 7 & 7 & 11 & 7 \\
\hline 2 & 15 & 14 & 14 & 15 & 14 \\
\hline 3 & 16 & 16 & 16 & 16 & 16 \\
\hline 4 & 17 & 17 & 17 & 17 & 17 \\
\hline 5 & 18 & 18 & 18 & 18 & 18 \\
\hline
\end{tabular}

The distribution of sites for BC amphibians is shown for all $n$ in Figure 4.2.

Rarity solutions are shown as a surrogate for Summed Irreplaceability and Irreplaceability results since they have similar suboptimality. Richness results are shown as a surrogate for a sample (i.e., one of many possibilities) optimal solution set.

For all $n$, the general distribution of cells around BC for Richness was similar but not identical. The concentration of cells in the southern fringe, especially for low values on $n$, is because of the generally higher levels of species richness there, as the model goal was to maximise the number of 
Figure 4.2: C-Plan MCLP solution distributions for $18 \mathrm{BC}$ amphibian species. The red circles highlight solution cell locations that are different for the tow criteria. The number of species covered for each $n$ is shown with each map.

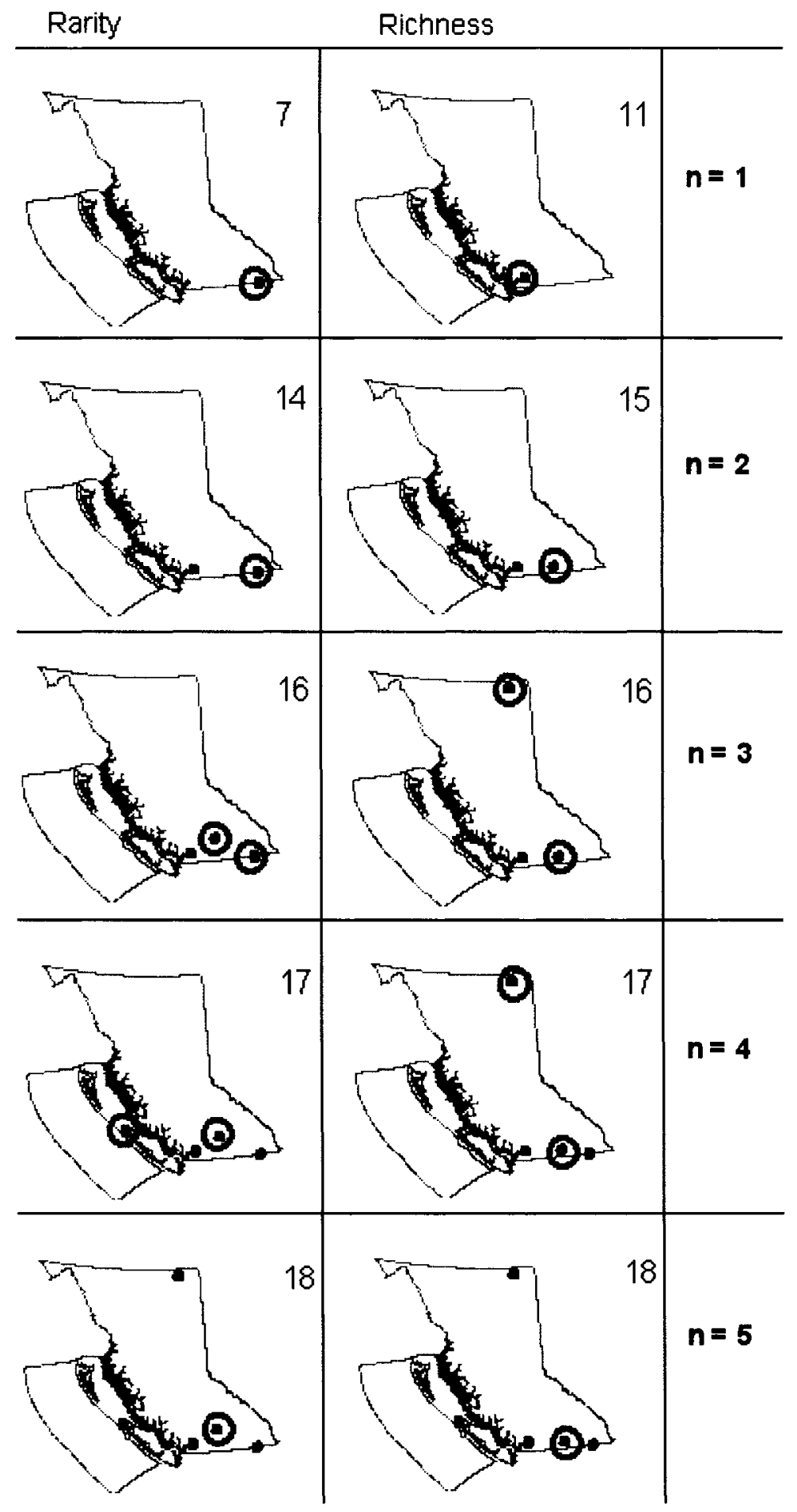


species selected regardless of prioritisation criterion. However, the difference between Rarity and Richness is seen immediately with $n=1$, as the Richness solution consists of one of the cells with the highest richness (see Figure 4.3 below) and the Rarity solution is a cell with the highest richness of rare species. As the sets grow, cells can only be added because C-Plan uses a greedy heuristic. When $n=2$, the solutions are again quite similar, but when $n=3$, Richness has added a cell from an area lower in richness than Rarity has, which is probably due to having different species covered so far and adding cells with different joint richness. The final solutions are quite similar, since, as with $n=2$, sites are added that are similar to those selected by the other attribute although in a different order.

MCLP suboptimality for BC birds at a range of sample $n$ values, including $n$ for the LSCP value (14 sites), is shown in Figure 4.4. This larger dataset had more $n$ values before reaching the LSCP condition and had some suboptimal results for LSCP which may contrast with mapping results for amphibians. Both Summed Irreplaceability and Irreplaceability results began with some suboptimality but converged with the optimal results as they did for amphibians. Rarity results for amphibians also followed that pattern but for birds they remained diverged from optimal. Richness results for amphibians were optimal at every stage, but for birds, they are 1 (of 274) spp. short of optimal and remain diverged by that amount for all $n$ tested. It was not unexpected for them to 
Figure 4.3: BC amphibian richness classes (map scale as in Figure 2.2).

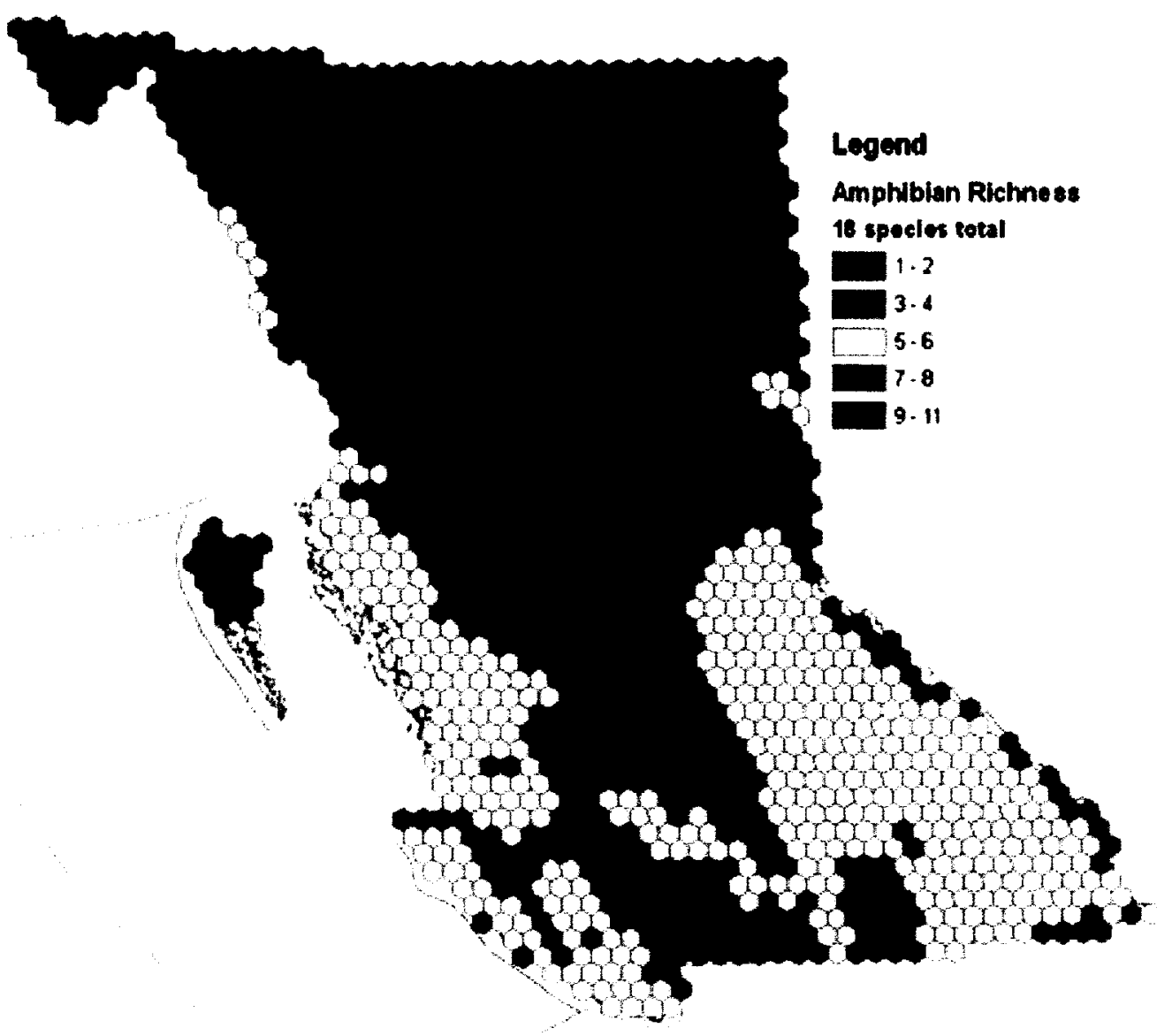

nearly match optimal results since the optimal algorithm was using richness to find the maximum number of species. However, the Richness results for birds eventually diverged from optimal, showing that a 'local minimum' (see Section 2.4.1) was reached by the time all species were covered (it is assumed that the Richness solution for $n=1$ was optimal).

Each of the single C-Plan solution sets from Figure 4.4 were mapped in order to see if patterns of distribution change could be detected (Figure 4.5). As 
with amphibians, sample OPL results were not shown as there were numerous multiple sets to select from, but again, Richness solutions are nearly optimal for every $n$ tested and may be representative of an optimal set. The right hand column of maps deviates from the pattern of adding 4 more $n$ to the previous map by using the number of sites needed to cover all species.

Figure 4.4: Sample MCLP suboptimality values for OPL and all C-Plan sorting criteria (BC birds).

\section{MCLP Suboptimality (BC Birds)}

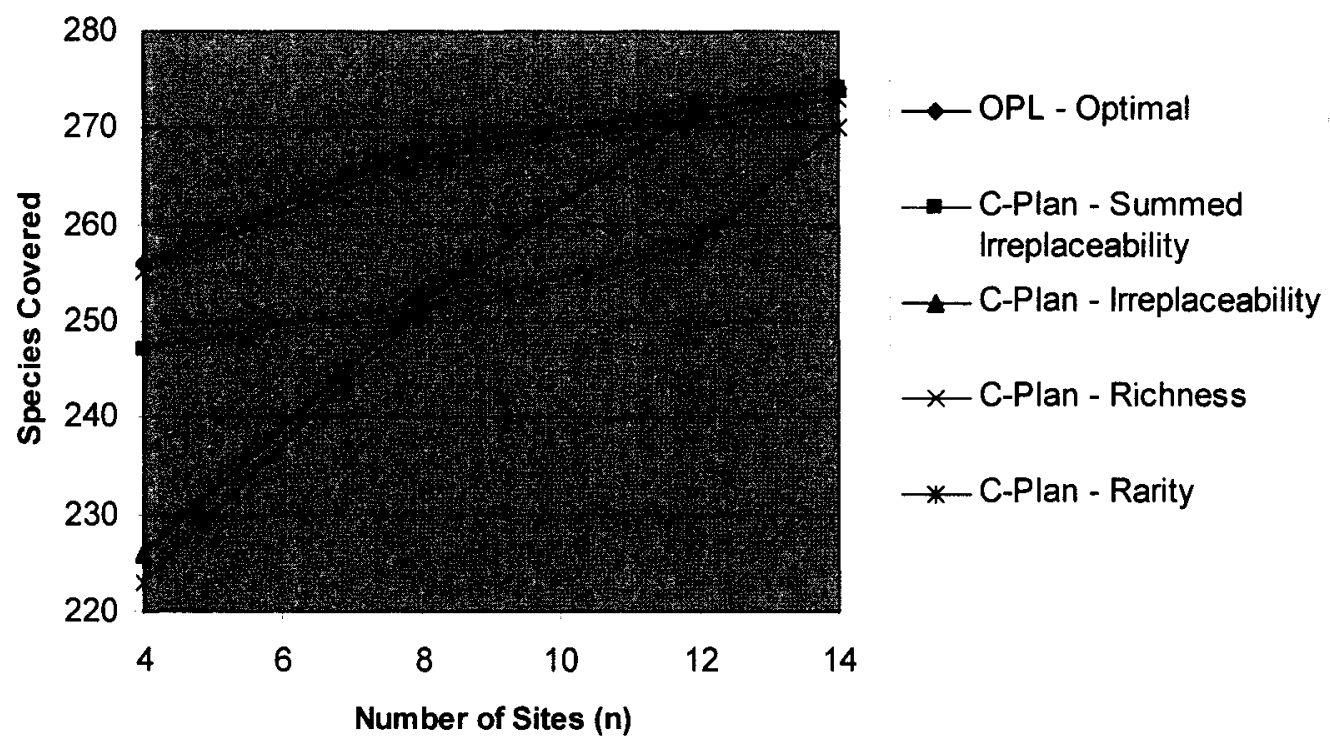

For all columns, the optimal number of species that can be found for each $n$ is shown in the heading, and the number that were actually covered for each result is shown with the individual maps (also in Figure 4.4). 
Figure 4.5: Site distributions for different values of $n$ for BC birds. Columns are maps by number of sites $(n)$ with last column having $n$ for LSCP (where all 274 species are covered).

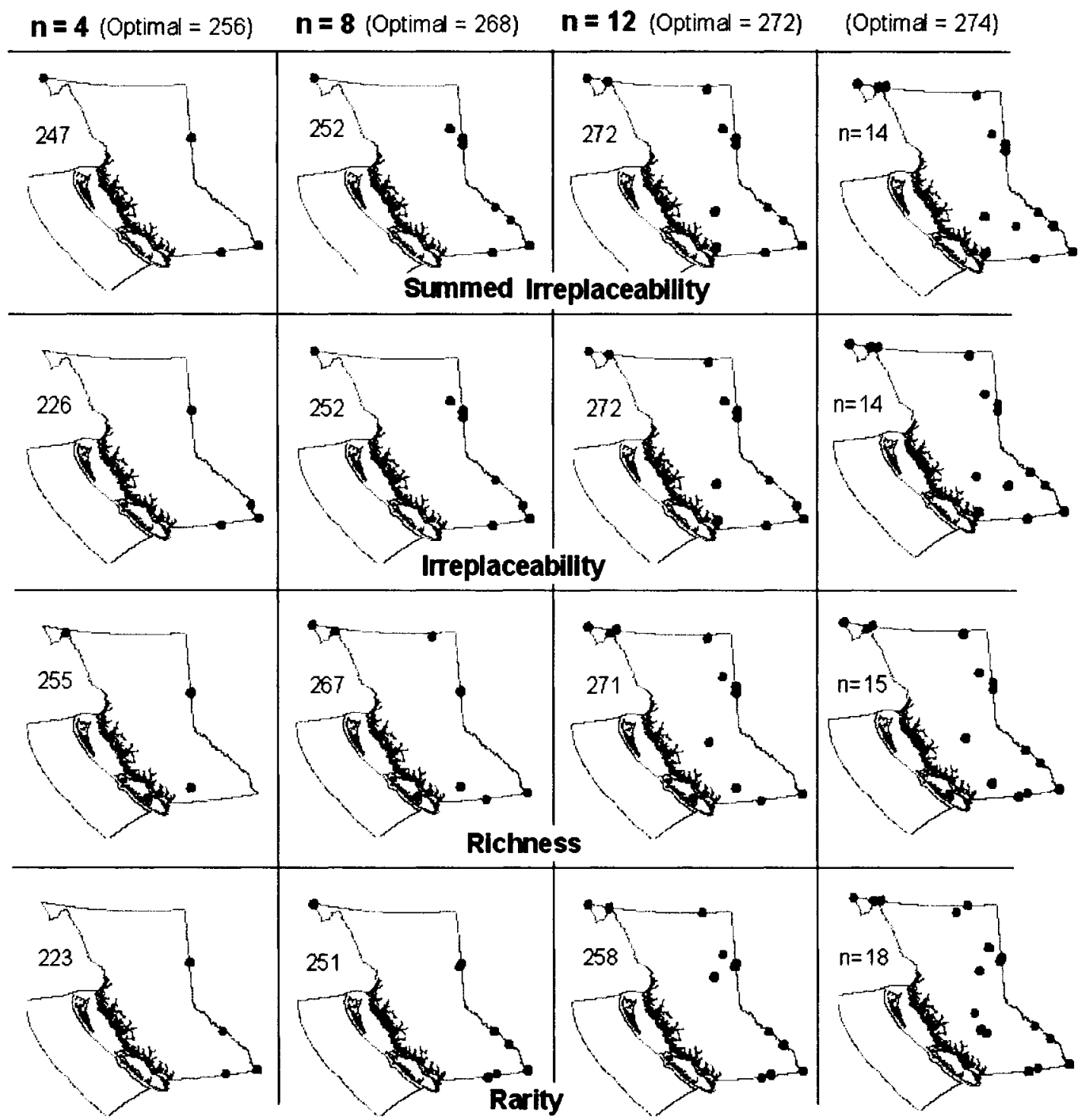

There were a number of trends that could be observed, although the fact that alternative distributions for each model were possible should be considered. In general terms, very few sites were located in large clumps once the number of sites approached the solution to the LSCP, as they probably would have been if richness without complementarity were used to select sites. This reflects the 
contribution from disparate ecoregions according to a number of authors (White et al., 1999; Moritz et al., 2001; Williams et al., 2004). BC ecoregions are quite evenly sized and distributed although some northeast to southeast trending in shape occurs due to tectonic folding (Figure 4.6).

Figure 4.6: British Columbia ecoregions.

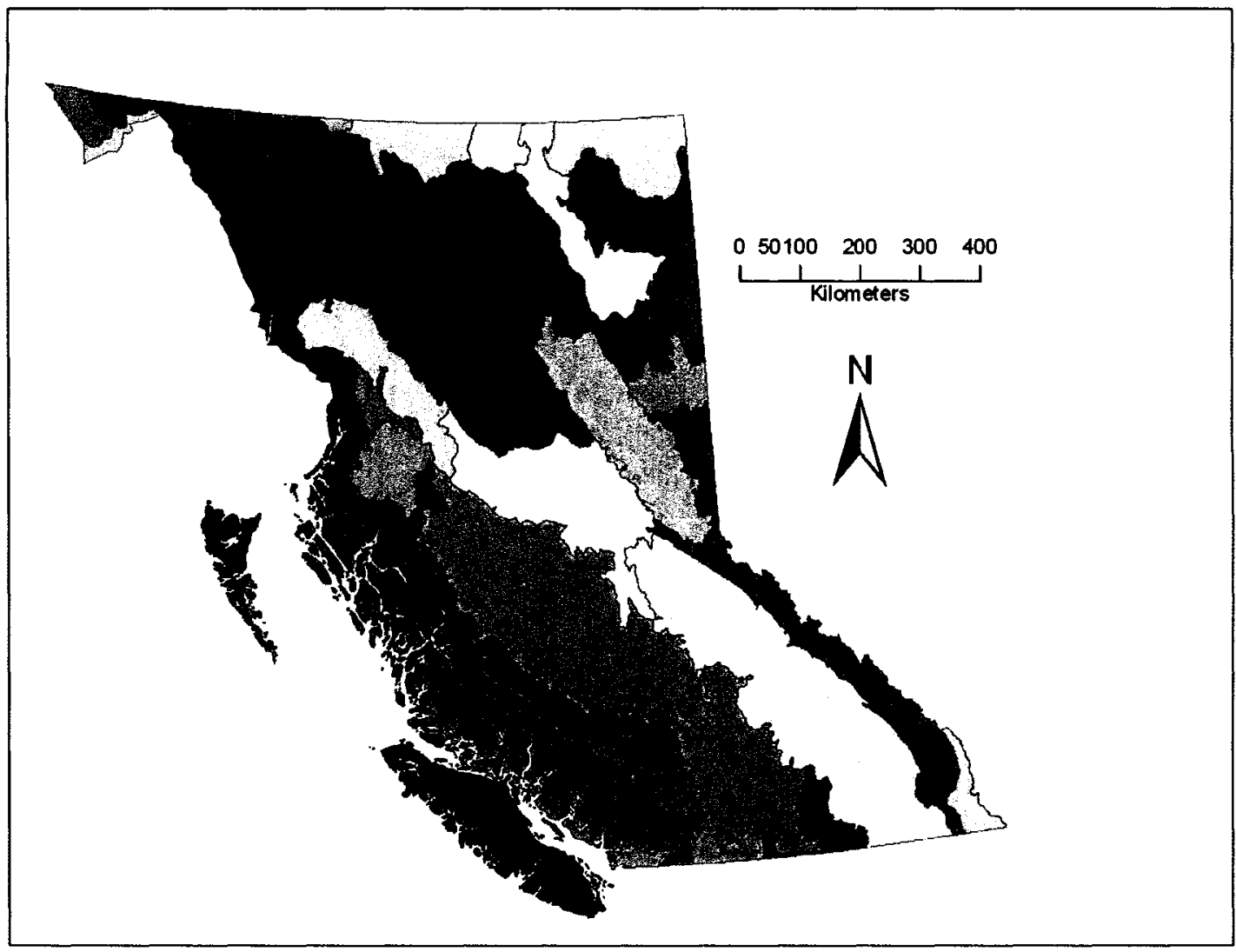

As well, the sites selected by each criterion were, roughly speaking, located in similar parts of the region. That is less often the case for low $n$, but even those maps showed a number of sites that were at, or close to, the same location. For low $n$, Richness showed the most difference from the others and only shared 1 of 4 cells. As $n$ increased, the distributions seemed to converge more closely, 
perhaps complementary with the suboptimality, as all got quite close to optimal for this dataset. This pattern was not as consistent for Rarity results, which had no sites located in the southwest corner of the province, but this is probably explained by its high suboptimality at $n=12$. The changing patterns also suggest that the method C-Plan used to pick each next site when there were ties (using cell ID as opposed to random or varied methods) may find similar cells in similar circumstances. For other methods of breaking ties, for example, the results may not have been similar if there were a large number of solution sets available. In this regard, Richness cells were again most different from the others, and it was evident that the differences in $n=8$ had forced it into a different final pattern, which in this case, as shown previously, had prevented it from finding an optimal solution to the LSCP. On the other hand, Summed Irreplaceability and Irreplaceability did end up with optimal results for the LSCP even though at earlier $n$ they tended to find marginal locations and were suboptimal. This was probably due to irreplaceable features sometimes being only marginally in the region (fewer locations increases irreplaceability). Richness patterns seem to be more evenly spread around the region, except for the largest $n$, and the Rarity pattern seems to be least spread over the entire region.

MCLP suboptimality shows little evidence of a trend to divergence from optimal to suboptimal results as $n$ increases except in small increments such as with BC bird Summed Irreplaceability $(n=1$ to $n=4)$ (Figure 4.4 above). The opposite is true in numerous cases, however, which supports previous 
contentions that as more sites are available, convergence of suboptimality and locations can occur (Polasky et al., 2000).

The suboptimality of results varied for C-Plan solutions to the LSCP (14 sites are the optimal number) (Figure 4.5). Summed Irreplaceability and Irreplaceability results are both optimal in size and match each other's cell locations exactly. Richness results have one extra site that stands out on Vancouver Island, which is not represented by the previous two. The remaining Richness sites coincide in general with the distribution of sites from the previous two results, with most differences occurring in the south-central area. The Rarity result has 3 extra sites in its LSCP solution which seem to be clumped with sites that exist in other maps but were non-represented areas in Rarity results for $n=$ 12. This can probably be thought of as the spatial equivalent of a local minimum, where having selected sites at lower $n$ values that were not as widely distributed as the others (especially evident for $n=12$ ), it finds itself with redundant sites as it selects the final few.

These findings agree with other studies that found suboptimality higher for lower values of $n$, and with Csuti et al. (1997) and Polasky et al. (2000) that convergence may be common when that occurs. However, care in making assumptions should be taken since numerous alternatives exist and C-Plan always seems to pick the same (first occurrence by ID) cell from alternative choices. 


\subsubsection{Gap Analysis Comparison}

The outputs from the two algorithms were used in a gap analysis to examine the similarity of their spatial distribution to a grid showing the presence of existing reserves. A solution that provided more overlap with existing reserves would require fewer new reserves and therefore be potentially less problematic or costly to complete. A solution that provided less overlap could signal that the goal of the model was quite different from the goals of the designers of the existing system. If resources were limited in that case, it may then be worthwhile to consider which values are more important and, if the regional plan was held to be more desirable, resources from some of the existing sites could be redirected to creating sites that make up the regional plan.

As discussed in Section 3.2.2, C-Plan solution sets were a single list of sites for each prioritisation attribute used (in this case there were four). An example for the $\mathrm{ON}$ region is shown in Figure 4.7 where the solution set includes 3 existing reserves. Even though there could have been numerous sets of sites that satisfy the goal, C-Plan's prioritisation process for finding minimum sets only produced one set for a given sorting criterion and dataset. OPL, on the other hand, found numerous optimal sets. All BC reptile solutions were found, for example, and are illustrated with existing reserves in Figure 4.8 (mapping of multiple optimal solutions using irreplaceability values, as shown in the legend, is described in the following subsection). 
Figure 4.7 : Example results of a gap analysis as done in this study (C-Plan results for ON bird data using Summed Irreplaceability).

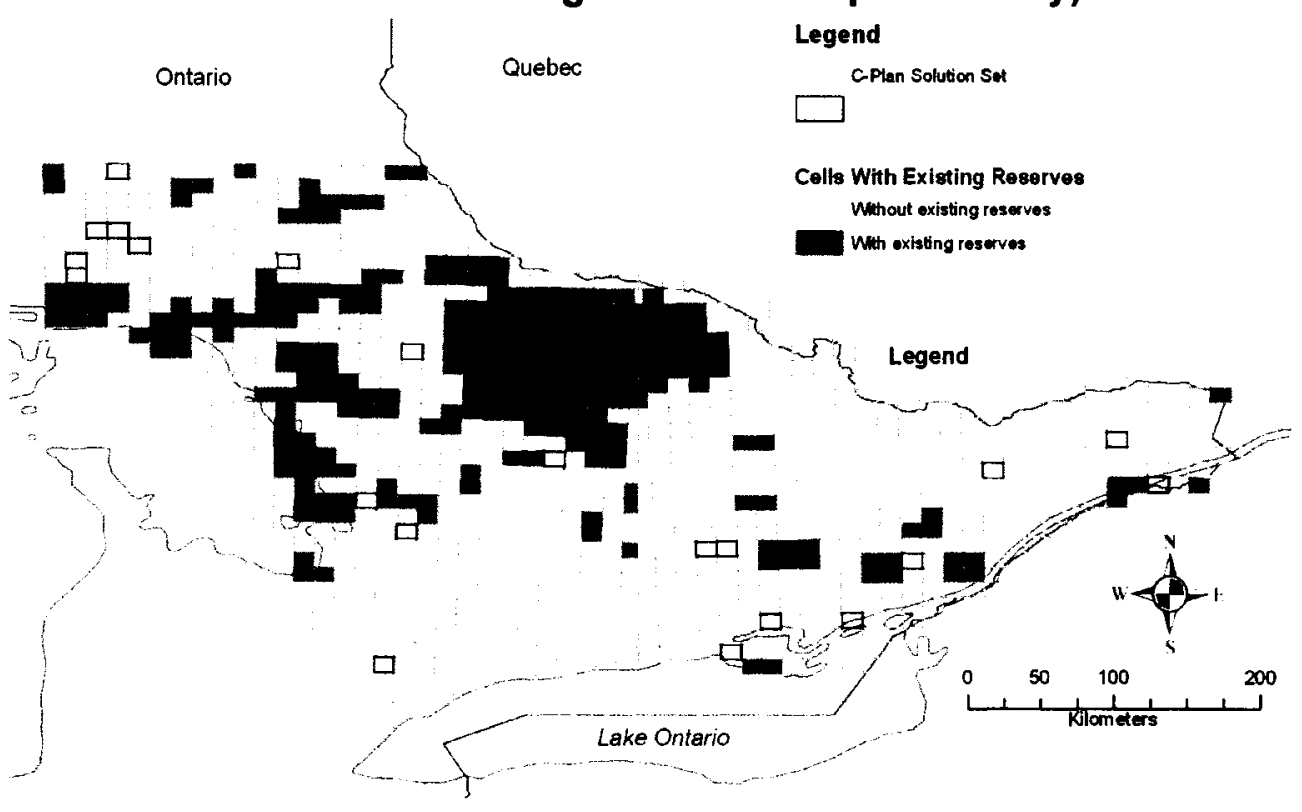

Figure 4.8: Distribution of $\mathrm{BC}$ reptile solutions shown on a base map of species richness classes and overlain by existing reserves.

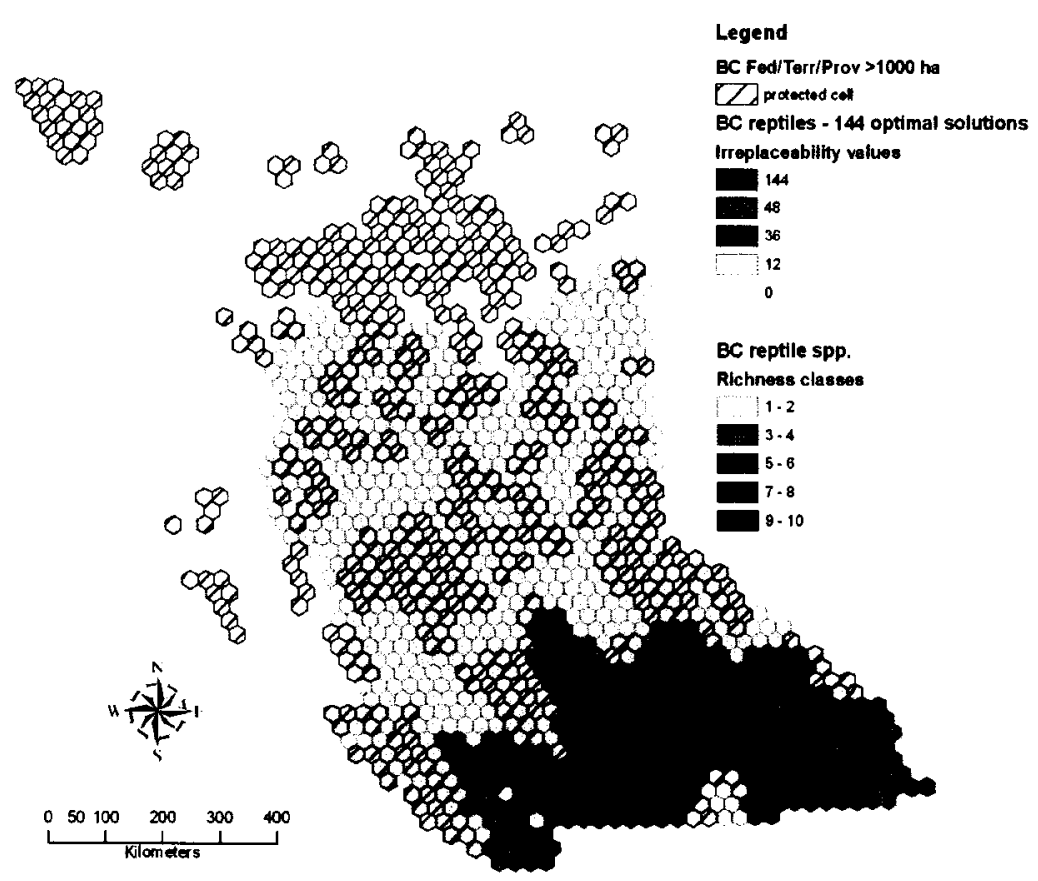


The results for the overlap test are provided in Table 4.4. In general terms, it provides the size of the solution set ("Solution Set Cells") and the number of those cells that overlapped the most with cells containing existing conservation reserves ("Overlap with Existing Reserves"). These fields are found in both the C-Plan and OPL sections. There are two main ways that the results from C-Plan and OPL differ. First, although each shows four results for each surrogate taxon group, the C-Plan results are single sets from four different sorting criteria and the OPL results are the four sets of solutions that have the most overlap with existing reserve cells for the LSCP model.

Second, as a result, the OPL section has two additional fields showing information relating to the multiple solutions found. The first, "\# of Solution Sets with Overlap Number Shown at Left", is the number of solutions that existed or were found that contained the amount of overlap shown in the column to the left (i.e., "Overlap with Existing Reserves"). The BC birds feature group, for example, had 7 solutions that had 9 cells overlapping, 84 solutions that had 8 cells overlapping, 362 solutions that had 7 cells overlapping, and 944 solutions that had 6 cells overlapping. The second, "Solutions Available", is the number of solutions that existed (e.g., BC reptiles) or were found before stopping the program.

The results answered the question of whether or not there was a difference in the amount of overlap with existing reserves that each algorithm's solution(s) could provide. In all cases, even when both algorithms found the same optimal 
Table 4.4 : The number of cells for each algorithm solution that overlap with cells from existing reserves. For each algorithm, the highlighted text shows the number of cells in the smallest solution set and the number of those cells that overlap with existing reserve cells. See text for details.

\begin{tabular}{|c|c|c|c|c|c|c|c|c|c|}
\hline \multirow[b]{2}{*}{ Group } & \multirow[b]{2}{*}{$\begin{array}{l}\frac{8}{0} \\
\frac{0}{2} \\
\frac{8}{5} \\
\frac{5}{0} \\
\end{array}$} & \multirow[b]{2}{*}{ 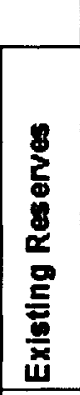 } & \multicolumn{3}{|c|}{ C-Plan } & \multicolumn{4}{|c|}{ OPL } \\
\hline & & & 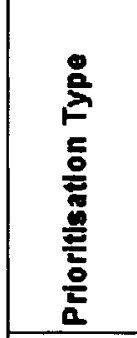 & 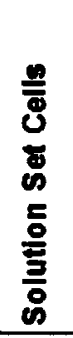 & 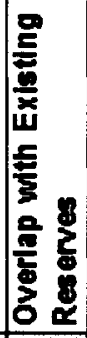 & 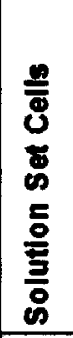 & 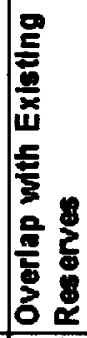 & 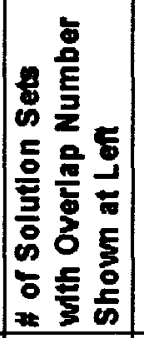 & 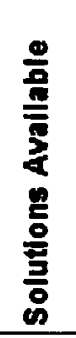 \\
\hline \multirow{4}{*}{$\begin{array}{c}B C \\
\text { birds }\end{array}$} & \multirow[t]{4}{*}{274} & \multirow{4}{*}{$\begin{array}{l}1589 \\
\text { cells }\end{array}$} & SUM_RRR & 14 & 6 & \multirow[t]{4}{*}{14} & 9 & 7 & \multirow[t]{4}{*}{3201} \\
\hline & & & IRREPL & 14 & 5 & & 8 & 84 & \\
\hline & & & \multirow{2}{*}{$\begin{array}{l}\text { RICHNESS } \\
\text { RARTY }\end{array}$} & 15 & 6 & & 7 & 362 & \\
\hline & & & & 18 & 6 & & 6 & 944 & \\
\hline \multirow{4}{*}{$\begin{array}{c}\text { ON } \\
\text { birds }\end{array}$} & \multirow[t]{4}{*}{213} & \multirow{4}{*}{$\begin{array}{l}1203 \\
\text { cells }\end{array}$} & SUM_IRR & 24 & 3 & \multirow[t]{4}{*}{24} & 7 & 4) & \multirow[t]{4}{*}{3434} \\
\hline & & & \multirow{3}{*}{\begin{tabular}{|l} 
IRREPL \\
RICHNESS \\
RARTY
\end{tabular}} & 24 & 3 & & 6 & 102 & \\
\hline & & & & 26 & 2 & & 5 & 759 & \\
\hline & & & & 29 & 5 & & 4 & 1178 & \\
\hline \multirow{4}{*}{$\begin{array}{c}B C \\
\text { mam- } \\
\text { mals }\end{array}$} & \multirow[t]{4}{*}{102} & 710 & \multirow{4}{*}{\begin{tabular}{l||l}
10 & SUM_RR \\
39 & IRREPL \\
S & RICHNESS \\
RARTY \\
\end{tabular}} & 1 & 3 & \multirow[t]{4}{*}{7} & 5 & 152 & \multirow[t]{4}{*}{3141} \\
\hline & & \multirow{3}{*}{$\begin{array}{c}\text { of } \\
1589 \\
\text { cells }\end{array}$} & & 1 & 3 & & 4 & 1074 & \\
\hline & & & & 8 & 2 & & 3 & 1568 & \\
\hline & & & & 12 & 5 & & 2 & 340 & \\
\hline \multirow{4}{*}{$\begin{array}{c}\text { BC } \\
\text { Species } \\
\text { at } \\
\text { Risk } \\
\end{array}$} & \multirow[t]{4}{*}{59} & \multirow{4}{*}{\begin{tabular}{|c|}
710 \\
of \\
1588 \\
cells \\
\end{tabular}} & \multirow{4}{*}{$\begin{array}{l}\text { SUM_RR } \\
\text { IRREPL } \\
\text { RICHNESS } \\
\text { RARTY } \\
\end{array}$} & 18 & 9 & \multirow[t]{4}{*}{18} & 13 & 22 & \multirow[t]{4}{*}{2040} \\
\hline & & & & 20 & 10 & & 12 & 92 & \\
\hline & & & & 19 & 11 & & 11 & 425 & \\
\hline & & & & 20 & 10 & & 10 & 795 & \\
\hline & 25 & 710 & SUM_RR & 6 & 2 & 6 & 4 & 9 & 3566 \\
\hline Spe & & of & IRREPL & 6 & 2 & & 3 & 406 & \\
\hline c & & 1589 & RICHNESS & 6 & 2 & & 2 & 1917 & \\
\hline Concern & & cells & RARTY & 8 & 3 & & 1 & 1102 & \\
\hline$B C$ & 18 & 710 & SUM_RR & 5 & 1 & 5 & 5 & 12 & 4368 \\
\hline amphi- & & of & IRREPL & 5 & 1 & & 4 & 477 & \\
\hline bians & & 1551 & RICHNESS & 5 & 2 & & 3 & 1908 & \\
\hline & & cells & RARTY & 5 & 1 & & $\underline{2}$ & 1037 & \\
\hline$B C$ & 15 & 710 & SUM_RR & 5 & 3 & 5 & 4 & 18 & $* 144$ \\
\hline reptiles & & of & RREPL & 5 & 3 & & 3 & 72 & \\
\hline & & 1048 & RICHNESS & 5 & 3 & & 2 & 54 & \\
\hline & & cells & RARTY & 5 & 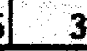 & & 1 & 0 & \\
\hline
\end{tabular}


size of solution set, the OPL outputs included numerous sets that had more spatial overlap with existing reserve cells than C-Plan outputs. Sometimes there were hundreds of OPL solution configurations that had more overlap than the single C-Plan solutions.

Among the C-Plan prioritisation criteria, Rarity often gave solutions that had the most or nearly the most overlap with existing reserves. This suggests that the reserves in all three regions may have historically been designed more often for local endemic species conservation than for regional, multi-species reasons. Rarity also often required more cells to solve the LSCP, although the correlation between this and overlap with existing reserves is not perfect.

\section{Mapping Multiple Sets}

Csuti et al. (1997) have mapped all 144 optimal solutions from their terrestrial vertebrate species dataset for Oregon (Ibid., Figure 2, p.92) in an elegant way. They labelled each of the solution cells with the frequency of occurrence of that cell in the total set of solution sets. For example, if a cell occurred in 48 of 144 total solutions, it had a score of $33 \%$. Once all solution set cells were labelled, solutions were reconstructed from the map by selecting all cells with a value of $100 \%$ (cells that occur in all solutions) and one cell from each group with the same frequency value. The number of combinations therefore added up to 144 since there were 19 cells labelled with $100 \%, 3$ with $33 \%, 4$ with $25 \%$ and 6 with $17 \%\left(1^{19} \times 2 \times 3 \times 4 \times 6\right)$. White et al. (1999) also used this technique, requiring the selection of a single cell from each group in 
order to make an optimal set. It is unclear if all possible solutions are included as their map shows a possibility of only 10 solutions sets of 8 cells each. This same method was also used in Figure 4.8 above, where the cells are coloured by frequency value scaled from 0 to 1 . By selecting the 2 red cells, plus one of every other colour, a total, and maximum, of 144 sets can be recreated $\left(1^{2} \times 3 \times 4 \times\right.$ 12). The colours in Figure 4.8, as shown in the legend, are derived from the irreplaceability values of each cell which is equivalent to the frequency of occurrence. If a cell occurs in more of the multiple solutions (because there are fewer of that combination of features), its frequency and irreplaceability go up.

This method maps multiple solutions sets in a way that can be visualised correctly in the cases above. This system fails, however, when the number of sites involved becomes too high. Lindsay et al. (unpublished) have attempted to map each BC taxon group, and mapped the 144 solutions for $B C$ reptiles successfully (Figure 4.9) (although the colouring of the cells represents solution set groups but not irreplaceability). When they map amphibians, however (Figure 4.10), the total number of combinations of 5 cells is approximately $430,000(3 \times 9$ $\times 20 \times 21 \times 38$ ), more than were actually found to be optimal sets by the algorithm. This demonstrates that simply selecting one site from each colour code may not produce an optimal set as identified by the original algorithm.

The problem of potential incorrect solutions was also encountered here with the OPL results for datasets larger than BC reptiles. The 4,368 OPL solution sets for $\mathrm{BC}$ amphibian data are displayed in Figure 4.11 using their irreplaceability 
Figure 4.9: BC reptile data optimal solutions map (map scale as in Figure 2.2) (Lindsay et al., unpublished).

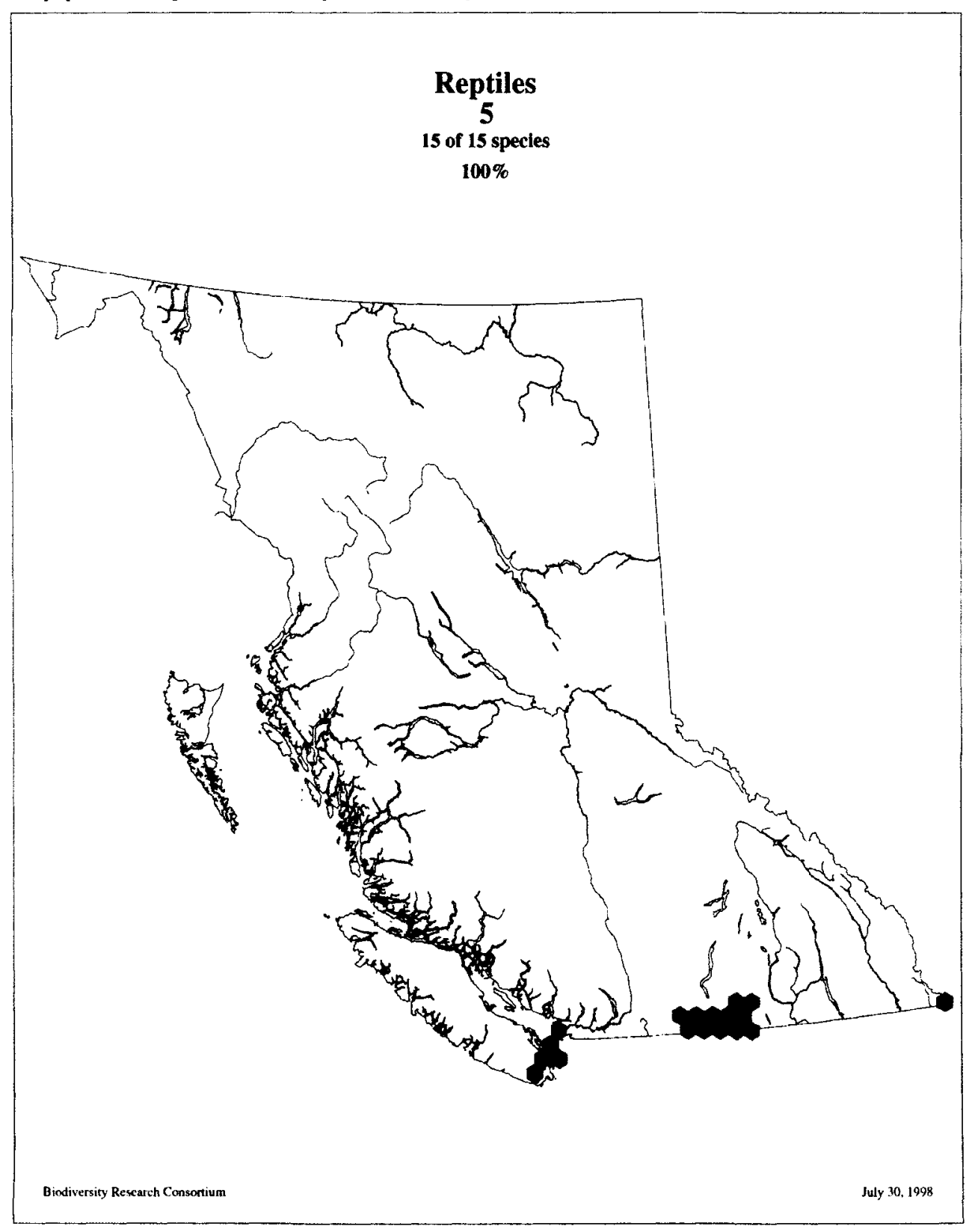

value so far. The cell with the highest irreplaceability value has occurred 3985 times out of 4368 solutions so no single site is totally irreplaceable. With this number of individual irreplaceability values, the ability to use them to reconstruct 
Figure 4.10: BC amphibian data optimal solutions map (map scale as in Figure 2.2) (Lindsay et al., unpublished).

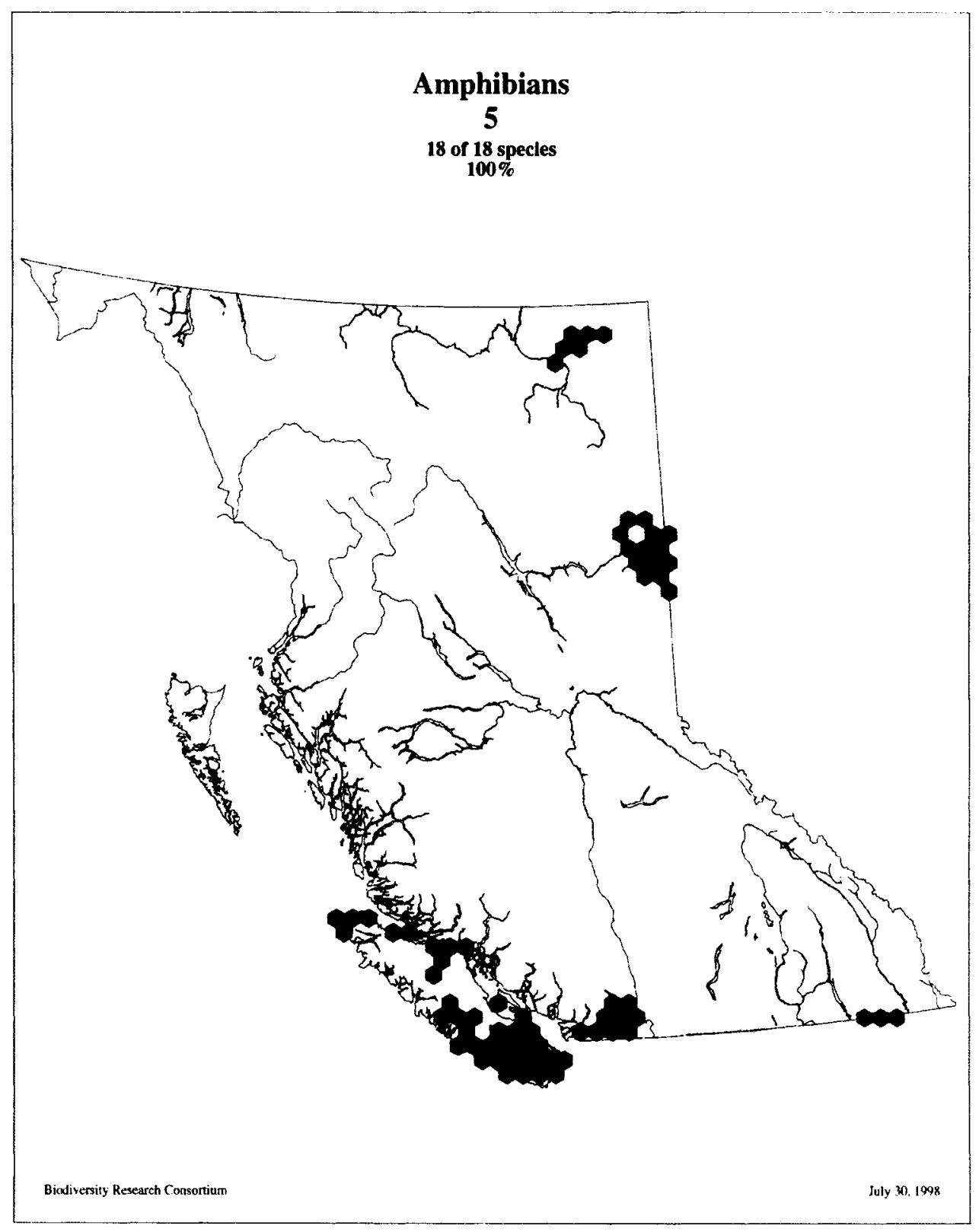

optimal solutions of 5 sites is again lost. The solution to this problem by Lindsay et al. was to filter the solutions to show only a subset of groups of 5 solution sites (Figure 4.10) (Lindsay, pers. comm., 2004) although it still did not prevent the 
Figure 4.11: Distribution of OPL irreplaceability values shown on a base map of species richness classes for the BC amphibian dataset (map scale as in Figure 2.2).

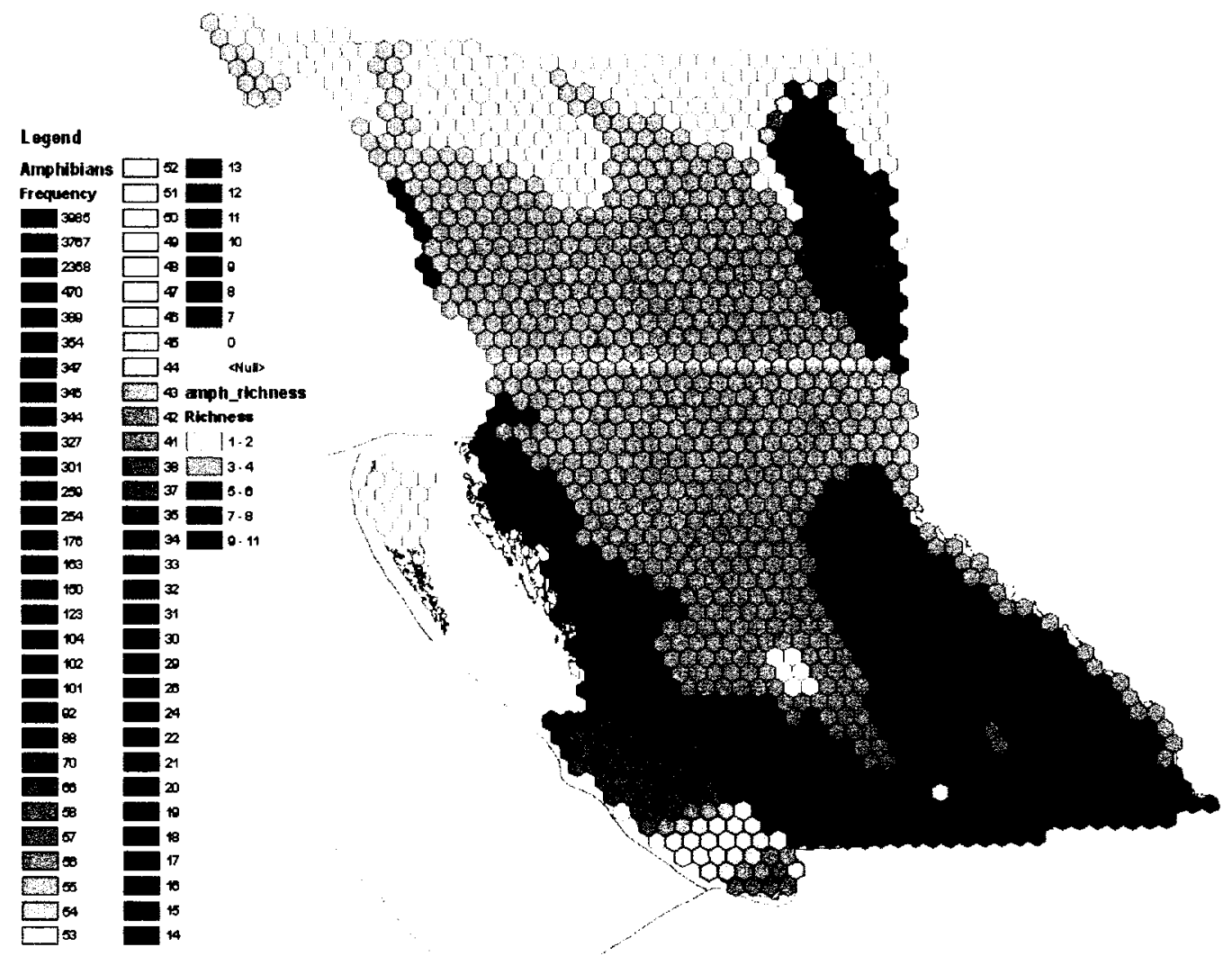

possibility of selecting a solution that was an artefact of the translation process instead of a true solution. C-Plan also uses the same method to calculate its Irreplaceability sorting attribute value, but the calculations are done using a priori statistics (Ferrier et al., 2000) instead of the a posteriori method used above for OPL. The differences in irreplaceability for both algorithms are shown in Table 4.5. C-Plan results are equal to OPL results in most cases and the difference seems to be related to the number of irreplaceable sites. However, OPL results are for incomplete solution sets except for $\mathrm{BC}$ reptiles, so care must be taken in drawing conclusions. 
Table 4.5: Number of totally irreplaceable cells for each taxon group by solver.

\begin{tabular}{|c|c|c|}
\hline $\begin{array}{c}\text { Taxon Group } \\
\text { (no. of solutions used) }\end{array}$ & OPL & C-Plan IRREPL \\
\hline $\begin{array}{c}\text { ON Birds } \\
(3434)\end{array}$ & 14 & 11 \\
\hline $\begin{array}{c}\text { BC SAR } \\
(2040)\end{array}$ & 7 & 2 \\
\hline $\begin{array}{c}\text { BC Birds } \\
(3210)\end{array}$ & 2 & 2 \\
\hline $\begin{array}{c}\text { BC Reptiles } \\
(144 \text { (all)) }\end{array}$ & 2 & 1 \\
\hline $\begin{array}{c}\text { BC SOC } \\
(3566)\end{array}$ & 1 & 1 \\
\hline $\begin{array}{c}\text { BC Mammals } \\
(3141)\end{array}$ & 1 & 0 \\
\hline BC Amphibians \\
$(4368)$
\end{tabular}

Figure 4.12 provides $B C$ reptile irreplaceability information as calculated by C-Plan using its a priori statistical method. The same 2 cells as in the OPL results (Figure 4.8) are completely irreplaceable and the remaining cells found in OPL solutions are recognised here as having better than minimal irreplaceability.

Figure 4.13 provides $B C$ amphibian irreplaceability information as calculated by C-Plan. As with the OPL results (Figure 4.11, Table 4.5), there are no sites that are irreplaceable. Although the OPL results are not final, the C-Plan results suggest they will not change. Unlike the OPL results, there is no recognition of higher irreplaceability in the northeast part of the province.

\subsubsection{Algorithm Speed Comparison}

The speed at which algorithms provide solutions in reserve selection problems has been an important issue in several past studies. The flexibility needed to work with alternative solutions is diminished when results are not available for interactive use. Although computer speed has increased 
Figure 4.12: Distribution of C-PIan irreplaceability values for BC reptiles. The legend and a priori irreplaceability values are created by the program.

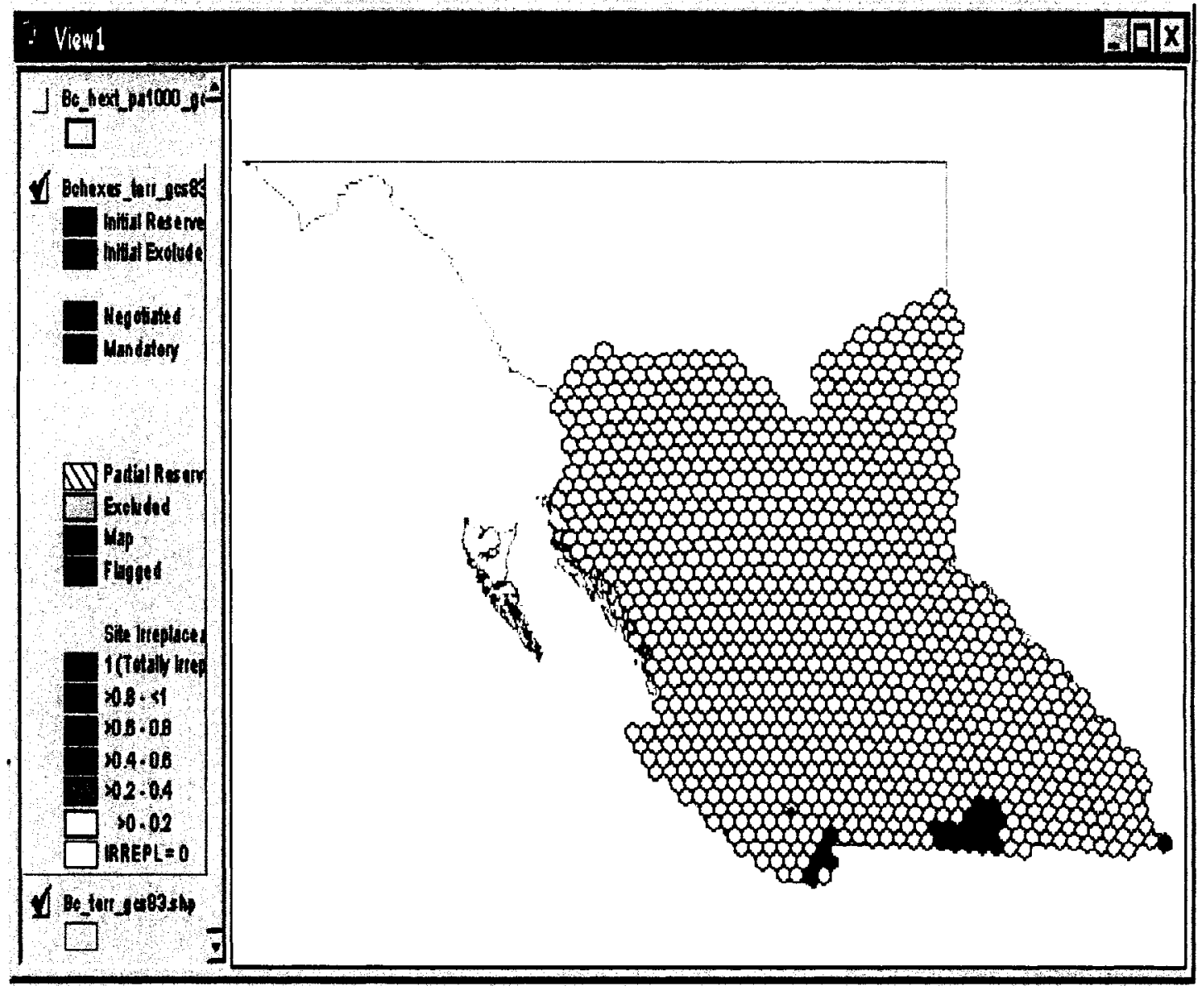

tremendously in recent years and algorithm design has improved, Önal (2003) has suggested that slow results for some optimal solutions are not surprising, and fast results (e.g., Rodrigues and Gaston, 2002) may not be true optimal results at all (Önal, 2003).

A wide variety of sizes of dataset were compared in this study for differences in processing time to produce one solution to the LSCP. The results, shown in Figures 4.14a (Figure 4.14b zooms in to show the results for the 
Figure 4.13: Distribution of C-Plan irreplaceability values for BC amphibians. The scale is as in Figure 4.12

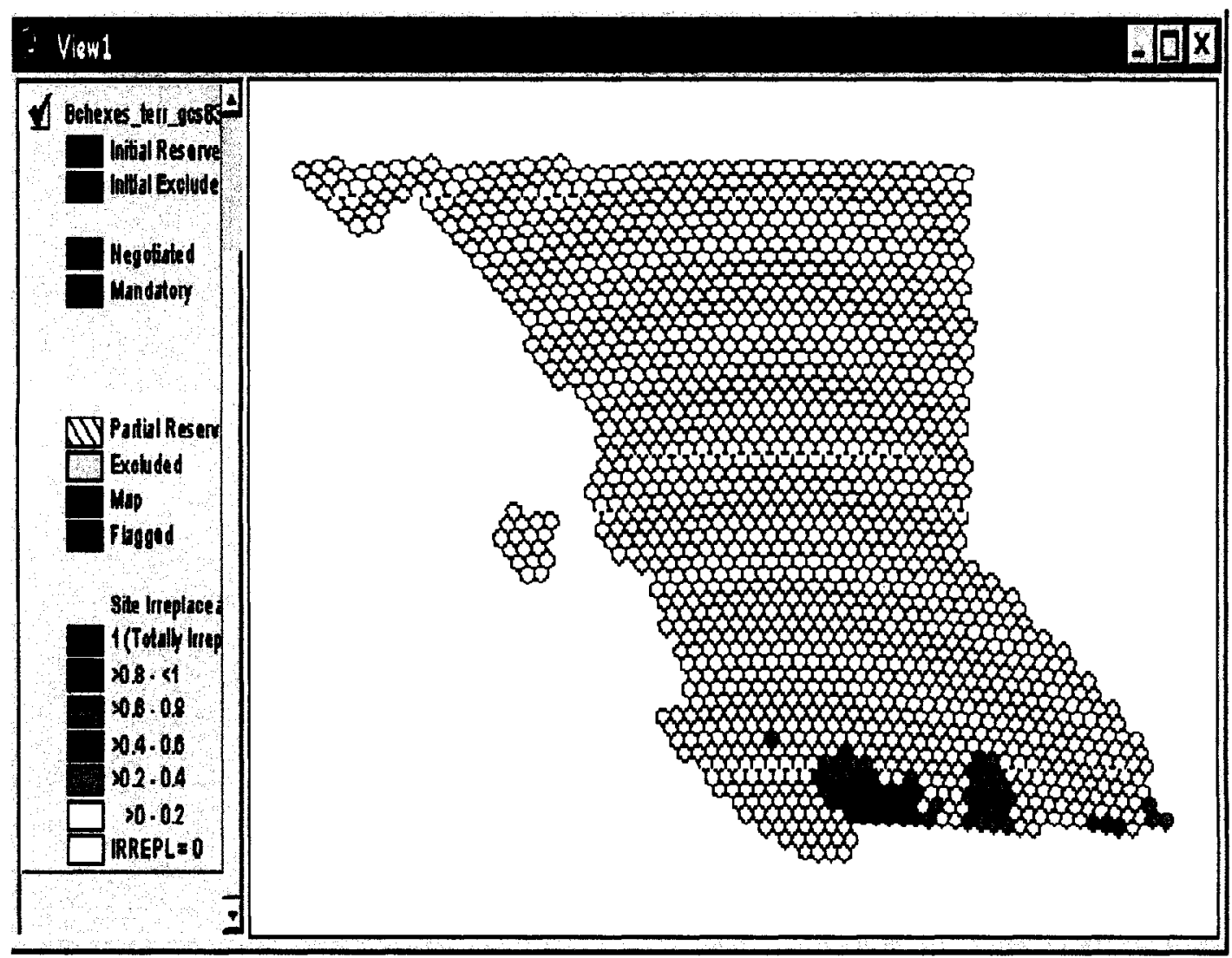

smallest sets), show that OPL speed was consistently equivalent to or lower than C-Plan times, often being as little as $25 \%$ to $50 \%$ of C-Plan times. These overall fast times for OPL results are explained by the fact that long times are expected when finding optimal results only when complete enumeration is used in the optimal algorithm. Algorithms in modern solvers such as OPL and OSL use numerous mathematical strategies and tools to minimise the number of solutions that need to be tested. 
Figure 4.14a : Times to solve LSCP for all nine datasets from Table 3.1. The bottom left corner is expanded for viewing in Figure 4.14b.

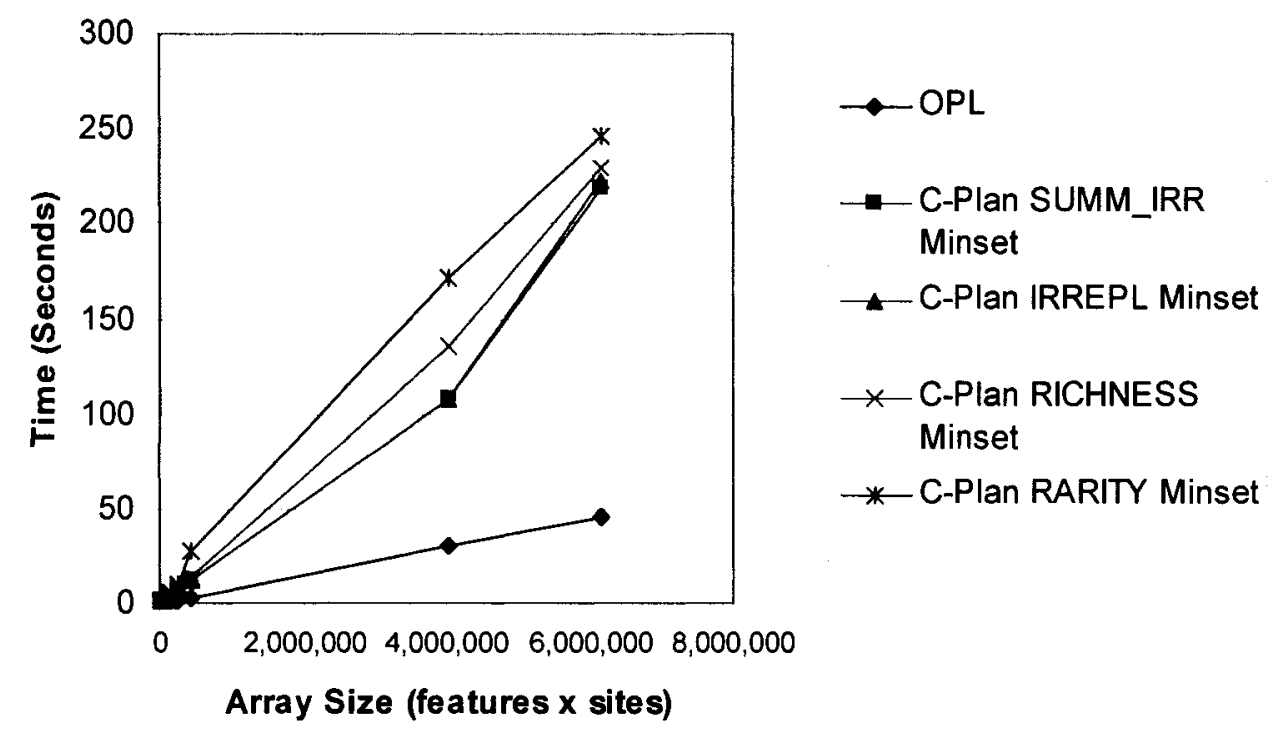

Figure 4.14b : Times to solve LSCP for seven smallest datasets from Table 3.1. These are shown separately from Figure 4.14a to show detail.

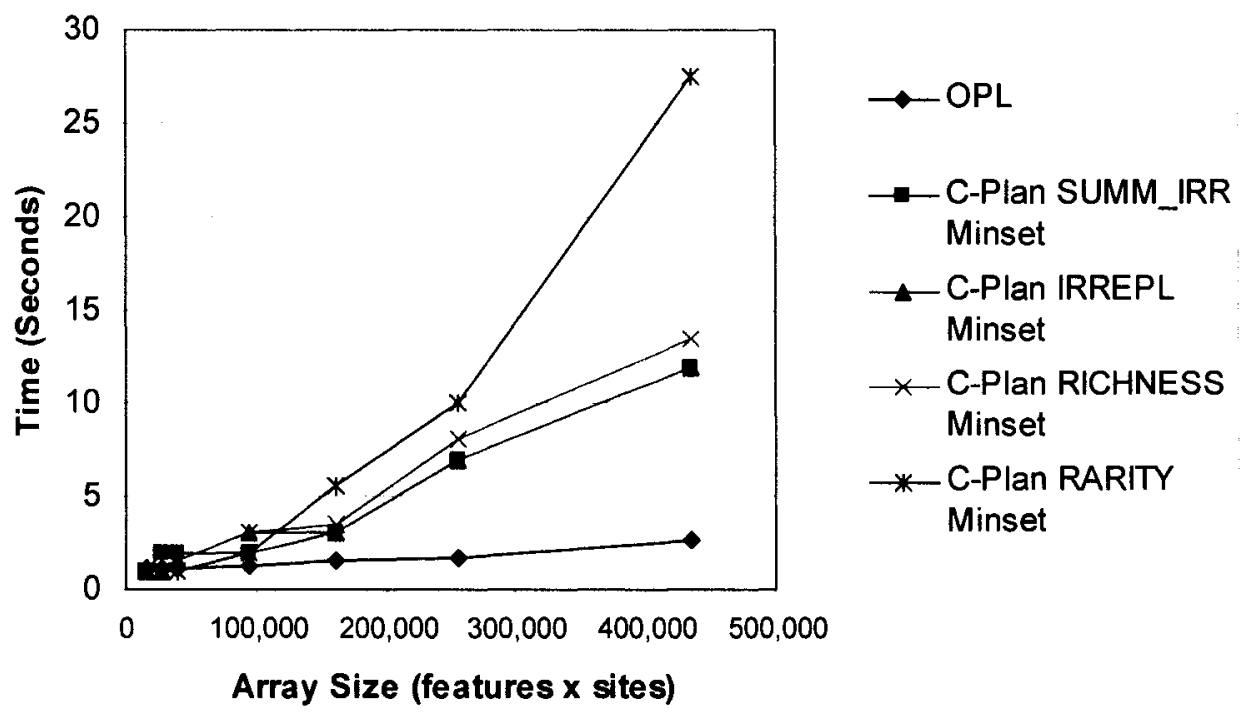


Finding multiple solutions using OPL took extra time. As more solutions were found, they needed to be kept in memory and used as constraints to ensure new solutions were unique. Figure 4.15 shows the general increase in time needed to find each solution for two sample datasets, BC reptiles and BC amphibians. Some of the variation in time may have been due to the computer being used for other purposes but the growth in time per solution is generally linear. Table 4.5 shows the total and average times needed to find the number of solutions listed in Table 4.4 for each LSCP model.

Table 4.6 : Time needed to find multiple solutions to LSCP model for each group.

\begin{tabular}{|c|c|c|c|c|}
\hline Dataset & $\begin{array}{l}\text { Number of } \\
\text { solutions }\end{array}$ & $\begin{array}{l}\text { Total time to } \\
\text { find solutions }\end{array}$ & $\begin{array}{l}\text { Ave. time to } \\
\text { find solutions }\end{array}$ & $\begin{array}{l}\text { Time to find } \\
\text { first solution }\end{array}$ \\
\hline $\mathrm{BC}$ birds & 3201 & $41 \mathrm{~h} \mathrm{38m} \mathrm{13.2s}$ & $46.8 \mathrm{~s}$ & $1.7 \mathrm{~s}$ \\
\hline ON birds & 2000 & $9 \mathrm{~h} \mathrm{31m} \mathrm{1s}$ & $17.1 \mathrm{~s}$ & $0.7 \mathrm{~s}$ \\
\hline $\mathrm{BC}$ mammals & 3141 & $45 \mathrm{~h} 12 \mathrm{~m} \mathrm{44.8s}$ & $51.8 \mathrm{~s}$ & $0.7 \mathrm{~s}$ \\
\hline BC COSEWIC & 2040 & $5 \mathrm{~h} \mathrm{39m} \mathrm{40s}$ & $10.0 \mathrm{~s}$ & $0.2 \mathrm{~s}$ \\
\hline BC SPoC & 3566 & $23 \mathrm{~h} 59 \mathrm{~m} 55.4 \mathrm{~s}$ & $24.2 s$ & $0.1 \mathrm{~s}$ \\
\hline BC amphibians & 4368 & $23 \mathrm{~h} \mathrm{32m} \mathrm{23s}$ & $19.4 \mathrm{~s}$ & $0.1 \mathrm{~s}$ \\
\hline BC reptiles & 144 (all) & $0 \mathrm{~h} 0 \mathrm{~m} 35.6 \mathrm{~s}$ & $0.25 s$ & $0.7 \mathrm{~s}$ \\
\hline
\end{tabular}


Figure 4.15: Graphs of the time required to find each solution by OPL for two datasets. In general, as more solutions were found, the time required to find each additional solution grew linearly.

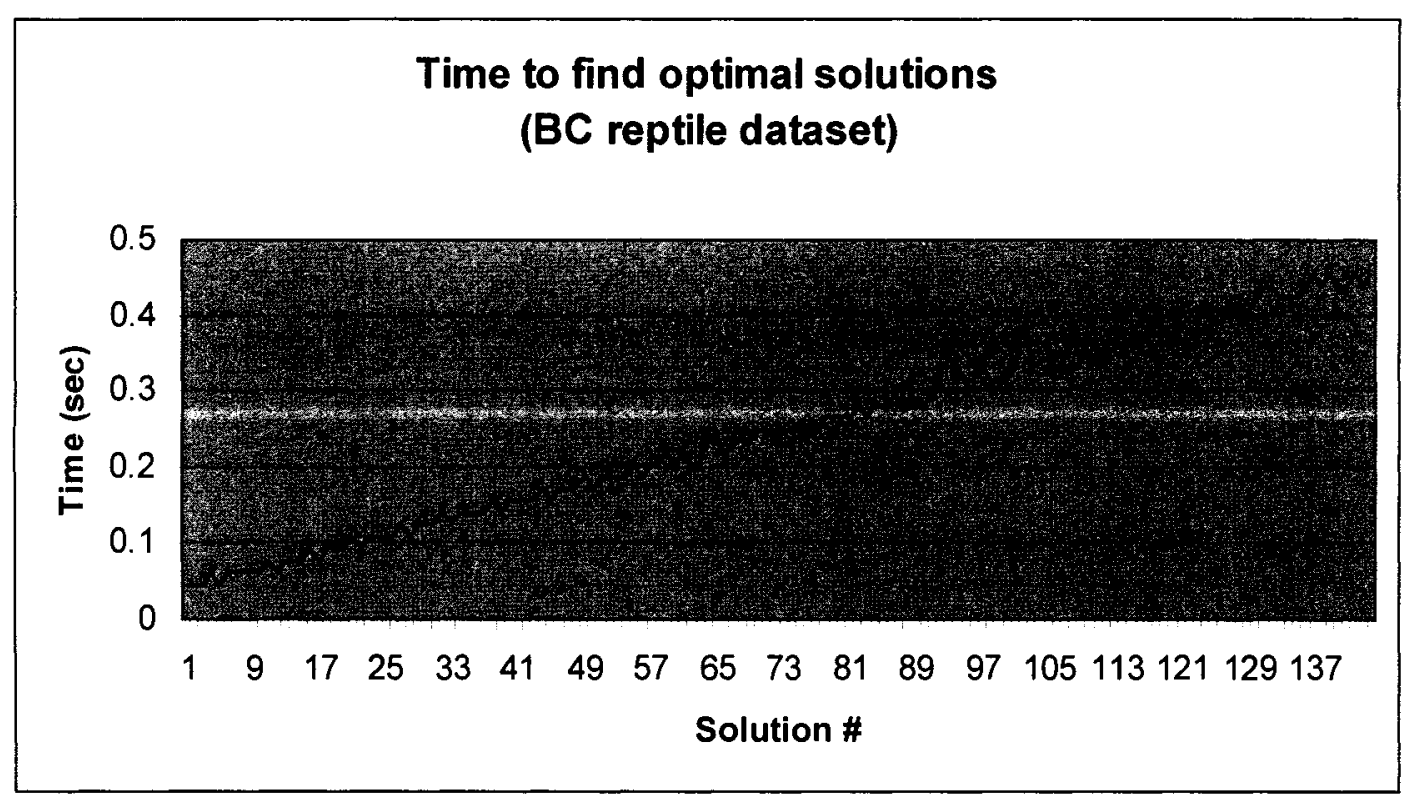

Time to find optimal solutions with OPL (BC amphibian dataset)

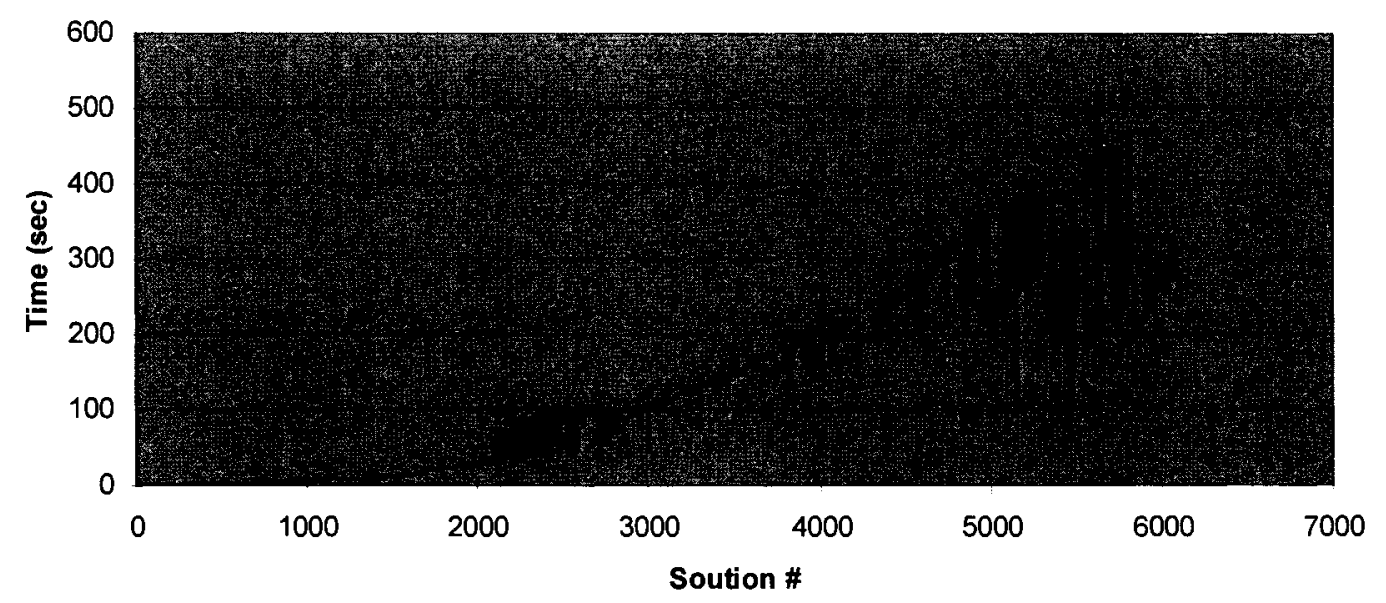




\subsection{Discussion}

This thesis examined a small component of the large and integrated process of systematic conservation planning. The results inform researchers and planners about the impacts, on suboptimality, spatial distribution, flexibility, and speed, of using heuristic and optimal algorithms for reserve selection. This knowledge may increase confidence in the model solutions as well as provide more planning options. The sections below place the results of the comparisons into academic and scientific context in order to make the benefits and drawbacks of using either algorithm more clear.

\subsection{Optimal Algorithm Baseline Comparison}

No other studies have compared outputs from two optimal solvers using biodiversity data, although optimal algorithms are often used as a reference against which to evaluate the suboptimality of heuristic reserve selection algorithm results. Optimal results compared here included the number of sites (cells) in solution sets (LSCP) or features covered (MCLP), the number of solutions generated, and, where possible, the distribution of solution set cells. Spatial distribution of multiple optimal sets is discussed in Section 5.2.1.

It was expected that the two optimal solvers would provide the same solution size to the LSCP and MCLP reserve selection models, and those expectations held true here. Unexpectedly, each optimal algorithm found different numbers of solution sets for some of the IP models. The expectations were that any combination of input data would have a limited and precise number of 
solution combinations regardless of the solver used. Although this may be a minor difference in terms of the number of occurrences and because it only occurs when there are numerous alternative sets to choose from, it may indicate a larger problem unless the cause can be explained, especially since many comparisons could not be made.

Arnold (pers. comm., 2004) speculated that the differences may be a result of the OSL solver being 5 years older and that small errors in a branch and bound process may become obvious only when the number of branches becomes sufficiently large. The OPL process is a proprietary mix of methods and processes which raises the possibility that every solver is slightly different. Önal (2003) states that ILOG optimal solvers, which include OPL, may use some strategic approximation methods rather than ensuring the results are optimal. In general, these results may indicate problems with the optimal algorithms or models that should be investigated if confidence in the results is important, especially for comparison to heuristic results. No other known conservation publications have examined this type of situation but an examination of OR setcovering literature may be productive.

\subsection{Heuristic and Optimal Algorithm Comparison}

\subsubsection{Output Solution Comparison}

\section{Solution Set Size Differences}

Previous studies have found variation in suboptimality to be common and that it apparently varied with the design of the heuristic and the distribution of the 
features in the region. Two studies (Pressey et al., 1997 and Csuti et al., 1997) using a single dataset each found that suboptimality varied with differences in heuristic algorithm design. Comparing richness and rarity based heuristic algorithms, Csuti's group found that richness based algorithms gave better results than other heuristics for the MCLP, and rarity based algorithms gave better results for the LSCP. This was supported by Moore et al. (2003). Saetersdal et al. (1992) used a heuristic algorithm on two datasets and found that having more rare species gave better results, which was substantiated by Pressey et al. (1999) in a simulation study and Moore et al. (2003) using a variety of datasets. Willis et al. (1996) found no suboptimality in output from two heuristic algorithms using a single dataset. Pressey et al.'s (1999) simulation study, in addition, found that the amount of nestedness or overlap of feature ranges was not related to suboptimality for a number of heuristics.

In this study, as shown in section 4.2.1, there was considerable variation in suboptimality of solution set sizes for the LSCP (Figure 5.1) and some of the levels would represent significant impacts on the implementation of conservation plans. In comparing different types of heuristic algorithm, there is a trend towards higher suboptimality for the Rarity based algorithm compared to the Richness based algorithm. This does not support the two previous findings which found that rarity based algorithms were closer to optimal in almost all cases (Csuti et al., 1997; Moore et al., 2003). It was also found here that the newer statisticbased heuristics (Summed Irreplaceability and Irreplaceability) produced lower 
suboptimality than the simpler, algebraic sorting criteria (Richness and Rarity) in most cases. No tests in the literature using these criteria are known.

Figure 5.1: Percent suboptimality occurrences from all 32 tests for the LSCP.

\section{Suboptimality Distribution}

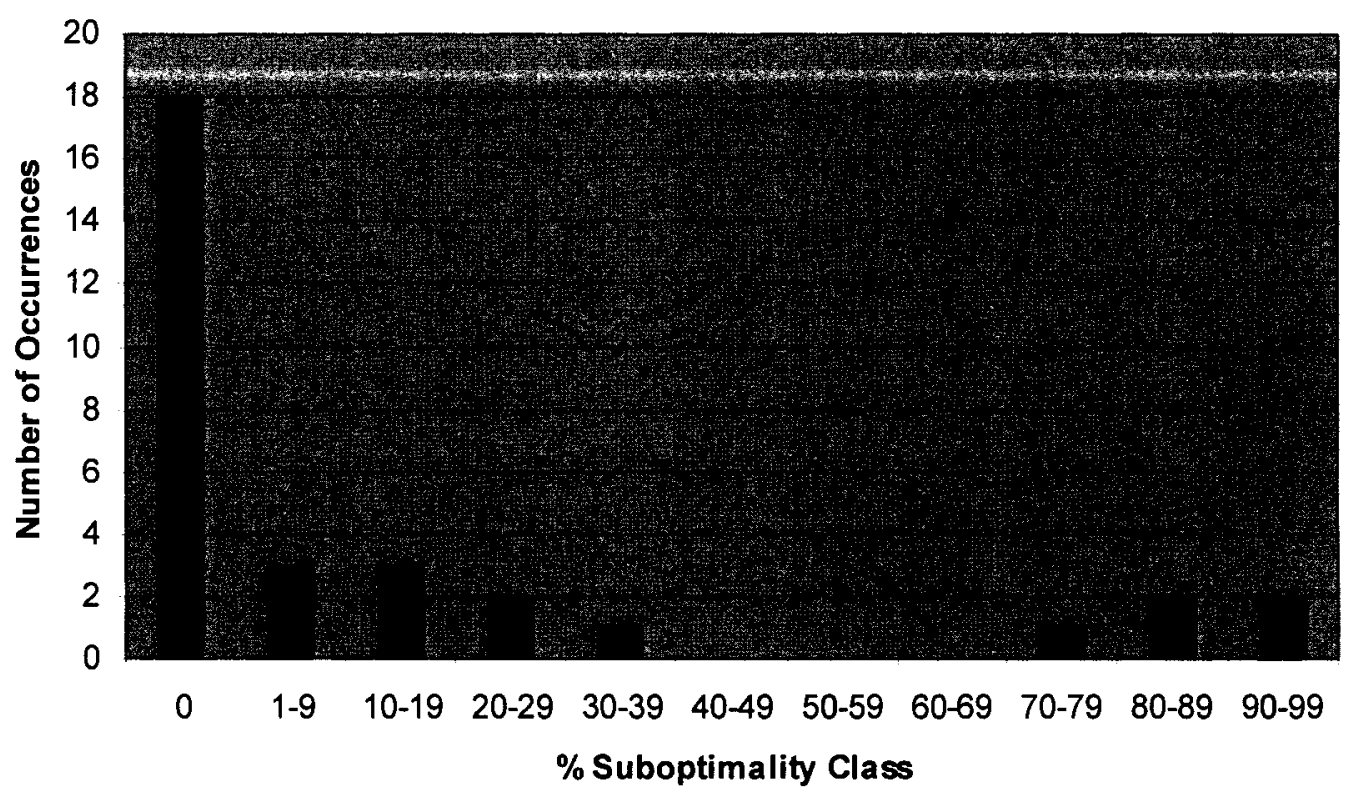

The highest suboptimality is found in the data that seems to have the least nestedness (overlap between features, sensu Pressey et al., 1999). AU data are composed of sites that are only 1 of 29 soil types and 1 of 36 environmental variables. Pressey et al. (1999) suggest that increased nestedness would result in lower suboptimality since solutions should become identical. However, it may be that they could become identical and optimal for either (opposite) extreme perfect nestedness or perfect allopatry. 
It is likely that the amount of suboptimality that is acceptable by a planner varies depending on the species, the nature of the conservation problem, and the planner(s). Moore et al. (2003) said their results of 0 to $9 \%$ suboptimality were close to optimal because they translated into additions of less than $1 \%$ of total area in the region. Onal (2003) notes that even a small overall regional percentage of land can have very large cost consequences. Rodrigues et al. (2000), assessing previous comparisons, report a range of 0 to $50 \%$ suboptimality, suggesting that results greater than about $25 \%$ were unacceptable, although these figures were not translated into percent of total area. Pressey et al. (1996), on the other hand, suggested that results in the range of $40 \%$ were not grossly suboptimal.

Here, 27 of 32 results ( $>84 \%$ ) had less than $40 \%$ suboptimality and 25 of 32 (>78\%) had less than $25 \%$ suboptimality. These results are good by most standards, although the $\mathrm{AU}$ results suggest caution is required when heuristics are used without knowing the level of suboptimality (e.g., McDonnell et al., 2002).

Because of the extreme suboptimality of some of these results, especially the $\mathrm{AU}$ data, it would also be interesting to test them on the other class of heuristics, the stochastic global search methods (sensu Cabeza and Moilanen, 2001) such as simulated annealing (Possingham et al., 2000). These are reported to perform better than greedy-type richness and rarity-based criteria. As well, as mentioned by Moore et al. (2003), numerous other heuristic algorithms exist that are well studied in the field of Operations Research, from which these 
algorithms arise. It may be informative to the conservation community to learn about how heuristics are being used to solve set covering and maximal locationtype problems in fields other than conservation.

These results may support some previous results and may counter others, but more clarity is needed regarding data quality and other possible variables of influence. The recommendation by Moore et al. (2003) for more simulation studies as a way of controlling these variables seems appropriate. These findings and observations on suboptimality of results are important because heuristic solvers, which are available as easily installed and utilised desktop computer packages, are becoming more popular (Williams et al., 2004). They are held to be intuitive and effective (Moore et al., 2003) but may not be (Underhill, 1994; Rodrigues and Gaston, 2002; Önal, 2003), especially as more complex IP models are developed (Rodrigues et al., 2000). With this in mind, a planner using a heuristic should probably do more than just run a variety of formulations of their heuristic to increase confidence, as suggested by Pressey et al. (1997). They would benefit in many ways by obtaining optimal results for comparison.

\section{Spatial Differences}

Changes in the solution set patterns using different sorting criteria and varying numbers of sites for the heuristic solver were examined here. The results supported previous findings that convergence of spatial distribution occurred as the number of sites designated (i.e., " $n$ ") increased if suboptimality decreased. Csuti et al., (1997) noted that for a model that needed 23 sites to cover all 
species, a suboptimal heuristic (396 spp. vs. $406 \mathrm{spp}$. possible for $n=10$ ) had at most 3 cells overlapping an optimal set for $n=10$ and had 19 overlapping for $n=$ 23 (with 425 spp. vs. 426 spp. possible for $n=23$ ). Polasky et al. (2000) found that as long as sites remained unclumped, as they generally are due to complementarity, they will converge to similar spatial patterns as the number of sites grows. Having found here that trends to decreased suboptimality seem to be stronger than trends to increased suboptimality as $n$ grows, it may be that all three ideas are connected, and the convergence mentioned by Csuti's group is due to the decrease in suboptimality which is related to the overall widely distributed nature of complementarity-based model solutions.

For a planner, this means that if more sites are to be used, using complementarity has the advantage of possibly reducing suboptimality as well as providing a larger number of alternative solutions. For example, a planner may have less confidence and less flexibility if only a few sites are to be funded. The fact that only one solution from each model has been examined here calls for caution in drawing conclusions, however, but may be an important consideration for those planners who only have a budget for one or two new sites. It may be better to do a complete regional analysis using LSCP and optimal algorithms before selecting the individual new sites. C-Plan can also be used but the LSCP minimum set is based on statistical assumptions which may lose their accuracy for regions with high numbers of sites. Further research is needed to clarify if $\mathrm{C}$ Plan statistical approaches are less reliable in that kind of situation. 


\subsubsection{Gap Analysis Comparison}

In order to further evaluate the differences between the heuristic and optimal algorithms, both were applied in a gap analysis exercise. The complex relationship between gap analysis and reserve selection in systematic planning helped illustrate a number of key ways that the algorithms differ, including in irreplaceability values and visualisation of results.

\section{Visualising Multiple Sets}

The benefits of multiple solutions are conveyed to gap analyses because different configurations may provide solutions that have a reduced requirement for new sites when existing sites are considered, as shown in the results (section 4.2.2) or may provide different levels of coverage for specific features (Gaston et al., 2001; Rodrigues et al., 2000; Noss, 2003; Bryan, 2003). Making use of the multiple solutions in a gap analysis, as was done here, is a novel response to the question of how multiple optimal output sets can be manipulated to aid conservation efforts.

Csuti et al. (1997) and Possingham et al. (2000) reported that simulated annealing algorithms can provide multiple solutions when the set size is optimal. C-Plan also has the ability to find multiple sets if different choices are made during manual runs. This could be used, for example, to select those sites that overlap with existing reserves in order to reduce the number of new reserves required by the solution. Using this method with Summed Irreplaceability, overlap for the Ontario birds' dataset increased from 3 of 24 (see Table 4.4) sites to 5 of 24. The BC mammals' dataset found that the overlap was improved from 3 of 7 
to 5 of 7 . This latter improvement matched the best result found in 3141 solutions from OPL. The fact that the multiple OPL results provided solutions with more or equal overlap with existing reserves than C-Plan could do automatically or manually supports the contention that multiple sets can be useful for this type of goal.

Pressey (1999b) states that being able to map irreplaceability helps to visualise the options that exist with respect to desired conservation outcomes, especially if there is a need to consider connectedness, patch size, corridors and other landscape configuration options. The irreplaceability value for a site, as calculated by Pressey's team and others using C-Plan, is dependent on assumptions about the size, number, and distribution of potential solution sets for the IP problem (Ferrier et al., 2000). Although it is understood that the true irreplaceability values for sites in the model can be known only if both the objective function size and all true solution sets to the problem model are known, Ferrier et al. (Ibid.) state that due to the speed limitations of the branch and bound algorithms, that value is too problematic to calculate in real-time. This statement was made in 2000 , and researchers since then have shown very fast results for very large tables using products associated with OPL (Bryan, 2003; Moore et al., 2003; Rodrigues and Gaston, 2002). If speed is no longer a factor (see Section 5.2 .3 below), it suggests that the optimal methods should be used to calculate irreplaceability from the actual results. 
C-Plan may be a better choice for finding irreplaceability when the number of solutions is high, as the user at least has a useful approximation about the final irreplaceability numbers. On the other hand, as Lindsay et al., (unpublished) have done, it may also be appropriate to use a small subset of solution sets for mapping. This project shows, for example, that compiling and mapping only those sets that minimise the need for new reserves can be a useful way of finding alternative sets.

\subsubsection{Algorithm Speed Comparison}

It has often been stated that heuristics are being developed or used in a project because optimal algorithms are unable to produce results in a time frame that allows interactivity, meaning seconds or hours per solution. Recent tests have been done by a number of researchers that report optimal algorithms as being capable of interactive speeds with most datasets (Rodrigues and Gaston, 2002; Bryan, 2003; Moore et al., 2003). The results here use the same software and draw similar conclusions when single solutions sets are required.

One author, however, suggests that there is still some doubt that optimal solvers are doing as well as it seems (Önal, 2003). Reeves (1996) states that there are likely to be conditions, such as the type of problem, problem size, or algorithm used, where even branch-and-bound or branch-and-cut methods will function no more quickly than complete enumeration. Church et al. (1996), who wrote up the earliest reserve selection version of the MCLP and solved it with a proprietary algorithm, suggested that although many reasonable sized problems 
of this type are resolved quickly, there may still be cases where they will not be. Although these references are not current, the fact remains that if a problem cannot be reduced by branch-and-cut or pre-processing, either within the solver or manually, it may remain intractable. Rodrigues and Gaston (2002) concur, and had much slower results for one MCLP problem of a number of similar MCLP and LSCP problems.

Finding single optimal solutions quickly does not ensure fast results for multiple results, which may be needed to find a single 'best' solution. However, the time needed to run a heuristic multiple times or to find alternative solutions interactively also takes longer than finding a single solution. The number of solutions needed to provide flexibility to planners may not be extremely high, and a subset of 50 or 100 can be used to begin looking at alternatives, perhaps in a gap analysis as discussed above, while the program continues to provide more solutions. 


\subsection{Conclusion}

Significant resources are being brought to bear to ensure the conservation of threatened elements of biodiversity, and systematic planning approaches are attempting to contribute objective, accountable reserve design recommendations to planners and decision makers. Designing reserve networks for varied regional situations is a common conservation research activity, but the results are not often implemented. One reason for this may be a lack of understanding about reserve selection algorithms, which have different forms that function differently and sometimes provide different results. Although Underhill, ten years ago, found fundamental reasons to focus on optimal algorithms in reserve network design, heuristics have remained popular. These two types of algorithm were compared here for differences in output (network size and distribution) and flexibility (the ability to provide multiple solutions and deliver results quickly) using a variety of regional datasets.

The results add evidence that suboptimality of heuristic results may be excessive in some cases and cannot be predicted. This is intuitively correct, as predicting them would imply knowing the optimal solution, which would eliminate the need for a heuristic. They also show that suboptimality may increase as fewer sites are stipulated compared to the number needed to encompass all features of concern, and this can lead to more chance of a single site being redundant (and therefore not efficient) from the regional perspective of the IP model. Spatially, all networks designed here, due to the principle of 
complementarity, reflect the effects of ecosystem-based input data and provide a less clustered network than hotspot-based approaches.

Heuristic algorithms can be programmed to provide multiple solutions but the results will all carry the disclaimer about possible suboptimality. As well, programming a step-wise heuristic to use existing solutions as a constraint, as is done easily in ILOG OPL, may be problematic since the final solution is not known until all iterations are complete and there is no guarantee that the next solution will be different or as close to optimal as the previous solution(s).

C-Plan provides a good a priori irreplaceability estimation. ILOG OPL provides multiple, optimal solutions that can be filtered in many ways and used to find true irreplaceability values, although it takes much longer than C-Plan. Both of the algorithms tested here worked very quickly to provide single solutions sets and speed should not be a barrier to using either one.

Before improved computer speeds and solver design made use of optimal algorithms unrestrictive, there were many cases where heuristics were advantageous. Despite the possibility of increased land purchase and management costs due to additional and possibly redundant sites for a given network, planners found heuristic solvers intuitive and easy to use, although that assessment may have been simplistic. Today, although there are other reasons to debate the use of conservation optimisation models and systematic planning, the use of optimal solvers is practical and provides flexible, concise solutions to regional, multi-feature conservation problems. 


\subsection{Literature cited}

Aggarwal, A., Garson, J., Margules, C.R., Nicholls, A.O., and S. Sarkar, 2000. ResNet Version 1.1 Manual, Report, Biodiversity and Biocultural Conservation Laboratory, University of Texas, Austin.

Andelman, S.J., and W.F. Fagan. 2000. Umbrellas and flagships: Efficient conservation surrogates or expensive mistakes. Proceedings of the National Academy of Sciences of the United States of America, 97: 5954-5959.

Andelman, S.J., and M.R. Willig. 2003. Present patterns and future prospects for biodiversity in the Western Hemisphere. Ecology Letters, 6: 818-824.

Ando, A., J. Camm, S. Polasky, and A. Solow. 1998. Species distributions, land values, and efficient conservation. Science, 279: 2126-2128.

Arcese, P., and A.R.E. Sinclair. 1997. The role of protected areas as ecological baselines. Journal of Wildlife Management, 61: 587-602.

Arnold, R. 2004. Carleton University, Canada. Personal communication.

Arthur, J.L., M. Hachey, K. Sahr, M. Huso, and A. R. Kiester. 1997. Finding all optimal solutions to the reserve site selection problem: formulation and computational analysis. Environmental and Ecological Statistics, 4: 153-165.

Aspinall, R.J. 1999. GIS and landscape conservation. In Geographical Information Systems: Principles and Technical Issues. Goodchild, M.F., P.A. Longley, D.J. Maguire, and D.W. Rhind (eds.). John Wiley \& Sons, Inc., New York. pp. 967-980.

Beasley, J.E. unpublished. Operations Research Notes online, $<$ http://people.brunel.ac.uk/ mastjib/jeb/or/contents.html>as of May, 2005.

Bowker, G.C. 2000. Mapping biodiversity. International Journal of Geographical Information Science, 14: 739-754.

Bryan, B.A. 2003. Linking spatial optimisation and GIS: Using integer programming to find the best places to plant trees in a landscape for conservation. Proceedings SSC Conference of the Spatial Sciences Institute of Australia. Canberra, Australia, 23-25 September, 2003. pp. 1-17.

Bryan, B. 2004. Commonwealth Scientific and Industrial Research Organisation, Australia. Personal communication. 
Cabeza, M., and A. Moilanen. 2001. Design of reserve networks and the persistence of biodiversity. Trends in Ecology and Evolution, 16: 242-248.

Cabeza, M., and A. Moilanen. 2003. Site-Selection Algorithms and Habitat Loss. Conservation Biology, 17: 1402-1413.

Camm, J.D., S. Polasky, A. Solow, and B. Csuti. 1996. A note on optimal algorithms for reserve site selection. Biological Conservation, 78: 353-355.

Canadian Council on Ecological Areas. 2004. Personal Communication.

Carignan, V., and M-A Villard. 2002. Selecting Indicator Species to Monitor Ecological Integrity: A Review. Environmental Monitoring and Assessment, 78: 45-61.

Chown, S.L., B.J. van Rensburg, K.J. Gaston, A.S.L. Rodrigues, and A.S. van Jaarsveld. 2003. Energy, species richness, and human population size:

Conservation implications at a national scale. Ecological Applications, 13: 12331241.

Church, R.L., D.M. Stoms, and F.W. Davis. 1996. Reserve selection as a Maximal Covering Location Problem. Biological Conservation, 76: 105-112.

Cocks, K.D., and I.A. Baird. 1989. Using Mathematical Programming to Address the Multiple Reserve Selection Problem: An Example from the Eyre Peninsula, South Australia. Biological Conservation, 49: 113-130.

Cortner, H.J. 2000. Making science relevant to environmental policy. Environmental Science and Policy, 3: 21-30.

Cowling, R.M. 1999. Planning for persistence - systematic reserve design in southern Africa's Succulent Karoo desert. Parks, 9: 17-30.

Cowling, R.M., R.L. Pressey, R. Sims-Castley, A. le Roux, E. Baard, C.J. Burgers, and G. Palmer. 2003. The expert or the algorithm? - comparison of priority conservation areas in the Cape Floristic Region identified by park managers and reserve selection software. Biological Conservation, 112: 147167.

Csuti, B., S. Polasky, P.H. Williams, R.L. Pressey, J.D. Camm, M. Kershaw, A.R. Kiester, B. Downs, R. Hamilton, M. Huso, and K. Sahr. 1997. A Comparison of Reserve Selection Algorithms Using Data on Terrestrial Vertebrates in Oregon. Biological Conservation, 80: 83-97. 
Dasgupta, P, S. Levin, and J. Lubchenco. 2000. Economic pathways to ecological sustainability. Bioscience, 50: 339-345.

Davis, F.W., D.M., Stoms, and S. Andelman. 1999. Systematic reserve selection in the USA: an example from the Columbia Plateau ecoregion. Parks, 9: 31-41.

Davis, F.W., D.M. Stoms, C.J. Costello, E.A. Machado, J. Metz, R. Gerrard, S. Andelman, H. Regan, and R. Church. 2003. A framework for setting land conservation priorities using multi-criteria scoring and an optimal fund allocation strategy. Report to the Resources Agency of California. University of California, Santa Barbara. $72 \mathrm{pp}$.

Diamond, J.M., 1975. The island dilemma: lessons of modern biogeographic studies for the design of natural reserves. Biological Conservation, 7(2): 129-146.

Faith, D.P. 2003b. Environmental diversity (ED) as surrogate information for species-level biodiversity. Ecography, 26: 374-379.

Faith, D.P., and P.A. Walker. 1996. How do indicator groups provide information about the relative biodiversity of different sets of areas?: on hotspots, complementarity and pattern-based approaches. Biodiversity Letters, 3: 18-25.

Ferrier, S., R.L. Pressey, and T.W. Barrett. 2000. A new predictor of the irreplaceability of areas for achieving a conservation goal, its application to realworld planning, and a research agenda for further refinement. Biological Consenvation, 93: 303-325.

Garson, J., A. Aggarwal, and S. Sarkar. 2002. Birds as surrogates for biodiversity: an analysis of a data set from southern Québec. Journal of Bioscience, 27 (Suppl.2): 347-360.

Gaston, K.J., and A.S.L. Rodrigues. 2003. Reserve Selection in Regions with Poor Biological Data. Conservation Biology, 17: 188-195.

Gaston, K.J., A.S.L. Rodrigues, B.J. van Rensburg, P. Koleff, and S.L. Chown. 2001. Complementary representation and zones of ecological transition. Ecology Letters, 4: 4-9.

Groombridge, B., and M.D. Jenkins. 2002. World Atlas of Biodiversity: Earth's Living Resources in the 21st Century, University of California Press, California, USA. 
Haight, R.G., C.S. ReVelle, and S.A. Snyder. 2000. An integer optimization approach to a probabilistic reserve site selection problem. Operations Research, 48: 697-708.

Hoctor, T.S., M.H. Carr, and P.D. Zwick. 1999. Identifying a linked reserve system using a regional landscape approach: the Florida Ecological Network. Conservation Biology, 14: 984-1000.

ILOG Technical Support. 2004. Personal communication.

Iverson, L.R., and A. Prasad. 1998. Estimating regional plant biodiversity with GIS modelling. Diversity and Distributions, 4: 49-61.

Janzen, D.H. 1986. The future of tropical ecology. Annual Review of Ecology and Systematics, 17:305-324.

Jennings, M.D. 2000. Gap analysis: concepts, methods, and recent results. Landscape Ecology, 15: 5-20.

Justus, J., and S. Sarkar. 2002. The principle of complementarity in the design of reserve networks to conserve biodiversity: a preliminary history. Journal of Bioscience, 27 (suppl.2): 421-435.

Kerr, J.T., 1997. Species richness, endemism, and the choice of areas for conservation. Conservation Biology, 11(5): 1094-1100.

Kiester, A. R., J. M. Scott, B. Csuti, R.F. Noss, B. Butterfield, K. Sahr, and D. White. 1996. Conservation Prioritization Using GAP Data. Conservation Biology, 10: $1332-1342$.

Kingsland, S.E. 2002. Creating a science of nature reserve design: Perspectives from history. Environmental Modeling and Assessment, 7: 61-69

Kirkpatrick, J.B. 1983. An iterative method for establishing priorities for the selection of nature reserves: an example from Tasmania. Biological Conservation, 25: 127-134.

Klosterman, R.E. 1999. The What If? collaborative planning and support system. Environment and Planning, B: Planning and Design, 26: 393-408.

Kupfer, J.A. 1995. Landscape ecology and biogeography. Progress in Physical Geography, 19: 18-34. 
Lawler, J.J., D. White, J.C. Sifneos, and L.L. Master. 2003. Rare Species and the Use of Indicator Groups for Conservation Planning. Conservation Biology, 17: 875-882.

Lindsay, K. 2004. Environment Canada, Canada. Personal communication.

Lindsay, K.E., M. Meyers, D. White, A.R. Kiester, and P. Lumban-Tobing. (unpublished). Species richness and prioritization for wildlife in British Columbia.

Loiselle, B.A., C.A. Howell, C.H. Graham, J.M. Goerck, T. Brooks, K.G. Smith, and P.H. Williams. 2003. Avoiding Pitfalls of Using Species Distribution Models in Conservation Planning. Conservation Biology, 17: 1591-1600.

Loreau, M., S. Naeem, P. Inchausti, J. Bengtsson, J.P. Grime, A. Hector, D.U. Hooper, M.A. Huston, D. Raffaielli, B. Schmid, D. Tilman, and D.A. Wardle. 2001. Biodiversity and Ecosystem Functioning: Current Knowledge and Future Challenges. Science, 294: 804-808.

MacArthur, R. H., and E.O. Wilson. 1967. The Theory of Island Biogeography. Princeton Univ. Press, Princeton.

Malcolm S.A., and C. ReVelle. 2002. Rebuilding migratory flyways using directed conditional covering. Environmental Modeling and Assessment, 7: 129-138.

Margules, C.R., and R.L. Pressey. 2000. Systematic conservation planning. Nature, 405: 243-253.

Margules, C.R., R.L. Pressey, and P.H. Williams. 2002. Representing biodiversity: data and procedures for identifying priority areas for conservation. Journal of Bioscience, 27 (Suppl.2): 309-326.

McDonnell, M.D., H.P. Possingham, I.R. Ball, and E.A. Cousins. 2002. Mathematical methods for spatially cohesive reserve design. Environmental Modeling and Assessment, 7: 107-114.

Mitchell, J.E. 2002. Branch-and-Cut Algorithms for Combinatorial Optimization Problems. In: Handbook of Applied Optimization. P.M. Pardalos and M.G.C. Resende, (eds.). Oxford University Press. pp. 65-77.

Moore, J.L., M. Folkmann, A. Balmford, T. Brooks, N. Burgess, C. Rahbek, P.H. Williams, and J. Krarup. 2003. Heuristic and optimal solutions for set-covering problems in conservation biology. Ecography, 26: 595-601. 
Moritz, C., K.S. Richardson, S. Ferrier, G.B. Monteith, J. Stanisic, S.E. Williams, and $T$. Whiffin. 2001. Biogeographical concordance and efficiency of taxon indicators for establishing conservation priority in a tropical rainforest biota. Proceedings of the Royal Society of London - B, 268: 1-7.

Nantel, P., A. Bouchard, L. Brouillet, and S. Hay. 1998. Selection of areas for protecting rare plants with integration of land use conflicts: a case study for the west cost of Newfoundland, Canada. Biological Conservation, 84: 223-234.

Noss, R.F. 2003. A Checklist for Wildlands Network Designs. Conservation Biology, 17: 1270-1275.

Noss, R.F., and M.E. Soulé. 1998. Rewilding and Biodiversity: Complementary Goals for Continental Conservation. Wild Earth, 3.

Noss, R.F., C. Carroll, K. Vance-Borland, and G. Wuerthner. 2002. A Multicriteria Assessment of the Irreplaceability and Vulnerability of Sites in the Greater Yellowstone Ecosystem. Conservation Biology, 16: 895-908.

Olsen, L. Master of Science thesis. Ongoing. Carleton University, Ottawa, Ontario.

Önal, H. 2003. First-best, second-best, and heuristic solutions in conservation reserve site selection. Biological Conservation, 115: 55-62.

Ontario Breeding Bird Atlas. Draft data summaries (2001-2004). Web site <http://www. birdsontario.org >

Poiani, K.A., M.D. Merrill, K.A. Chapman. 2001. Identifying Conservation-Priority Areas in a Fragmented Minnesota Landscape Based on the Umbrella Species Concept and Selection of Large Patches of Natural Vegetation. Conservation Biology, 15(2): 513-522.

Polasky, S., J.D. Camm, A.R. Solow, B. Csuti, D. White, and R. Ding. 2000. Choosing reserve networks with incomplete species information. Biological Conservation, 94: 1-10.

Possingham, H., J. Day, M. Goldfinch, and F. Salzborn. 1993. The mathematics of designing a network of protected areas for conservation. In: Decision sciences, tools for today. Proceedings of the 12th Australian Operations Research Conference, Sutton, D., E. Cousins, and C. Pierce (eds.). Australian Society for Operations Research, Adelaide, Australia. pp. 536-545. 
Possingham, H., I. Ball, and S. Andelman. 2000. Mathematical methods for identifying representative reserve networks. In: Quantitative methods for conservation biology. Ferson, S., and M. Burgman, (eds.). Springer-Verlag, New York. pp. 291-305.

Prendergast, J.R., R.M. Quinn, and J.H. Lawton. 1999. The Gaps between Theory and Practice in Selecting Nature Reserves. Conservation Biology, 13(3): 484-492.

Pressey, R.L. 1999a. Editorial-systematic conservation planning for the real world. Parks, 9: 1-6.

Pressey, R.L. 1999b. Applications of irreplaceability analysis to planning and management problems. Parks, 9: 42-51.

Pressey, R.L. 2002. Classics in physical geography revisited. Progress in Physical Geography, 26: 434-441.

Pressey, R.L., R.M. Cowling. 2001. Reserve Selection Algorithms and the Real World. Conservation Biology, 15: 275-277.

Pressey, R.L., and V.S. Logan. 1998. Size of selection units for future reserves and its influence on actual vs. targeted representation of features: a case study in western New South Wales. Biological Conservation, 85: 305-319.

Pressey, R.L., I.R. Johnson, and P.D. Wilson. 1994. Shades of irreplaceability: towards a measure of the contribution of sites to a reservation goal. Biodiversity and Conservation, 3: 242-262.

Pressey, R.L., H.P. Possingham, and C.R. Margules. 1996. Optimality in reserve selection algorithms: when does it matter and how much? Biological Conservation, 76: 259-267.

Pressey, R.L., H.P. Possingham, and J.R. Day. 1997. Effectiveness of alternative heuristic algorithms for identifying indicative minimum requirements for conservation reserves. Biological Conservation, 80: 207-219.

Pressey, R.L., H.P. Possingham, V.S. Logan, J.R. Day, and P.H. Williams. 1999. Effects of data characteristics on the results of reserve selection algorithms. Journal of Biogeography, 26: 179-191.

Ratcliffe, D.A. 1971. Criteria for the selection of nature reserves. Advances in Science, 27: 294-296. 
Reeves, C.R. 1996. Modern heuristic techniques. In Modern Heuristic Search Methods, Rayward-Smith, V.J., I.H. Osman, C.R. Reeves, and G.D. Smith (eds.) John Wiley and Sons, Toronto. pp. 1-25.

ReVelle, C.S., J.C. Williams, and J.J. Boland. 2002. Counterpart models in facility location science and reserve selection science. Environmental Modeling and Assessment, 7: 71-80.

Reyers, B., A.S. van Jaarsveld, \& M. Kruger. 2000. Complementarity as a biodiversity indicator strategy. Proceedings of the Royal Society of London - B, 267: 505-513.

Roberge J-M., and P. Angelstam. 2002. Usefulness of the umbrella species concept as a conservation tool. Conservation Biology, 18: 76-85.

Rodrigues, A.S.L., and K.J. Gaston. 2001. How large do reserve networks need to be? Ecology Letters, 4: 602-609.

Rodrigues, A.S.L., and K.J. Gaston. 2002. Optimisation in reserve selection procedures-why not? Biological Conservation, 107: 123-129.

Rodrigues, A.S.L., R. Tratt, B.D. Wheeler, and K.J. Gaston. 1999. The performance of existing networks of conservation areas in representing biodiversity. Proceedings of the Royal Society of London - B, 266: 1453-1460.

Rodrigues, A.S., J.O. Cerdeira, and K.J. Gaston. 2000. Flexibility, efficiency, and accountability: adapting reserve selection algorithms to more complex conservation problems. Ecography, 23: 565-574.

Rodrigues, A.S.L., S.J. Andelman, M.I. Bakarr, L. Boitani, T.M. Brooks, R.M. Cowling, L.D.C. Fishpool, G.A.B da Fonseca, K.J. Gaston, M. Hoffmann, J.S. Long, P.A Marquet, J.D. Pilgrim, R.L. Pressey, J. Schipper, W. Sechrest, S.N. Stuart, L.G. Underhill, R.W. Waller, M.E.J. Watts, and X. Yan. 2004. Effectiveness of the global protected areas network in representing species diversity. Nature, 428: 640-643.

Root, K.V., H.R. Akçakaya, and L. Ginzburg. 2003. A multispecies approach to ecological valuation and conservation. Conservation Biology, 17: 196-206.

Rosenzweig, M.L., W.R. Turner, J.G. Cox, and T.H. Ricketts. 2003. Estimating diversity in unsampled habitats of a biogeographical province. Conservation Biology, 17: 864-874. 
Rosing, K.E., C.S. ReVelle, and J.C. Williams. 2002. Maximizing species representation under limited resources: A new and efficient heuristic. Environmental Modeling and Assessment, 7: 91-98.

Rothley, K.D. 1999. Designing Bioreserve Networks to Satisfy Multiple, Conflicting Demands. Ecological Applications, 9: 741-750.

Saetersdal, M., J.M. Line, and H.J.B. Birks. 1992. How To Maximize Biological Diversity In Nature Reserve Selection: Vascular Plants And Breeding Birds In Deciduous Woodlands, Western Norway. Biological Conservation, 66: 131-138.

Sala, E., O. Aburto-Oropeza, G. Paredes, I. Parrar, J.C. Barrera, and P.K. Dayton. 2002. A general model for designing networks of marine reserves. Science, 298: 1991-1993.

Sarakinos, H., A.O. Nicholls, A. Tubert, A. Aggarwal, C.R. Margules, and S. Sarkar. 2001. Area prioritization for biodiversity conservation in Québec on the basis of species distributions: a preliminary analysis. Biodiversity and Conservation, 10: 1419-1472.

Sarkar, S. "Conservation Biology", The Stanford Encyclopedia of Philosophy (Winter 2004 Edition), Edward N. Zalta (ed.), forthcoming URL = <http://plato.stanford.edu/archives/win2004/entries/conservation-biology/>. (see http://plato.stanford.edu/cgi-

bin/encyclopedia/archinfo.cgi?entry=conservation-biology for updates on this reference)

Sarkar, S., and C. Margules. 2002. Operationalizing biodiversity for conservation planning. Journal of Bioscience, 27(Suppl.2): 299-308.

Scott, J.M., F. Davis, B. Csuti, R. Noss, B. Butterfield, C. Groves, H. Anderson, S. Caicco, F. D'Erchia, T. C. Edwards, Jr., J. Ulliman, and G. Wright. 1993. Gap analysis: A geographic approach to protection of biological diversity. Wildlife Monographs 123.

Scott, M.J., F.W. Davis, R. G. McGhie, R.G. Wright, C. Groves, and J. Estes. 2001. Nature reserves: do they capture the full range of America's biological diversity? Ecological Applications, 11: 999-1007.

Scudder, G.G.E. 2003. Biodiversity Conservation and Protected Areas in British Columbia. University of British Columbia, Department of Zoology and Centre for Biodiversity Research. 
Secretariat of the Convention on Biological Diversity. 2004. Programme of Work on Protected Areas (CBD Programmes of Work). Montreal: Secretariat of the Convention on Biological Diversity. $31 \mathrm{pp}$.

Simberloff, D. 1998. Flagships, umbrellas, and keystones: Is single-species management passé in the landscape era? Biological Conservation, 83: 247-257.

Stoms, D.M. 1994. Scale dependence of species richness maps. Professional Geographer, 46: 346-358.

Underhill, L.G. 1994. Optimal and suboptimal reserve selection algorithms. Biological Conservation, 70: 85-87.

United Nations Environment Programme. 1992. (http://www.biodiv.org) Convention on Biological Diversity.

Vane-Wright, R.I., C.J. Humphries, and P.H. Williams. 1991. What to protect?systematics and the agony of choice. Biological Conservation, 55: 235-254.

Vitousek P.M., H.A. Mooney, J. Lubchenco, and J.M. Melillo. 1997. Human domination of Earth's ecosystems. Science, 277: 494-499.

Warman, L.D., A.R.E. Sinclair, G.G.E. Scudder, B. Klinkenberg, and R.L. Pressey. 2004. Sensitivity of Systematic Reserve Selection to Decisions about Scale, Biological Data, and Targets" Case Study from Southern British Columbia. Conservation Biology, 18: 655-666.

White, D., E. M. Preston, K.E. Freemark, and A.R. Kiester. 1999. A Hierarchical Framework for Conserving Biodiversity. In Landscape Ecological Analysis: Issues and Applications, Jeffrey M. Klopatek and Robert H. Gardner (eds.), Springer-Verlag, New York. pp. 127-153.

White D. 2000. Global grids from recursive diamond subdivisions of the surface of an octahedron or icosahedron. Environmental Monitoring and Assessment, 64: 93-103.

Williams J.C., C.S. ReVelle, and S.A. Levin. 2004. Using mathematical optimization models to design nature reserves. Frontiers in Ecology and the Environment, 2: 98-105.

Williams, P.H. 1998. Key sites for conservation: area-selection methods for biodiversity. In Mace, G. M., Balmford, A. \& Ginsberg, J. R. (eds), Conservation in a changing world: integrating processes into priorities for action. Symposia of 
the Zoological Society of London no. 72, Cambridge University Press. pp. 211249

Williams, P.H., and M.B. Araújo. 2000. Using probability of persistence to identify important areas for biodiversity conservation. Proceedings of the Royal Society of London - B, 267: 1959-1966.

Williams, P.H., and M.B. Araújo. 2002. Apples, oranges, and probabilities: Integrating multiple factors into biodiversity conservation with consistency. Environmental Modeling and Assessment, 7: 139-151.

Williams, P.H., C.R. Margules, and D.W. Hilbert. 2002. Data requirements and data sources for biodiversity priority area selection. Journal of bioscience, 27(Suppl.2): 327-338.

Willis, C.K., A.T. Lombard, R.M. Cowling, B.J. Heydenrych, and C.J. Burgers. 1996. Reserve systems for limestone endemic flora of the Cape Lowland Fynbos: iterative versus Linear Programming. Biological Conservation, 77: 53-62.

World Conservation Union. 1994. Guidelines for Protected Areas Management Categories. Gland, Switzerland. (http://www.unep-

wcmc.org/index.html?http://www. unep-

wcmc.org/protected areas/categories/ main)

World Resources Institute, The World Conservation Union, United Nations Environment Programme. 1992. Global Biodiversity Strategy, Washington DC. 